\title{
Marine Renewable Energy in the Mediterranean Sea: Status and Perspectives
}

\author{
Takvor H. Soukissian ${ }^{1, *}$ (D), Dimitra Denaxa ${ }^{1}$, Flora Karathanasi ${ }^{1,2}$, Aristides Prospathopoulos ${ }^{1}$, \\ Konstantinos Sarantakos ${ }^{1}$, Athanasia Iona ${ }^{1}$, Konstantinos Georgantas ${ }^{1}$ and \\ Spyridon Mavrakos ${ }^{2,3}$ \\ 1 Institute of Oceanography, Hellenic Center for Marine Research, 19013 Anavyssos, Greece; \\ ddenaxa@hcmr.gr (D.D.); fkarathanasi@hcmr.gr (F.K.); aprosp@hcmr.gr (A.P.); ksarant@hcmr.gr (K.S.); \\ sissy@hnodc.ncmr.gr (A.I.); kgeorgantas@hcmr.gr (K.G.) \\ 2 Department of Naval Architecture and Marine Engineering, National Technical University of Athens, \\ Zografos, 15780 Athens, Greece; mavrakos@naval.ntua.gr \\ 3 Hellenic Center for Marine Research, 19013 Anavyssos, Greece \\ * Correspondence: tsouki@hcmr.gr; Tel.: +30-22910-76420
}

Received: 28 July 2017; Accepted: 20 September 2017; Published: 29 September 2017

\begin{abstract}
In this work, an extended overview of the marine renewable energy in the Mediterranean Sea is provided as regards current status, potential problems, challenges, and perspectives of development. An integrated and holistic approach is necessary for the economic viability and sustainability of marine renewable energy projects; this approach comprises three different frameworks, not always aligned, i.e., geotechnical/engineering, socio-economic, and environmental/ ecological frameworks. In this context, the geomorphological, climatological, socio-economic, and environmental/ecological particularities of the Mediterranean basin are discussed, as they constitute key issues of the spatial context in which marine renewable energy projects are to be implemented. General guidelines for the sustainable development of marine renewable energy in the Mediterranean are also provided.
\end{abstract}

Keywords: marine renewable energy; ocean energy; offshore wind energy; marine spatial planning; Mediterranean Sea; roadmap for marine energy development

\section{Key Topics}

The main topics that this paper deals with, can be summarized as follows:

- Global status of the different types of marine renewable energy (MRE), i.e., offshore wind, wave, tidal, thermal, and salinity gradients energy conversion:

global estimates of available resources

relevant technologies

potential synergies;

- Main characteristics of the Mediterranean basin:
geomorphological features
$\bigcirc \quad$ wind and wave climate
- ecological and oceanographic characteristics
○ important economic sectors associated with MRE development;

- Current energy status and future scenarios for the Mediterranean European Union (EU) member states; 
- Current status, potential problems, challenges, and perspectives of MRE development in the Mediterranean Sea (MS):

- key issues of the geotechnical/engineering framework: MRE potential, distance from shore, electricity infrastructure, technology development, grid availability, intermittency, energy transmission, and energy storage

○ key issues of the socio-economic framework: economics of MRE, legal and regulatory framework, employment opportunities, different uses of the marine space (tourism and visual disturbance, maritime transport, fisheries and aquaculture, marine mineral resources), finance and markets, and administrative and socio-economic constraints

- key issues of the environmental/ecological framework: environmental impacts, Marine Protected Areas, Environmental Impact Assessment studies necessity for Marine Spatial Planning;

- A roadmap for the sustainable development of MRE in the MS:

recommendations and guidelines involving technical, environmental, and socio-economic aspects.

\section{Introduction}

The ocean is an abundant, clean, and renewable energy source. The increasing need to replace fossil fuels with alternative energy sources that are free from risk of depletion, with reduced environmental cost and ecological footprint, has highlighted the necessity for MRE development. MRE consists in:

1. Offshore (marine) wind energy, i.e., the energy that can be harvested from the marine wind, and;

2. Ocean Energy (OE), i.e., the energy that can be harvested from the ocean. Ocean energy can also be referred to as 'Blue Energy' and 'renewable energy from the ocean', and is divided into four types according to the origin of the extracted power, namely sea surface waves, tidal/sea currents, and thermal and salinity gradients; see also [1,2].

Marine wind energy is the most mature type of renewable energy as regards technological development, commercialization, policy frameworks, and installed capacity among all forms of MRE [3]. On these grounds, offshore wind energy is the most promising and favorable type of MRE to be developed in the MS within the next few years. According to [4], by the end of 2016, 86\% of the worldwide offshore wind capacity has been installed in the seas of the top-five European countries with offshore wind installations (UK, Germany, Denmark, Netherlands and Belgium). "Renewable Energy Sources and Climate Change Mitigation", a special report published by the Intergovernmental Panel on Climate Change (IPCC), has highlighted that tidal energy technology, regarding specifically tidal barrages, is also in a mature state, however, this is not the case as regards exploitation of tidal current energy. The relevant technologies are still at an early development stage. See Section 2.3 while the rest of $\mathrm{OE}$ technologies mostly range from the conceptual to the prototype phase [5]. A potential timeline for the future development stages of the OE technologies (wave, current, and thermal/salinity gradients) has been provided in Figure 4 of [6]. Given the EU target of $20 \%$ energy generation from renewable sources by 2020 and at least $27 \%$ share for renewable energy by 2030 , significant MRE development is expected to be achieved over the next few years. It is anticipated that the installed capacity for marine wind up to 2020 will reach $24.6 \mathrm{GW}$ [7]. Critiques on the 2020 and $2030 \mathrm{EU}$ targets have been presented in [8,9], respectively. Despite Europe's leading role in MRE development, its status in the MS is still at its infancy; the development of MRE installations is, more or less, terra incognita, and, to some degree, it is expected to face similar but probably more intense problems than those encountered in the Northern European countries for reasons explained in the following sections. 
The objective of the present work is to provide an extended and pluralistic overview of the current status, potential problems, challenges, and perspectives of MRE development in the MS, with particular emphasis on offshore wind energy. The geomorphological, climatological, socio-economic and environmental/ecological particularities of the Mediterranean basin are also discussed, as they constitute the most important components of the spatial context in which MRE projects are to be implemented. General guidelines for the sustainable development of MRE in the MS are also provided, bearing in mind that, in a volatile economic environment, the key-role of the national and regional governments of the Mediterranean countries cannot be accurately prescribed.

Specifically, the following issues are elaborated in the remaining part of the paper: In Section 2, a description of the MRE sources and the current global development is presented. The particular geomorphological, ecological, oceanographic, and wind/wave climate features of the study area, along with some important economic activities (such as tourism and fisheries), relevant to the MRE development, are discussed in Section 3. Section 4 presents the available MRE potential in the Mediterranean, analyzes how the above-mentioned features are interrelated, and describes the way in which they are expected to shape the type and the degree of MRE penetration and development in the area. Moreover, the necessity of Marine Spatial Planning (MSP) and Environmental Impact Assessment (EIA) studies is also discussed and their importance is highlighted. In the last section, a potential roadmap for MRE development in the Mediterranean is proposed. The exploitation of the benefits and the necessary requirements that should be met for the rational MRE development in the basin are also discussed. Inevitably, the discussion is focused on the Mediterranean EU Member States.

\section{Global Status of Marine Renewable Energy}

In this section, the different types of MRE, in terms of existing technologies and global development status, are presented. Discussion of the various aspects of MRE development on a global basis will facilitate the subsequent discussion for MRE development in the MS. Current status and future perspectives of MRE have also been discussed in [10] with respect to technical, economic, administrative, and environmental issues; however, no specific reference has been made for the MS. See also [11] for a short introduction on the topic of MRE including some trends and challenges.

\subsection{Offshore Wind Energy}

Offshore wind power is generated from the wind blowing over the sea. Taking advantage of the existing experience from onshore wind turbine (WT) installations, offshore wind power referring to bottom fixed WTs is currently the most mature MRE source, along with tidal barrages.

Offshore winds exhibit significant advantages compared to the winds on land: they blow more consistently, the power produced is considerably higher, the variability is less and there is much more space available for offshore wind installations [12,13].

In the relevant literature, there is no consensus on the particular quantities to be evaluated in order to quantify the available offshore wind resource. Recent estimations suggest that total global theoretical resource of offshore wind power density (the authors call this quantity 'total storage per unit area') exceeds $2 \times 10^{3} \mathrm{kWh} / \mathrm{m}^{2}$ [14]. This number has been estimated through the following relation:

$$
E_{P T}=\bar{P} H,
$$

respectively, where $E_{P T}$ is the total storage of wind energy, $\bar{P}$ is the annual average wind power density, and $H=365$ days $\times 24 \mathrm{~h} /$ day $=8760 \mathrm{~h}$. The effective and the exploitable storage of wind energy are then provided as follows:

$$
E_{P E}=\bar{P} H_{E} \text { and } E_{P D}=E_{P E} C_{E}
$$

where $H_{E}$ is the effective number of hours per year (i.e., the number of hours that wind speed ranges between 5 and $25 \mathrm{~m} / \mathrm{s}$ ) and $C_{E}=0.785$. 
A more detailed spatiotemporal assessment can be found in [15]. In [16], using Quick Scatterometer (QuikSCAT) observations, it has been estimated that the global offshore wind power is of the order of 39 TW. This estimate is rather realistic since it has accounted a turbine hub height of $100 \mathrm{~m}$ (above sea level), a 90-m rotor diameter, 3.0 MW nominal power, and WTs not visible from the shore, while ice free waters with depths up to $200 \mathrm{~m}$ have been assumed. For an overview of global offshore wind energy evaluations see also [17].

Over the past two decades, investment in offshore wind power generation has increased significantly, although it still remains low compared to the onshore wind growth (mainly due to the higher installation and maintenance costs). However, recent studies in Europe have indicated that there may be cost reductions of $40-50 \%$ for new offshore wind farms by 2021 [18]. Europe keeps a leading position in offshore wind power generation, satisfying $0.85 \%$ of total EU's electricity demand by offshore wind [4]. 84 offshore wind installations are currently located in European seas of 11 European countries. The installed capacity in the North Sea is 9099 MW (i.e., $72 \%$ of all installed offshore wind capacity in Europe), 2689 MW (16.4\%) in the Irish Sea, 1457 MW (11.5\%) in the Baltic Sea and $5 \mathrm{MW}$ in the Atlantic Ocean, resulting in a total installed offshore wind capacity for Europe equal to 12,250 MW [7]. The largest number of grid-connected turbines belongs to the UK (1472), followed by Germany (947), Denmark (517), and Netherlands (365) [7]. In recent years, China, Japan, South Korea, Taiwan, and USA have shown increasing interest in offshore wind development [19]. China is now at the third position in global offshore rankings (after the UK and Germany), while in 2016, the first offshore wind installation took place in the USA [4].

Technology

Progress in offshore WTs comprises the evolution from the simple 'marinization' of onshore WTs towards an offshore wind technology of increased turbine size and various types of support structures [20]. WTs have either horizontal or vertical axis of rotation of their main rotor shaft, but horizontal axis is preferred in modern commercial WTs [21]. The average size of tower height and rotor diameter has been increasing since 1991. As of 2012, the largest commercial WT (7.5 MW) had a rotor diameter of $127 \mathrm{~m}$, but today there exist even larger offshore turbines available (8.0 MW rated capacity and $164 \mathrm{~m}$ rotor diameter) [20]. Turbines of greater rotor diameter (up to $250 \mathrm{~m}$ ) and power capacity are currently under research and development (R\&D) [12]. The trends and technologies as regards onshore and offshore WTs have been presented in [22,23], respectively.

The type of foundation required (monopile, gravity-based, jacket, tripod, tripile, spar, and semisubmersible platform) depends primarily on bottom depth and morphology. According to the cumulative offshore wind power market [7], at the end of 2016 monopile substructures have remained the most popular ( $80.8 \%$ of current installations), followed by gravity based $(7.5 \%)$, jacket $(6.6 \%)$, tripode $(3.2 \%)$, tripile $(1.9 \%)$, and floating foundations $(0.02 \%)$. In 2012 , the average water installation depth of offshore wind farms (OWFs) in European waters was $22 \mathrm{~m}$ with an average distance to shore $29 \mathrm{~km}$, whereas by the end of 2016, they were $29.2 \mathrm{~m}$ and $43.5 \mathrm{~km}$, respectively [7]. Since the general trend in offshore wind installations is moving towards greater distances from shore and deeper waters, the sustainability of OWFs requires a shift from fixed to floating support structures [24]. The progress of floating turbine demonstration projects has been presented in [25]; see also [26,27]. In Figure 1, a semisubmersible offshore wind turbine (WindFloat) with a rated capacity of $2 \mathrm{MW}$ operating offshore Aguçadoura (Portugal) is depicted.

It is anticipated that the commercial establishment of floating turbines will drastically change the status of the offshore wind industry and its development $[28,29]$. Recently, a world map has been published providing an overview of current and future floating WT projects, while future projects planned beyond 2020 are also included [30]. According to the same source, it is anticipated that more than 40 units will be connected to the grid by 2021 at a global scale. 


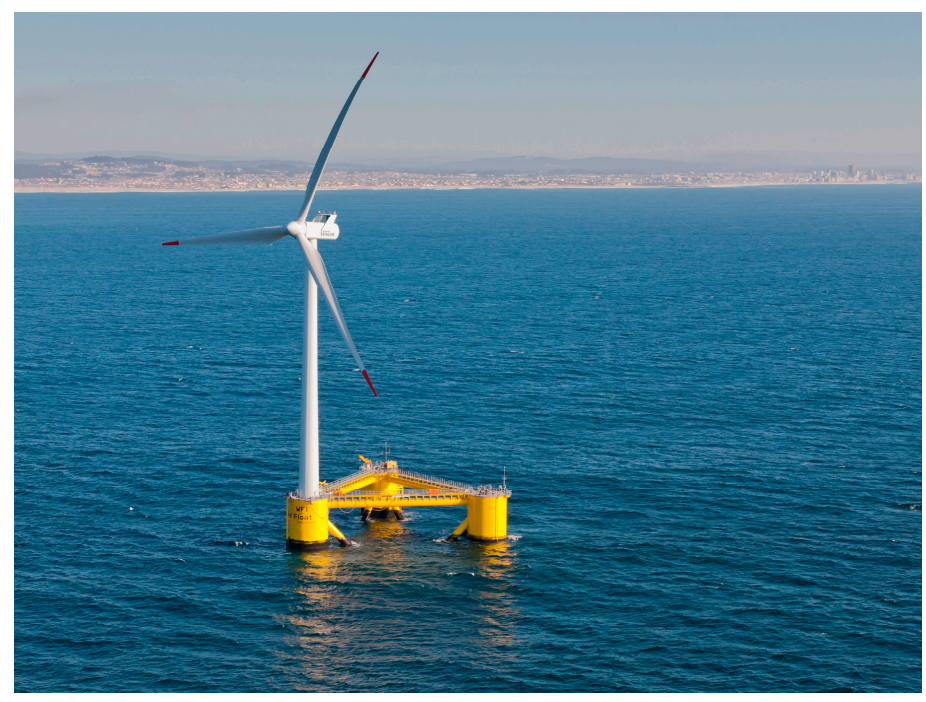

Figure 1. WindFloat: a semisubmersible floating $2 \mathrm{MW}$ offshore wind turbine installation offshore Aguçadoura, Portugal. (Source: A semi-submersible type floating offshore wind turbine foundation called the WindFloat operating at rated capacity (2 MW) approximately $5 \mathrm{~km}$ offshore of Agucadoura, Portugal by Untrakdrover, retrieved from https://en.wikipedia.org/wiki/File: Agucadoura_WindFloat_Prototype.jpg. Used under Creative Commons Attribution-Share Alike 3.0 Unported license).

Progress in R\&D as well as accumulated experience in the offshore wind sector are expected to further reduce high installation and connection costs. On March 2015, the European Wind Energy Association (EWEA) published a study on marine wind in Europe, pointing out that these costs could be reduced to $90 € /$ MWh by 2030 [31]. The levelized cost of energy (LCOE) is expected to be reduced to $100 € /$ MWh by 2020. The same study has highlighted the importance of specific actions that need to be taken in order to meet this goal; these actions include deployment of larger turbines, competition among industrial players, commissioning new projects, and existence of an appropriate and efficient policy framework [32].

\subsection{Wave Energy}

Wave energy is marine hydrokinetic energy that can be harvested from the motion of ocean waves. Sea surface waves are generated by wind, through complicated air-sea interaction processes. Evidently, wave energy largely depends on wind speed, fetch length, and fetch duration, as they determine, to a great extent, the most important wave properties (significant wave height, energy period). Wave energy has several advantages: waves present the highest energy density among other MRE sources (yet the main challenge is to develop an efficient device for highest wave power take-off), energy loss is rather small even for long distances of wave propagation in the form of swell, and seasonal variability of wave resource and electricity demand in moderate climates is highly correlated [33]. Compared with offshore wind energy, wave energy is more persistent and spatially concentrated [34]. On the other hand, waves present a largely random variability in several time scales (see e.g., [33,35]), while wave predictability is based on wind predictability and, therefore, is associated with even greater errors and uncertainties. Additionally, various hydrodynamic processes caused by wave phenomena, such as diffraction and radiation [36], complicate the exploitation of wave energy conversion into electrical power, adding structural and economic challenges.

Ocean waves constitute a huge (theoretical) global potential energy source. The theoretical (gross) wave potential limited to deep water off the coastlines has been estimated around $3700 \mathrm{GWh}$, while the theoretical net power (excluding areas where the power level is below $5 \mathrm{~kW} / \mathrm{m}$ and areas impacted by sea ice) has been estimated at 2985 GWh (for the Mediterranean basin, the corresponding estimates 
are 75 and $37 \mathrm{GWh}$ [37]. A recent estimate of the net global wave power resource, taking into account the mean direction of sea-state propagation and excluding areas of low energy levels and areas with ice coverage, is 15,270 TWh/year, excluding the coasts of the MS [38]. Disregarding the direction of sea-states, the net global wave power resource has been estimated at $3167.1 \mathrm{GWh}$, a value very close to that provided in [37]. Other assessments of the global wave resource can be found in $[39,40]$. Although based on rather short length time series of spectral parameters, an interesting and detailed work, as regards the estimation of the global wave resource, has been presented in [41].

In 2000, Islay Limpet was the first grid-connected commercial scale wave energy device (500 kW, Scotland). Islay Limpet was decommissioned in 2013. In 2004, two wave energy converter (WEC) prototypes were deployed in the UK (Pelamis, $750 \mathrm{~kW}$ ) and Portugal (Archimedes Wave Swing, $2 \mathrm{MW}$ ) [42]. The first wave energy project was the Aguçadoura wave farm in Portugal installed in 2008. The wave farm comprised three Pelamis WECs (2.25 MW total capacity). The farm stopped its operation after two months. In 2011, a commercial breakwater wave plant started operating in Spain (Mutriku) that consisted of 16 turbo generators with $296 \mathrm{~kW}$ of total capacity. In 2015, the first installation of the SINN Power WEC module $(20 \mathrm{~kW})$ was made in the port of Heraklion, Crete [43]. A current list of wave power projects in the world ocean has been provided in [44].

\subsubsection{Technology}

Wave energy technology is far behind offshore wind. An advantage of the wave energy technology, which can be considered as a disadvantage at the same time, is the wide diversity of design concepts. Different technologies use different solutions to harness energy from sea waves and are suited to operate at different water depths and locations. Although the wave energy sector has attracted remarkable R\&D over the past decades, leading to numerous prototypes, the marketing stage is still non-existent; on the other hand, this multitude of technologies does not allow the wave energy sector to reach convergence, except for a slight preference to point absorbers [45]. In [46], it has been mentioned that more than 100 wave energy projects are globally under development, while more than 1000 patents have been filed, with Europe keeping the leading role in wave energy development [36,47]. The predominant types of WECs based on their orientation (with regard to wave direction and principle of operation) are the attenuator, the point absorber, the oscillating wave surge converter, the oscillating water column, and the overtopping device; see $[48,49]$ and references cited therein. An alternative categorization of WECs has been presented in [40].

Wave attenuators are most commonly floating devices lying parallel to the predominant wave direction. They can be located either in shallow or deep waters, while the output power varies from $200 \mathrm{~kW}$ to 2.5 MW. A well-known example of wave attenuators is the P2 Pelamis device [50]; see also Figure 2. Point absorbers are smaller devices capable of collecting energy from all wave directions. They are either floating or submerged, deployed in deep waters, or near shore. They can be moored (e.g., AquaBuoy) or bottom fixed (e.g., Lysekil project) and the output power varies from $20 \mathrm{~kW}$ to $6 \mathrm{MW}$. Oscillating wave surge converters capture energy from wave surges as they are positioned perpendicular to the wave direction (terminator type). They are mostly bottom fixed and slack moored (e.g., WaveRoller, Wavepiston) and installed mainly nearshore (e.g., Aquamarine Power Oyster). Oscillating water column (OWC) consists of a column that is open to the sea below the water surface. In the inner space of the column and above the free-surface, the air is trapped. Then according to the wave momentum, the water oscillates up and down compressing and decompressing the air within the column forcing it to flow through an air turbine. It is mostly a shore-based structure, such as LIMPET, Mutriku [51], but it can also be anchored in deep waters; e.g., Ocean Energy Buoy [52]. The output power varies from $300 \mathrm{~kW}$ to $1 \mathrm{MW}$. A review on the OWC devices can be found in [53]. Overtopping devices (floating or bottom fixed) force water to pass over the structure, collect it in an above sea level reservoir, and then release it through hydro turbines. The potential energy of the water in the tank is converted to electricity. A typical overtopping device is Wave Dragon, with an output power ranging from 4 to $11 \mathrm{MW}[35,36,45,54]$. 


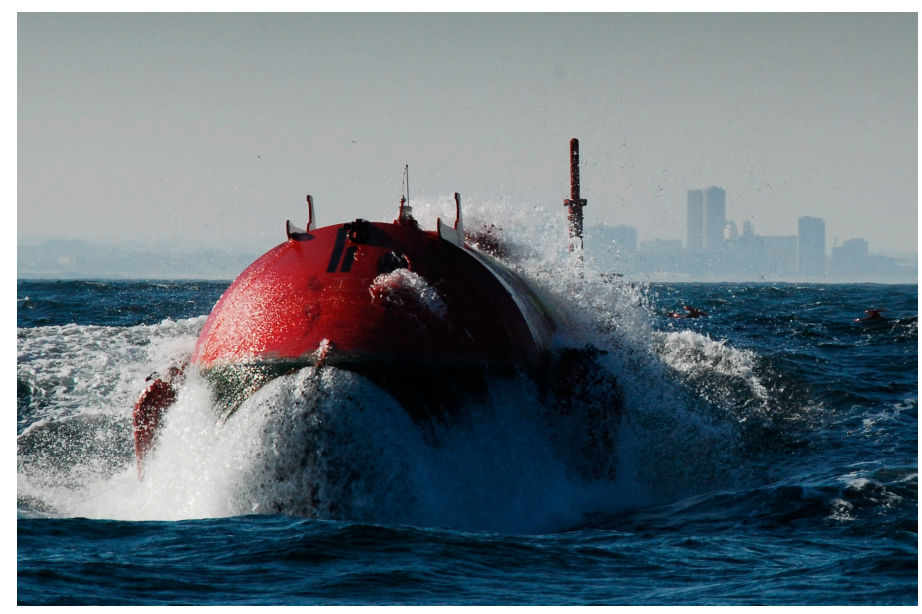

Figure 2. The Pelamis wave energy converter. (Source: Pelamis Wave Energy Converter on site at the European Marine Energy Test Center (EMEC) by P123, retrieved from https:/ / commons.wikimedia. org/wiki/File:Pelamis_at_EMEC.jpg).

Sea testing experience in several European test centers (Danish Wave Energy Center, European Marine Energy Center, Wave Hub, etc.) significantly contributed to the wave energy sector in approaching a commercially viable stage. However, installation of WECs away from shore is a considerable problem, suggesting that survivability and maintenance of the relevant equipment are still open problems demanding a solution [10]. According to [55], under the current conditions, wave energy is not expected to become cost-competitive in Europe within the next 30 years. Moreover, the power transmission options and specific problems for MRE converter farms (e.g., the multitude of the subsea components operating in harsh environments) have been analytically discussed in [56] along with some optimization schemes considering as a test case the Pelamis P1 device; see also [45,57]. The status of wave energy progress in Europe has been described in [58], while an overview of the wave energy economics can be found in $[59,60]$. An account of multiple aspects as regards wave energy, including wave energy resource, economics, and technology of WECs, has been provided in [40].

\subsubsection{Synergies with Offshore Wind}

During the last decade, the idea of harnessing the combined offshore wind and wave energy has arisen. Collocated, hybrid, and island systems are currently under research. A review of these issues can be found in [61], while an overview of modelling and control solutions for WTs and WECs has been made in [62]. In order to provide economically viable solutions, synergies through hybrid systems should be carefully studied with respect to the selection of suitable locations as well as the most appropriate options of combining entirely different and of dissimilar readiness level technologies into a sole device. A significant advantage of hybrid systems is the sharing of the same mooring system, electrical connection and other necessary infrastructure by the WEC and the floating turbine installation. Thus, it is anticipated that the costs of installation, and operation and maintenance (O\&M) may be decreased [63]. The most recent relevant patented technology is developed by the Danish company Floating Power Plant; for more details, see [64]. The model P80 consists in a single WT (5-8 MW) mounted on a floating platform capable also to produce 2-3.6 MW of wave power. For other innovative designs of hybrid systems; see [65-67]. In [66], a hybrid solution has been proposed combining a floating WT based on a spar substructure with an oscillating buoy serving as WEC. Although hybrid systems have attracted the most interest, collocated systems are associated with lower development costs combined with lower risk; therefore, they are likely to be preferred. Some guidelines for the optimal design of collocated wind and wave energy systems have been provided in [68]. For additional aspects of collocated systems; see [69-73]. A methodology for cost assessment regarding such hybrid systems has been provided in [74]. 


\subsection{Tidal Energy}

Tidal energy is the hydrokinetic energy extracted either from sea level fluctuations due to tidal range or from tidally driven currents [75]. Tidal energy technologies can be roughly classified into two categories: (i) tidal range technologies harnessing the tidal amplitude resource, usually referred to as tidal barrages; and (ii) tidal current or tidal stream technologies harnessing the tidal currents resource, referred to as tidal-stream energy converters (TECs).

Tidal energy devices extract energy from the flow of the currents in order to actuate a rotor or foil. A power take-off mechanism converts this mechanical motion to electricity. Tidal energy is a higher density energy form in comparison with marine wind. Global tidal energy potential is estimated to be approximately $3 \mathrm{TW}$, while $1 \mathrm{TW}$ is technically exploitable [76]. Since the variability of tides is to a great extent deterministic (unlike the wind/wave case), the main advantage of tidal energy is high predictability [75]. However, tidal energy is purely location dependent, as significant tidal ranges or current velocities occur only in particular sites. Local conditions further determine flow velocity profile according to bathymetry, seabed roughness and the surrounding land mass topography. Resonant estuaries have most commonly the largest tidal range and are in principle appropriate for tidal barrages installations. Examples of such locations can be found in Canada (Bay of Fundy, mean tidal range: $11.7 \mathrm{~m}$ ), France (La Rance, mean tidal range: $8.5 \mathrm{~m}$ ), and the UK (Severn Estuary, mean tidal range: $7.0 \mathrm{~m}$ ). Sihwa Lake in Korea $(254 \mathrm{MW})$ and La Rance Tidal Power Stations in France (240 MW) are the world's largest tidal barrages; see also [1,76].

Installation and grid-connection of TECs have taken place in several locations around the world. The UK, France, Norway, Germany, Denmark, Ireland, Netherlands, Sweden, Italy, Spain, South Korea, Australia, and USA have been involved in tidal energy sector. The Northern European Seas have a significant tidal energy potential, while the UK and France have the greatest resource [77]. The first full-scale prototype tidal energy turbine was installed in 2003 in the UK (Seaflow prototype). During the period 2006-2013, more than 40 new devices were introduced and their testing procedures were initiated [76]. In 2012, European Marine Energy Center (EMEC) installed five tidal devices (4 MW) in the UK waters for testing. Italy and Norway have also installed prototypes for testing, France has started testing a tidal energy farm of 2 MW since January 2013 [77], and a tidal floating platform $(200 \mathrm{~kW})$ was demonstrated in the Netherlands on March 2015 [78]. A list of tidal energy projects has been provided in [79].

Along with wave energy, tidal-stream energy evolution in Europe is currently moving towards the construction of tidal arrays. According to [55], tidal-stream energy may be cost-effective in 2050, provided that major technological advancements are achieved. Nevertheless, tidal barrages have a long history of implementation and utilization and are economically viable provided that they are built in appropriately chosen locations, combining other functions as well.

\section{Technology}

Tidal barrages are used since the middle of the 20th century. Their operation is based on impounding water (tidal flow) within an estuary or bay, which in turn is released through turbines. In this way, the potential energy stored behind the barrage is converted into electrical power. This technology is still in progress since some relevant new innovative concepts are introduced (tidal fences, tidal lagoons, etc.) [76].

Due to high capital costs and environmental impacts of tidal barrages, development interest is currently focused on generating power by harnessing the kinetic energy of currents through TECs [80]. TECs can be classified in seven types, according to the technical concepts underlying the devices' operation. The horizontal and the vertical axis turbines extract energy from the tidal flow using blades that are positioned either in parallel or perpendicular to the direction of the flow. Hydrofoil TECs (reciprocating devices) have hydrofoils that follow a vertical oscillatory motion as the tidal stream flows. This motion is used to support a hydraulic system for power generation. Ducted devices allow the use of rotors with smaller diameters by accelerating water flow. Rotating screw-like devices and 
tidal kites carry turbines below their wings. The latter have the advantage of energy extraction from considerably lower-velocity flows. Tidal energy technology has reached convergence (much more than wave energy technology) by adopting the horizontal axis turbines in most of the relevant projects [76]. According to the type of foundation, TECs can be classified into three categories: gravity structures, piled structures, and floating [81]. An example of a semi-submersible tidal energy device is shown in Figure 3.

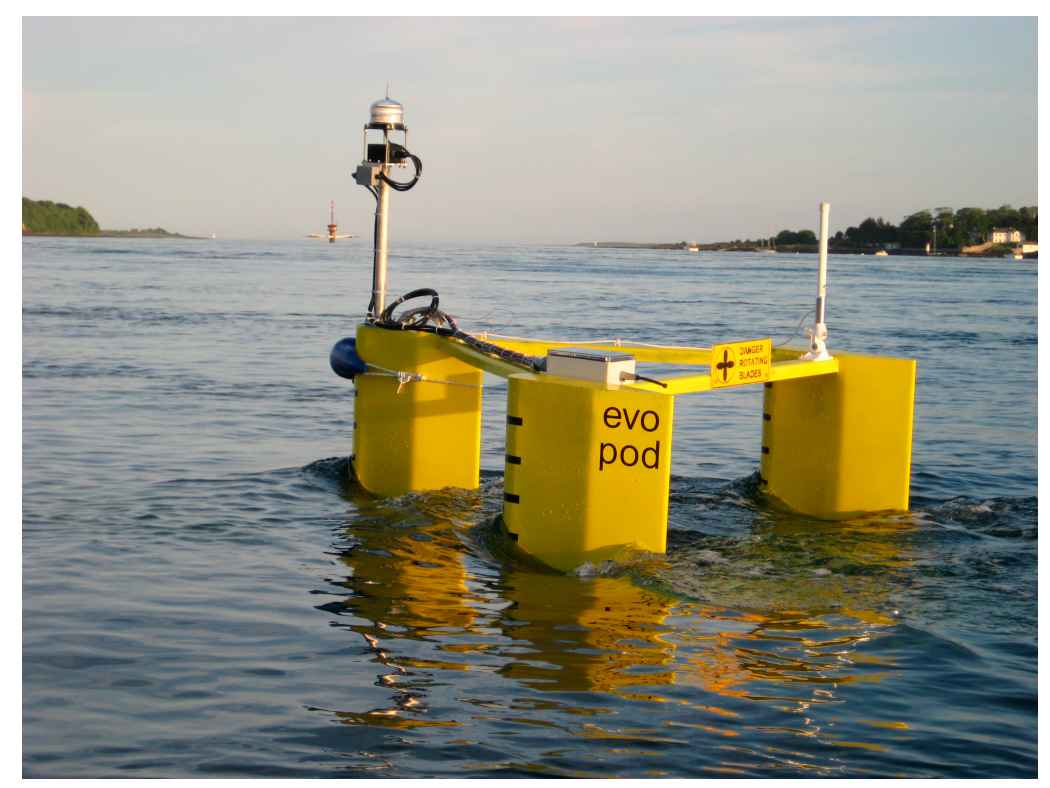

Figure 3. The prototype Evopod semi-submerged tidal energy device. (Source: A Picture of Evopod installed in Strangford Lough near Portaferry, Northern Ireland, by Ocean Flow Energy Ltd, retrieved from https:/ / commons.wikimedia.org/wiki/File:Evopod_in_Strangford_Lough_2008.jpg).

The choice for the foundation depends mostly on the bottom depth and the position of the device. As has been noted in [82], first-generation TECs operate with mean peak spring-tide speeds above $2.5 \mathrm{~m} / \mathrm{s}$ and at water depths $25-50 \mathrm{~m}$. The corresponding thresholds for more advanced TEC technologies are $2 \mathrm{~m} / \mathrm{s}$ and greater than $25 \mathrm{~m}$, respectively. In any case, though, the above current speed thresholds are restrictive for most areas of the world ocean, including the MS.

Summing up, regarding offshore wind, wave, and tidal energy, the EU is currently at the top position regarding technology development. Europe hosts about $45 \%$ of wave energy and more than $50 \%$ of tidal energy developers [10]. Given the rapid progress of the offshore wind sector and the beginning of tidal and, in smaller extent, wave energy commercial exploitation, the growing demand for further testing and modelling of all corresponding devices has been highlighted in [46]. In this context, certain methodologies have been introduced based on the International Towing Tank Conference (ITTC) guidelines. Finally, the most important issue related to the maintenance of the MRE devices and farms (with particular emphasis on tidal energy devices and WECs) has been discussed analytically in [83].

\subsection{Thermal and Salinity Gradients Energy Conversion}

\subsubsection{Ocean Thermal Energy Conversion}

Ocean thermal energy conversion (OTEC) is a technology that harnesses solar energy by making use of the differences between ocean surface and subsurface temperature. OTEC power generation requires a temperature gradient greater than $20^{\circ} \mathrm{C}$; this gradient is meaningful at depths of the order of $1 \mathrm{~km}$. Consequently, high potential for OTEC projects exists in tropical and equatorial areas where ocean thermocline is large. In a first attempt to theoretically evaluate the available energy 
potential regarding OTEC, it was estimated that the global OTEC resources have a limit of 3 to 5 TW [84]. However, in a subsequent work [85], where a three-dimensional circulation model has been implemented, the maximum for global OTEC power production has been estimated at $30 \mathrm{TW}$. In order to minimize the possible effects on the oceanic thermal structure, a more reasonable OTEC scenario with a global potential of the order of 7 TW has been proposed by the authors.

Heat exchangers and turbine generators are used to convert the temperature differences to electricity. OTEC converters can be either land- or sea-based, or mounted on floating platforms. Considering the operational concept of the existing convertors, three technology categories can be distinguished: open-cycle OTEC, closed-cycle OTEC, and hybrid systems. Open-cycle OTECs use the surface water as a working fluid. The evaporation of the warm water causes the production of low pressure steam in a low-pressure container. The vapor activates a generator and finally is condensed by the deep seawater. Open-cycle OTEC systems can be used for producing electricity and desalinating water through multiple condensers; these issues have been studied in [86], where a complete analysis of the requirements for an optimized dual use open-cycle OTEC have been also provided. The closed-cycle OTECs use, instead of surface water, a fluid of a lower boiling point. The upper sea surface water makes the fluid to boil. The created expanding vapor drives a generator through a turbine, producing electrical power. See also Figure 4, where the operating principle of OTEC is schematically depicted. Hybrid systems constitute a combination of the above categories [87].

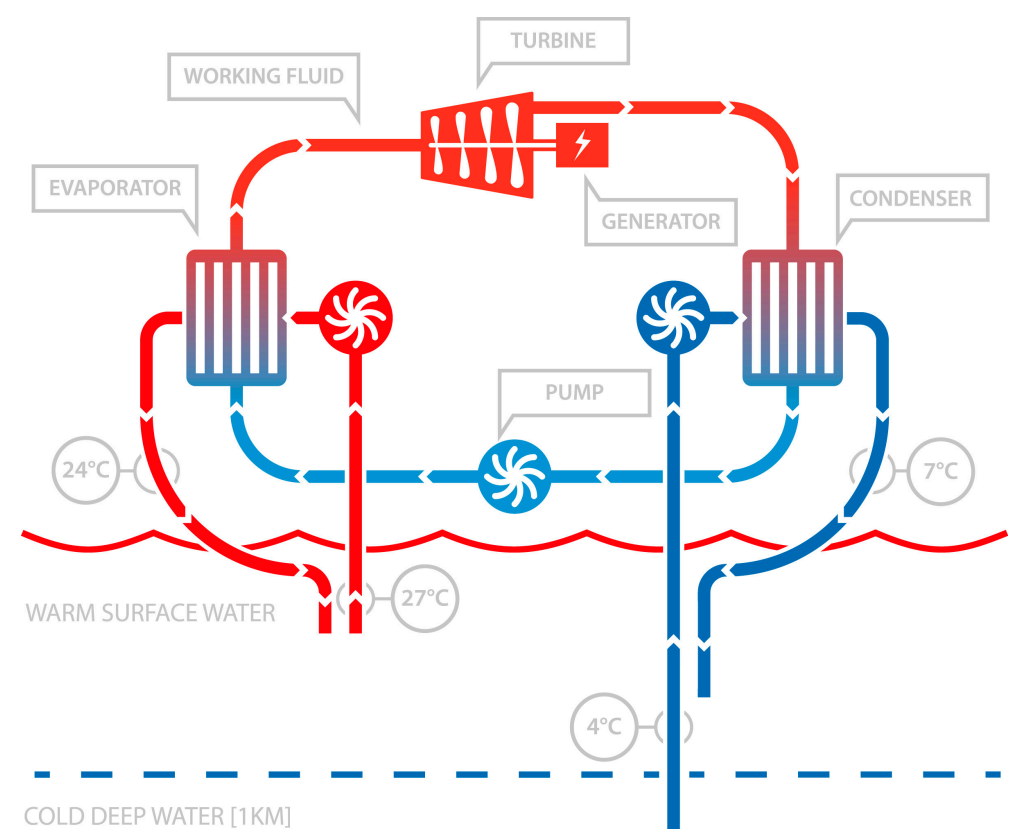

Figure 4. OTEC operation principle. [Source: OTEC working principle by Bluerise BV, retrieved from https://commons.wikimedia.org/wiki/File:OTEC_working_principle.jpg. Used under Creative Commons Attribution-Share Alike 4.0 International license].

Despite the first OTEC plant was constructed in Cuba in 1930, large scale projects have not been implemented yet. The largest (1 MW) OTEC plant ever built, operated from 1993 to 1998, in Hawaii. Currently, several projects of up to $10 \mathrm{MW}$ are under development, while concepts and prototypes concerning many countries around the world are currently being explored. Malaysia, Oman, China, Philippines, South Korea, USA, and Zanzibar are involved in OTEC sector [5]. In 2014, DCNS group and Akuo Energy were awarded a European NER 300 funding in order to develop an offshore pilot OTEC plant in Martinique (NEMO project) [88]. The 10.7 MW capacity plant will be operational by 2020. Lists of current OTEC projects can be found in $[89,90]$. 
Large resource potential, continuous energy supply, and the possibility of cooling without electricity consumption are the main advantages of OTECs [5]. A main technological challenge in the sector is the construction of large devices capable of resisting the harsh marine environment conditions. The need for large scale developments is due to the utilization of small temperature differences that demand very large volumes of water [91].

\subsubsection{Salinity Gradient Energy}

Salinity gradient energy (osmotic power) is based on the salinity gradients between fresh and salt water. Fluids of different concentration tend to diffuse until the mixture becomes homogeneous. River mouths are potentially abundant locations for the exploitation of salinity gradient energy [92]. Global technically exploitable potential is currently estimated at around $647 \mathrm{GW}$, although lack of consideration of legal and environmental parameters may have led to an overestimation [93]. Ocean salinity gradients have an estimated technical potential of about $1650 \mathrm{TWh} /$ year; see [1] and references cited therein. On the other hand, a practical and detailed account of the available salinity gradient energy resource has been presented in [94]; according to this source, the globally extractable energy from river mouths is $625 \mathrm{TWh}$ /year, equivalent to $3 \%$ of global electricity consumption.

The technical concept leading to potential energy gain is the installation of particular membranes between fresh and salt water in order to control the diffusion process. Two membrane-based technologies are mainly used to harness salinity gradient energy: reversed electro-dialysis process, based on fresh and salt water's difference in chemical potential, and pressure-retarded osmosis, driven by the natural mixing tendency of fresh and salt water. The existing applications are the "standalone power plants" (located in estuaries) and the hybrid solutions, recovering energy from production processes such as desalination or salt mining [93].

The first osmotic power plant was developed in Norway by Statkraft and became operational in 2009 with $10 \mathrm{~kW}$ capacity [5,95], but its operation was discontinued due to membrane fouling [1]. Further research has been conducted by the same company, but was not completed due to insufficient financial support. At present, pilot projects exist in Norway and the Netherlands, as well as research projects in Germany, Italy, Canada, Japan, Singapore, South Korea, and USA. Recent development in membrane technologies, aiming in cost reductions and economical energy production, has led to increasing interest in the sector, expecting membrane-based technologies to enter the commercial stage around $2020[5,93,95,96]$.

\section{The Mediterranean Basin at a Glance}

In this section, an overall description of the main, multifaceted characteristics of the Mediterranean basin is presented. These characteristics are interrelated and expected to shape to a large degree the MRE development in the examined area. Firstly, the most relevant geomorphological, ecological, and oceanographic issues are discussed, together with the main features of wind and wave climate since they impose some rigid frameworks that cannot be overlooked in any future MRE industry developments in the area. Moreover, since it is expected that MRE development will influence significantly important economic sectors in the Mediterranean countries (tourism, fisheries, maritime transport, fish farming, and aquaculture), their corresponding statuses are also described.

\subsection{Geomorphological Characteristics}

The Mediterranean basin is characterized by geomorphological particularities that are interconnected to the MRE feasibility of development. The coastline is remarkably long and irregular, mostly due to the presence of the Iberian, Italian, and Balkan peninsulas. Its length is estimated to be approximately $46,000 \mathrm{~km}$, of which nearly $19,000 \mathrm{~km}$ belong to islands [97]. The coastlines are surrounded by mountain ranges and deltaic zones of large rivers [98]. Of the coastal areas, $54 \%$ have rocky shores where even high cliffs exist (Spain, Croatia), while $46 \%$ have sandy shores (beaches, dunes, reefs, deltas) [99]. The average depth of the MS is approximately $1500 \mathrm{~m}$. The Strait of Sicily 
connects the western with the eastern Mediterranean sub-basin through a shallow ridge of $400 \mathrm{~m}$ depth [100]. The shallowest part of the entire basin $(50 \mathrm{~m})$ is in the northern Adriatic, while the deepest point $(5121 \mathrm{~m}$ ) is located at the Hellenic Trench in southwest Greece [101]. The western Mediterranean basin has a flat seabed, while the eastern presents a special sea floor topography [99].

The MS has a rather narrow continental shelf, as mountain slopes drop steeply into the sea. Specifically, narrow and steep continental shelves exist off the coasts of southern and northern Turkey, Crete, Maritime Alps, Africa, Sardinia, Corsica and western Italian coast, Iberian Peninsula, and the Balearic Islands. Wide (more than $50 \mathrm{~km}$ ) continental shelves are encountered off the estuaries of the Ebro and Rhone rivers. Due to the Po delta deposits, Adriatic Sea presents a particularly well-developed continental shelf with extended shallow areas (of less than $100 \mathrm{~m}$ water depths); see $[98,102]$. The same holds true for the area of the Nile estuary. Depth ranges that are currently appropriate for MRE applications in the MS are shown in the bathymetric map of Figure 5; see also Section 4.2.

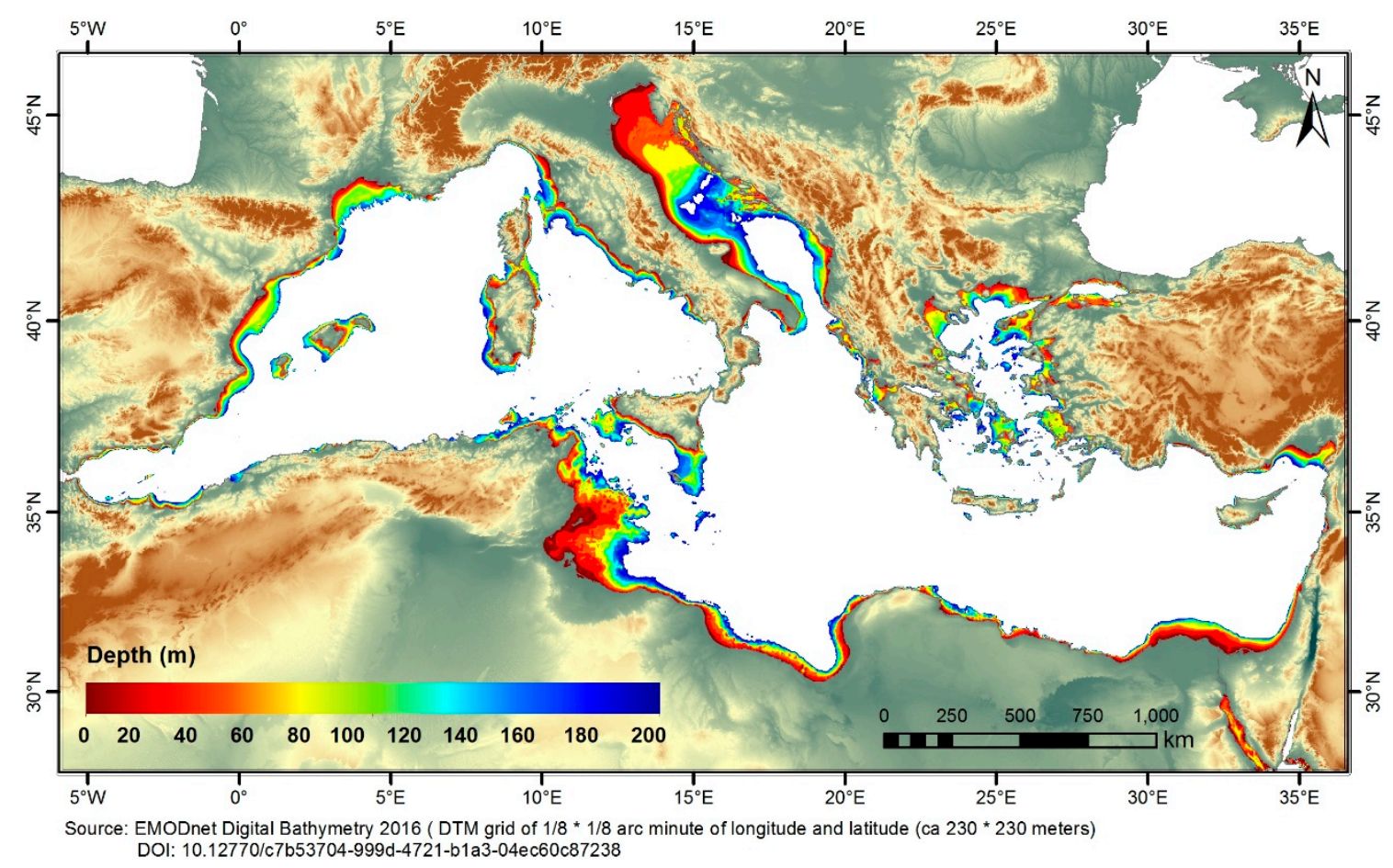

Figure 5. Bathymetric map of the Mediterranean Sea (depth range 0-200 m). Data analyzed by the Hellenic Center for Marine Research (HCMR).

\subsection{Wind and Wave Climate}

Several local and regional winds are characterized by a strong seasonal variability flow over the MS, such as Mistral, Tramontana, Sirocco, Etesian, and Bora. Mistral is a strong jet blowing over the Gulf of Lion and the Ligurian Sea, up to the southern Mediterranean shore and the Ionian Sea. Tramontana belongs to the Mistral local wind system and blows north-westerly over the Roussillon region. Sirocco blows north-westerly over the Adriatic where the channelling effect caused by the local orography intensifies the flow. Bora blows north-easterly over the Adriatic and the Aegean [103]. The Etesian winds are persistent northerly winds blowing during the summer over the Aegean Sea; their strength is affected by the tropospheric dynamics over the Eastern Mediterranean [104]. In Figure 6, the mean annual wind climate in the MS, obtained by the ETA numerical model results [105], is depicted. According to these results, the Mediterranean wind pattern presents several localized extremes, such as the Gulf of Lion and the central Aegean Sea (mean annual wind speed of the order of $8 \mathrm{~m} / \mathrm{s}$ ), and the Kasos Straits in south-eastern Aegean Sea. The highest mean annual variability is exhibited in 
the northern part of the Adriatic Sea, and then in the Ligurian Sea, the Tyrrhenian Sea (especially offshore the northern coasts of Sicily), the northern Aegean Sea, the Gulf of Antalya, and the Balearic Sea (between Palma de Mallorca, Ibiza, and the eastern coasts of Spain). The highest inter-annual variability appears near the coasts of Monaco and then in the northern Adriatic, Tyrrhenian, and Balearic Seas; the Gulf of Lion; the coasts of Algeria; and the Ionian and the central Aegean Sea. Recently, an in-depth assessment of the wind climate and its variability in the MS is analytically presented, using a 36-year dataset (1979-2014) from the ERA-Interim reanalysis [106]. The data were available from the European Centre For Medium-Range Weather Forecasts (ECMWF).

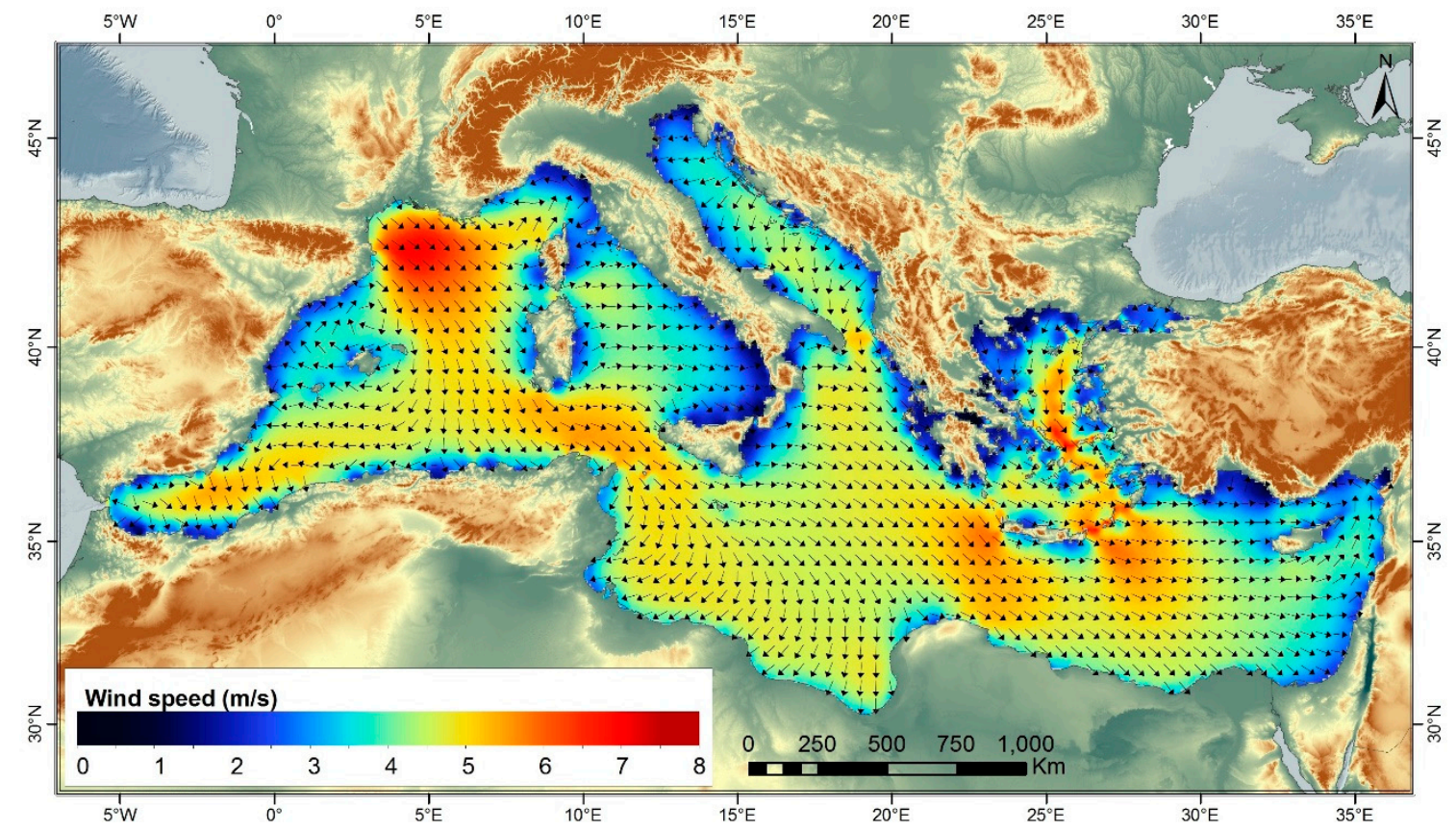

Figure 6. Mean annual wind climate (at $10 \mathrm{~m}$ above sea level) in the Mediterranean Sea according to the ETA model. Arrows indicate the mean annual wind direction (Source: [107]). Data analyzed by HCMR.

The Mediterranean waves are short-crested and highly dependent on the existence of wind forcing. They are much smaller than the Atlantic waves, as limited fetch lengths in the basin prevent waves from travelling for long distances without large dissipation (swell). Higher values of significant wave heights occur when strong winds and long fetch exist simultaneously. The most effective combination of the above features is met in the Western Mediterranean and the Ionian Sea. Despite the limited fetch, measurements with moored buoys in the Mediterranean as well as numerical modelling results reveal the existence of sea states with significant wave height of the order of 5-7 m, or even up to 10-11 m in the case of very extreme storms. In the Gulf of Lion, $70 \%$ of the waves have a wave height greater than $1 \mathrm{~m}$, while $20 \%$ have a wave height above $2.5 \mathrm{~m}$ (southeast of this zone) [103]. The mean annual wave climate of the MS, in terms of significant wave height-mean wave direction and energy period (defined as $T_{e} \equiv T_{-10}=m_{-1} / m_{0}$, where $m_{-1}$ and $m_{0}$ are the -1 and zero-th order wave spectral moments, respectively) is provided in Figure 7. The data are obtained from the ERA-Interim database (of the ECMWF) and cover the period 1979-2013. 


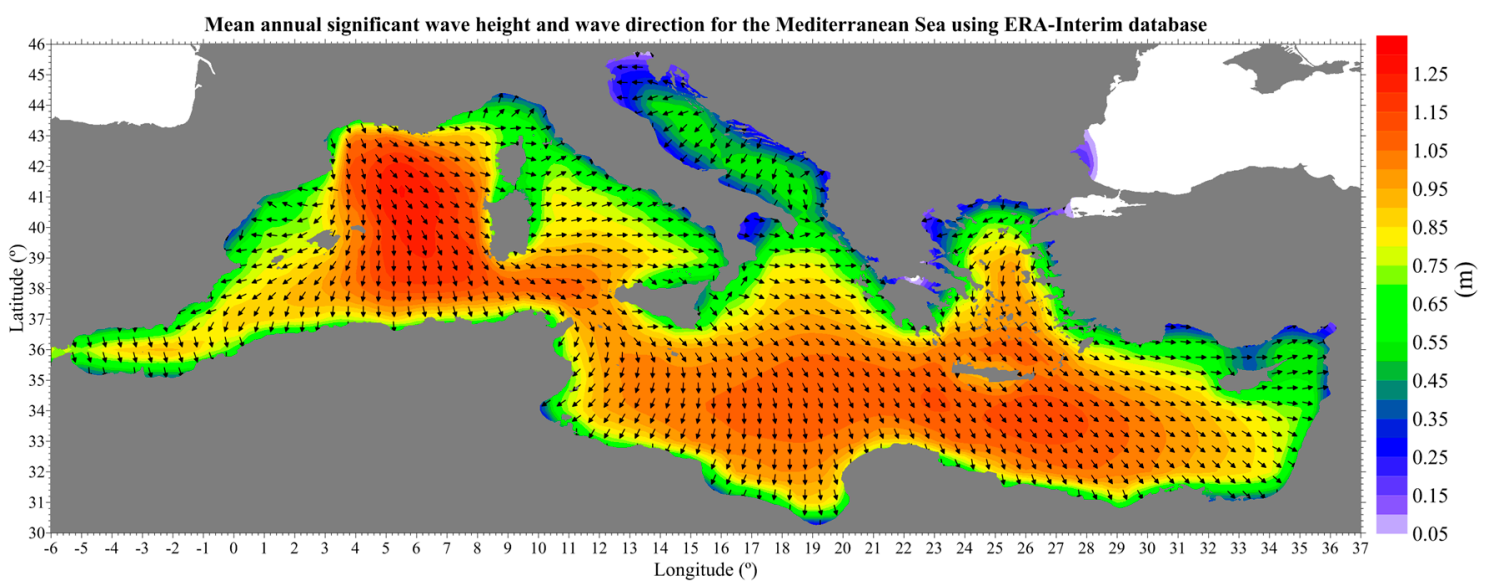

(a)

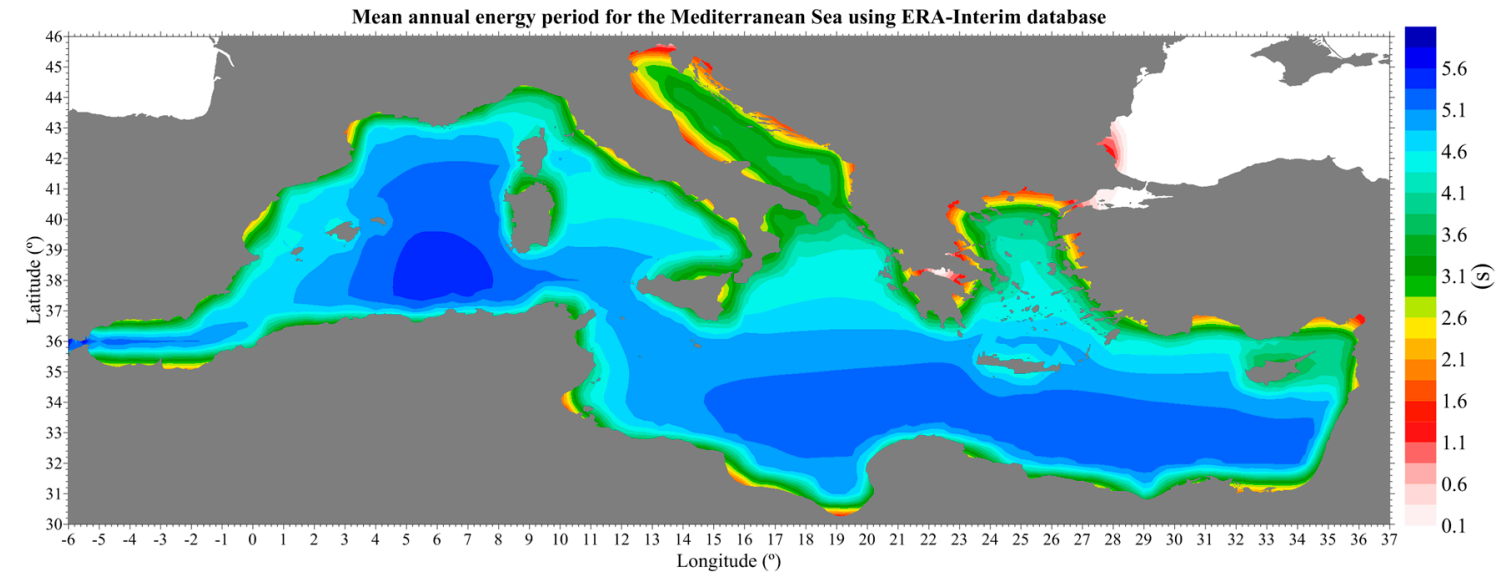

(b)

Figure 7. Mean annual wave climate in the Mediterranean Sea: (a) Significant wave height and mean wave direction; (b) Energy period. Data obtained from the ERA-Interim database (1979-2013) of the ECMWF and analyzed by HCMR.

\subsection{Ecological Characteristics}

The MS is characterized by high-level biodiversity, with a high percentage of endemic species $[101,108]$. The variable topography of the basin and the climatic and hydrologic conditions of its ecosystems allow the presence of both temperate and subtropical species. Specifically, the basin hosts between $4 \%$ and $18 \%$ of the world's marine species, many of which are endemic to the Mediterranean [109]. The Western Mediterranean hosts the greatest diversity of sea turtles, marine mammals, and seabird life [97].

The MS contains sensitive deep-sea, pelagic, and coastal habitats, intact shorelines, estuaries, underwater canyons, coralligenous assemblages, along with 150 important wetlands for birds, and around 5000 islands and islets; see [100,110]. The most important coastal habitats are sea grass ecosystems with the endemic Posidonia Oceanica meadows having the highest economic and ecologic value. They cover about $50,000 \mathrm{~km}^{2}$ of both sandy and rocky areas of the MS, reaching depths up to $45 \mathrm{~m}$. Meadows of Posidonia Oceanica are important nursery areas for fish, supporting 25\% of the MS fish species. They also have a major role in maintaining seashore stability. Along with Zostera Marina, Posidonia oceanica sea grass is considered endangered species, facing a number of pressures from human activities $[97,111,112]$.

Numerous protected areas (marine and coastal) are established in the MS in order to mitigate the effects of pressures on the fauna, flora, habitats as well as the biodiversity of the basin. Protected areas are considered as very effective tools for management and conservation purposes. According to the 
Regional Activity Center for Specially Protected Areas (RAC/SPA), conservation areas of high priority and of ecological significance are found mostly in the Gulf of Lion, the Gibraltar and Sicily Straits, and the Adriatic, Ionian, north Aegean and Levantine Seas [113]. A review on the Marine Protected Areas (MPAs) in the MS has been presented in [114], while a very detailed update for 2016 has been provided in [115]. According to [115], at the Mediterranean basin level, the total surface under protection status is $179,798 \mathrm{~km}^{2}$, comprising 1231 MPAs and Other Effective Area-based Conservation Measures, 186 MPAs of national status, 898 marine Natura 2000 sites, 3 General Fisheries Commission for the Mediterranean (GFCM) Fisheries Restricted Areas, and the Pelagos Sanctuary for marine mammals. Spain has the largest amount of small MPAs, while in Italy there are many medium-sized MPAs. The largest MPAs are off the coast of Greece and Turkey. MPAs have core zones in which specific regulations either prohibit or control non-consumptive and consumptive (commercial, recreational, or spear fishing) activities. In the core zones of most MPAs, consumptive activities are prohibited, while in the secondary zones, non-consumptive and consumptive uses are allowed or conditionally allowed, respectively $[116,117]$.

\subsection{Oceanographic Characteristics}

Characteristics of the sea surface layer are continuously modified due to mixing processes. The Mediterranean surface layer presents a longitudinal salinity gradient ranging from 36.2 psu near Gibraltar to $38.6 \mathrm{psu}$ in the Levantine basin [97]. In Figure 8, the spatial distribution of mean annual surface salinity in the Mediterranean basin is presented for the period 1987-2013 obtained from the Mediterranean Forecasting System reanalysis [118]. For details as regards salinity and temperature aspects in the MS, see $[119,120]$.

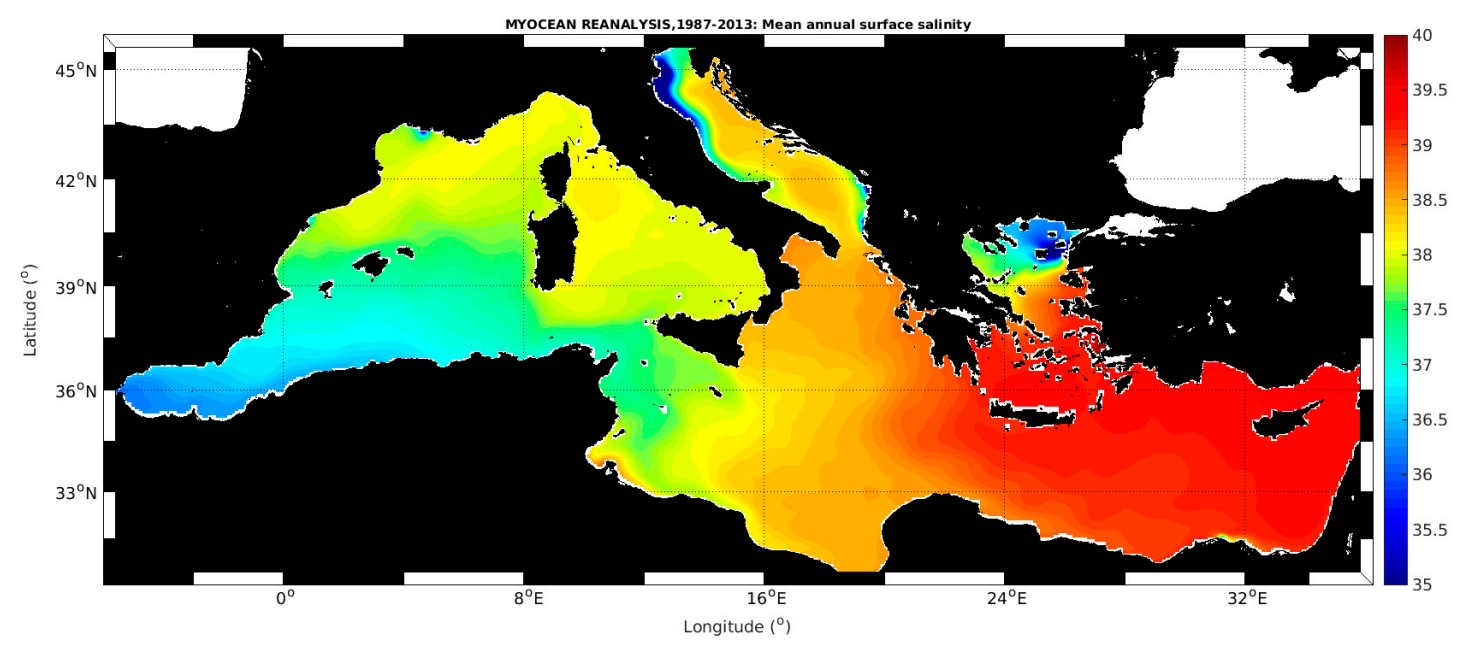

Figure 8. Mean annual surface salinity in the Mediterranean Sea. Data obtained from Mediterranean Forecasting System reanalysis [118], and analyzed by HCMR.

Surface temperature is clearly higher in the eastern than in the western sub-basin. The warmest surface waters are found in the Ionian Sea $\left(19.5-21^{\circ} \mathrm{C}\right)$ and the Levantine basin $\left(20-22^{\circ} \mathrm{C}\right)$, and the coldest in the Gulf of Lion $\left(17-19^{\circ} \mathrm{C}\right)$ [121]. The intermediate layer lies between $200 \mathrm{~m}$ and $800 \mathrm{~m}$ and its temperature varies from $13^{\circ} \mathrm{C}$ to $15.5^{\circ} \mathrm{C}$. The deep layer covers the depths between the intermediate layer and the bottom. The Western Mediterranean Deep Water has a mean temperature of $12.7^{\circ} \mathrm{C}$ and the Eastern has a mean temperature of $13.6^{\circ} \mathrm{C}$ [97]. In Figure 9, the spatial distribution of the mean annual sea temperature at $5 \mathrm{~m}$ (upper panel) and $1000 \mathrm{~m}$ (lower panel) below sea surface in the Mediterranean basin is presented for the period 2000-2015. The temperature data are obtained from the aggregated products of the Pan-European infrastructure for ocean and marine data management (SeaDataNet) [122], and analyzed by HCMR using the Data-Interpolating Variational Analysis (DIVA) 
software tool [123]. It is evident that the relevant temperature gradients at the particular depths are rather low compared to tropical and subtropical regions of the world ocean.

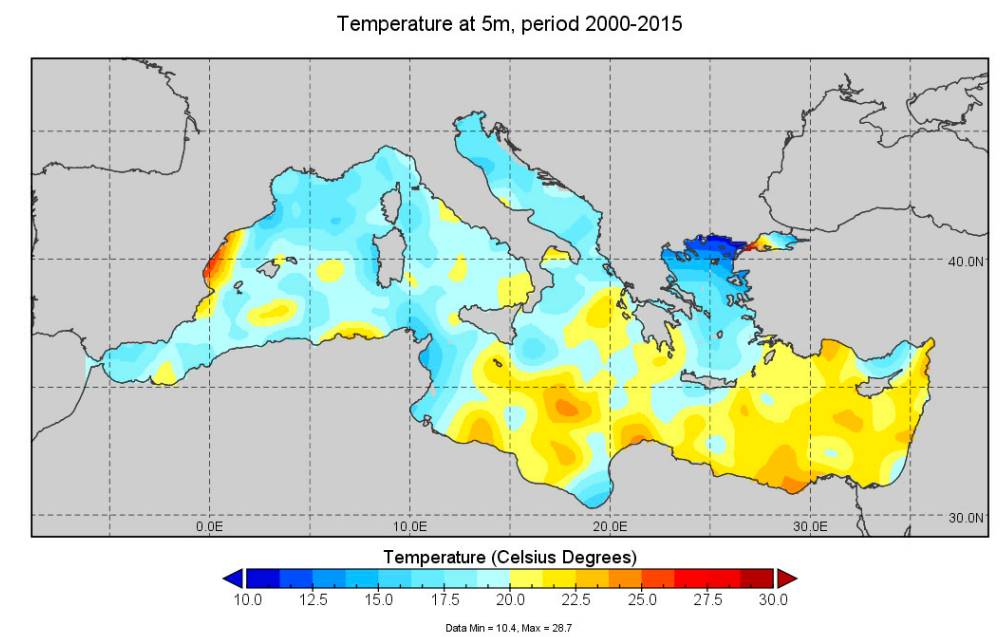

(a)

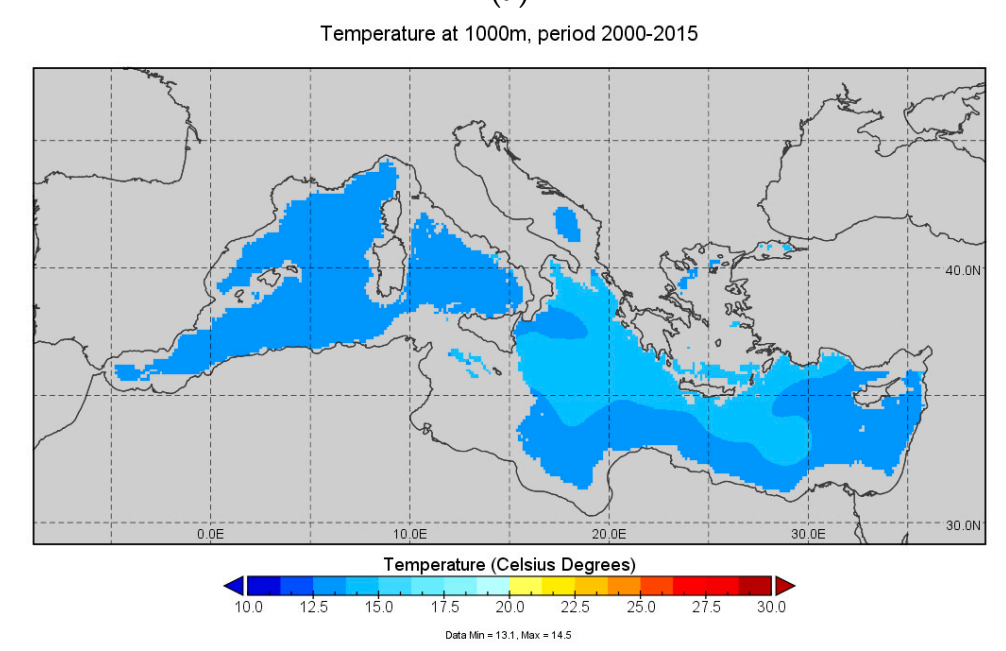

(b)

Figure 9. (a) Mean annual sea temperature at $5 \mathrm{~m}$ below sea level in the Mediterranean Sea; (b) Mean annual sea temperature at $1000 \mathrm{~m}$ below sea level in the Mediterranean Sea. Data obtained from SeaDataNet and analyzed by HCMR.

\subsection{Relevant Economic Activities}

\subsubsection{Tourism}

Tourism constitutes a substantial part of the Mediterranean economy and is a major pillar of local economies, serving as a significant source of employment [97]. It offers employment $(11.5 \%$ of total employment in 2014) and economic growth (11.3\% of regional GDP); for the coastal areas of the Mediterranean, tourism represents over $70 \%$ in terms of Production Value and Gross Value Added [124]. The Mediterranean region is the most preferable tourist destination, attracting one-third of the world's international tourists (for 2011, 306 million out of 980 million arrivals worldwide), while it is expected to reach 500 million tourists in 2030 [124]. The majority of tourists visiting the Mediterranean are of European origin, while domestic tourists also make a significant contribution. Tourism in Mediterranean countries is coastal oriented, with up to $90 \%$ of tourists visiting coastal areas. It is also particularly seasonal, as it increases dramatically during July and August. Detailed studies as regards tourism in the Mediterranean basin can be found in [124,125]. 


\subsubsection{Fisheries, Aquaculture, and Fish Farming}

Fisheries are another important economic sector of the Mediterranean countries that are related with offshore renewables. Fisheries constitute a vital component of the Mediterranean economy, accounting for about 220,000 jobs (directly employed on fishing vessels) [126]. The diverse morphology of the basin as well as the high proportion of small-scale commercial fishing (over $85 \%$ of the Mediterranean fishing fleet) are two important sustainability factors. Fishing in the MS usually takes place in depths ranging from $10 \mathrm{~m}$ to $800 \mathrm{~m}$ (mainly up to $400 \mathrm{~m}$ ) and is mostly concentrated in inshore areas. Fishing may also take place on the continental slope, while deep-water areas are currently not exploited. Among Mediterranean fisheries, $80 \%$ are currently attributable to five countries, including Greece, Spain, and Italy $[125,126]$.

Aquaculture and fish farming in the MS has a great contribution in meeting increasing demand for fishery products in the coastal nations. During the past decades, the Mediterranean aquaculture has expanded dramatically mostly due to the ideal physical characteristics of the Mediterranean marine environment as well as the proximity to viable markets. In [127], it has been mentioned that since 1970, the sector grows at a rate of around 9\% per year. As has been noted in [128], Greece, Turkey, and Spain are the main producers of seabream and seabass, and maintain a share of $\sim 80 \%$ of the world production. More detailed data on Mediterranean aquaculture and fish farming can be found in the recent report of FEAP (Federation of European Aquaculture Producers) [129].

\subsubsection{Maritime Transport}

Maritime transport is another important economic activity in the MS. According to the latest data published by Eurostat, with reference to ports of all EU Member States, the greatest number of passengers embarked or disembarked during 2015 refer to Italian and Greek ports [130]. The ports of Valencia and Algeciras (in Spain) and the port of Piraeus (in Greece) rank fifth, sixth, and eighth, respectively, as regards the volume of containers handled; while the ports of Algeciras, Marseille (in France), and Valencia rank fifth, sixth and ninth respectively, as regards the gross weight of goods handled. A detailed overview of the Mediterranean ship traffic for 2014, based on AIS signals, has been provided in [131]. In the same source, it is also highlighted that the MS is one of the busiest waterways of the world; 21 ports of the MS are among the 100 world top ports, while the maritime transport sector provides 550,000 direct jobs.

A detailed assessment of the most important economic sectors in the MS (maritime transport, fisheries and tourism) was made in the context of the Medtrends project [131]; see also [125]. Regularly updated statistics for all important economic sectors of the EU Member States can be found in [132].

\subsection{Energy Status and Scenarios}

As regards the recent situation of energy efficiency in the Mediterranean based on the MEDENER/OME report [133], the following facts can be mentioned for 2013: (i) the final energy consumption for the Mediterranean was 690 Mtoe (442 Mtoe for the Northern countries of the MS); (ii) the Mediterranean power generation was 1994 TWh (1354 TWh for the Northern countries of the MS); (iii) RES in total energy demand had 13\% share for the northern MS and 6\% for the southern MS. Let us note that the Southern Mediterranean region includes Algeria, Egypt, Libya, Morocco, Tunisia, Israel, Jordan, Lebanon, Palestine, Syria, and Turkey, while the Northern Mediterranean region includes Cyprus, France, Greece, Italy, Malta, Slovenia, and Spain, which are modelled as individual countries, and Albania, Bosnia Herzegovina, Croatia, Macedonia, Montenegro, and Serbia, which are considered as one model.

Forecasting scenarios for the Mediterranean energy, apart from the Conservative Scenario (CS) that considers previous trends and current policies and has a rather moderate approach as regards planned programs, take also into account the Energy Transition Scenario (TS). In the latter scenario, mature RE technologies, energy efficiency programs and integration of renewables to the energy mix 
are assumed, leading to a more ambitious scenario as regards development of RES projects in the Mediterranean. Based on the CS, the trend for final energy consumption in the MS is to be increased by $37.2 \%$ and $58 \%$ for 2030 and 2040 , respectively, while the forecast for the TS is $12.5 \%$ and $21.2 \%$, respectively, with both scenarios giving a higher Mtoe for the Southern MS. Regarding the electricity generation for the Mediterranean, the CS projects higher increased rates (48.6\% for 2030 and $77.5 \%$ for 2040) compared to the TS (12.9\% for 2030 and $22.1 \%$ for 2040) with respect to 2013; see also Figure 10. The share of renewables is expected to triple (39\% for the Northern MS and $16 \%$ for the Southern MS) based on the TS while lower percentages are expected with the CS (23\% for the Northern MS and 7\% for the Southern MS).

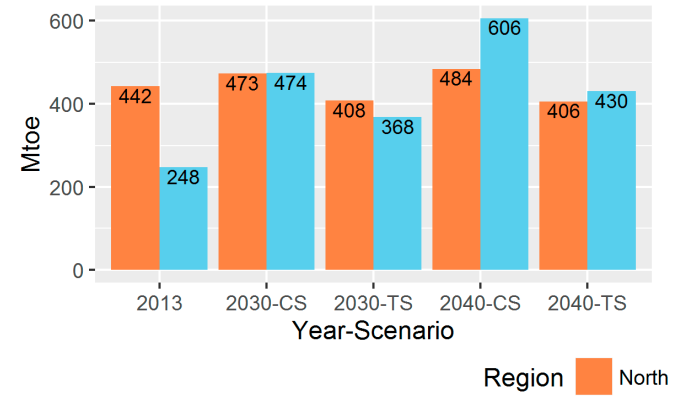

(a)

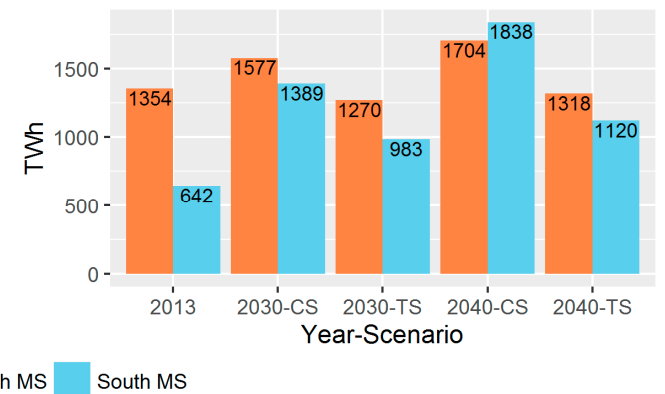

(b)

Figure 10. (a) Total energy consumption (in Mtoe) of the Northern and Southern Mediterranean Sea; (b) Electricity generation (in TWh) of the Northern and Southern Mediterranean Sea. Data obtained from [133].

From Figure 11, based on data published by Eurostat, it is evident that there is an increase of the renewable energy share in the gross final energy consumption between 2004 and 2015 for the Northern Mediterranean countries. Among these EU countries, Slovenia had the highest share of renewable energy (22\%) in 2015, Malta presented the highest relative change from 2004 to 2015, Italy has already surpassed its national binding target by little, while France has a long distance to cover yet until the final target of 2020.

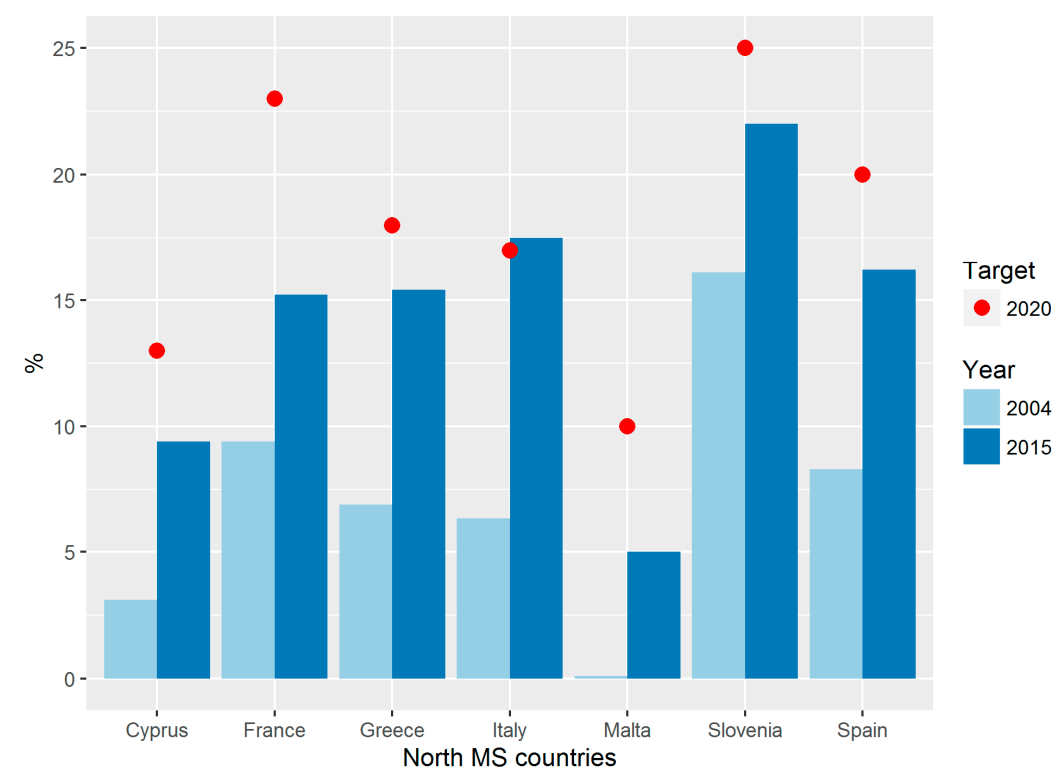

Figure 11. Overall share of energy from renewable sources (in \% of gross final energy consumption) of the Northern Mediterranean Sea. Data from http:/ / ec.europa.eu/eurostat/web/energy/data/shares. 
An overview of electricity statistics for individual EU-Mediterranean countries is presented in Table 1 by using monthly (for 2016) and annual (for 2014 and 2015) cumulated production and supply data from Eurostat. The total amount of energy consumption is calculated as the sum of the total net production and imports minus exports and electricity absorbed by pumping (not shown here). The highest percentage of electricity supply between 2015 and 2016 is observed for Cyprus (7.5\%) and the lowest for Italy $(-2.1 \%)$. Slovenia exhibits the highest percentage of total net production for the same years $(8.8 \%)$, while Cyprus and Greece have a steady increase of electricity generated during the triennial period examined.

Table 1. Electricity statistics for EU-MED countries (in GWh). Source: Eurostat (online data code: nrg_105a, nrg_105m).

\begin{tabular}{cccccc}
\hline EU-MED Country & Year & Total Net Production & Imports & Exports & Energy Supplied \\
\hline \multirow{3}{*}{ Cyprus } & 2014 & 4145 & - & - & 4145 \\
& 2015 & 4312 & - & - & 4312 \\
& 2016 & 4634 & - & - & 4634 \\
\hline \multirow{2}{*}{ France } & 2014 & 540,285 & 7873 & 75,063 & 465,138 \\
& 2015 & 544,693 & 9961 & 74,024 & 473,754 \\
& 2016 & 531,147 & 20,790 & 61,406 & 483,798 \\
\hline \multirow{2}{*}{ Greece } & 2014 & 46,702 & 9461 & 642 & 55,334 \\
& 2015 & 47,806 & 11,081 & 1473 & 57,340 \\
\multirow{3}{*}{ Italy } & 2016 & 48,052 & 9833 & 1037 & 56,815 \\
& 2014 & 269,148 & 46,747 & 3031 & 310,535 \\
& 2015 & 272,428 & 50,849 & 4471 & 316,897 \\
\multirow{2}{*}{ Malta } & 2016 & 275,649 & 43,181 & 6155 & 310,251 \\
& 2014 & 2137 & - & - & 2137 \\
& 2015 & 1239 & - & - & 2293 \\
\multirow{2}{*}{ Spain } & 2016 & 848 & - & - & 2375 \\
& 2014 & 268,380 & 12,310 & 15,716 & 259,772 \\
& 2015 & 269,750 & 14,956 & 15,089 & 265,097 \\
\multirow{2}{*}{ Slovenia } & 2016 & 264,356 & 21,845 & 14,178 & 267,204 \\
\hline & 2014 & 16,486 & 7254 & 9997 & 13,380 \\
& 2015 & 14,187 & 9045 & 9093 & 13,759 \\
\hline
\end{tabular}

\section{Marine Renewable Energy Status and Aspects in the Mediterranean Sea}

\subsection{Interweaving Different Viewpoints for MRE Development}

\subsubsection{Geotechnical/Engineering, Socio-Economic, and Environmental/Ecological Frameworks}

MRE sector in the Mediterranean basin is at its infancy and its development depends on a series of challenges and obstacles to be overcome. Rare practical experience combined with the rather poor number of studies focused on the potential impacts in the basin actually render the MS an unexplored region as regards MRE sector. Countries that already exploit MRE are therefore a valuable source of information and experience. The particularities of the Mediterranean basin presented in Section 3, along with financing capabilities, socioeconomic characteristics and availability of the MRE potential, set the context in which current status and future perspectives of MRE development in the Mediterranean are discussed. Important problems that are expected to occur in any attempt of MRE development in the MS refer to technology development (for wave and tidal energy), administrative, environmental, and socio-economic constraints, grid availability, and financial and market status [1,134]. Mediterranean region is also particular from other points of view: (a) the electricity costs for the numerous remote insular areas (especially in the Greek Seas) are clearly higher than the mainland due to the reliance on local generators; (b) the over-exploitation of insular aquifers has important impacts on the equilibrium between freshwater and sea water in the groundwater bodies. Desalination, although a high energy 
consuming process, is used in many Mediterranean areas. MRE applications seem to be very well tailored for providing viable solutions in these respects.

For the economic viability and sustainability of MRE projects, an integrated holistic approach is necessary. This approach comprises three different, not always aligned, frameworks: geotechnical/engineering, socio-economic, and environmental/ecological framework. In addition, they usually refer to different, yet highly interrelated, aspects of design, development, and operation of MRE installations, and are related to a variety of stakeholders with different requirements, standpoints and priorities. The frameworks actually consist of technical restrictions and potential spatial conflicts (ascribed to socio-economic and environmental aspects). All these restrictions/hindrances should be identified and resolved/overcome in order to implement the optimal solutions for the development of the MRE plants.

The technical/engineering framework refers mostly to the feasibility, development and installation phases of a MRE project. Decisions relevant to this framework have tangible and immediate consequences on the economic viability and survivability of the MRE installation during its operation. Clearly, technical considerations (and especially, bathymetry and power potential availability) are strict prerequisites and the relevant conditions should be necessarily met before proceeding to the analysis of other parameters.

The socio-economic framework refers to the identification of the diverse effects that a MRE project may have on the other uses of the marine space, and, therefore, on the socio-economic conditions of the neighboring coastal communities. These effects can be identified and measured along the various phases of the project, i.e., from planning phase and installation to operation and decommissioning, including also the supporting processes such as research, logistics, financial and consulting services.

The environmental point of view deals inter alia with the assessment of the ecological status of the candidate area in order to predict potential positive and negative effects that a MRE installation may have on the surrounding biotic (and abiotic) elements. The most common environmental restrictions for the MS are the following: (i) MPAs; (ii) Ramsar and Natura 2000 sites; (iii) cetacean sanctuaries; (iv) areas considered as migratory bird routes; (v) areas characterized by meadows of Posidonia Oceanica, fields of Phyllophora; and (vi) other priority habitats (e.g., coralligenous, maerl, and deep-water white coral formations). The identification of priority habitats can be based ideally on in situ surveys or can be estimated from habitat models.

\subsubsection{Intermittency of MRE, Energy Transmission, and Storage}

Another issue that has not been touched upon yet refers to the intermittency of MRE. Regarding especially marine wind, wave and tidal energy in the MS, there are natural time lags where the energy flow discontinues either due to the lack of appropriate conditions or due to harsh weather conditions that put in danger the safety of the MRE structures. A main requirement for an efficient power grid is to preserve the balance between the power supply and demand. The existing power grids are not yet entirely capable of appropriately regulating the intermittent energy generation from the renewable sources. Detailed description of the MRE transmission systems can be found in [135-137] and an extended review as regards grid integration for MRE installations can be found in [138].

In order to mitigate the intermittency of MRE and achieve the above-mentioned balance, energy storage is a necessary alternative that should be taken into consideration in the design of any future MRE project. Energy storage is especially important for remote islands disconnected from the main electrical grid system. It is usually confronted with pumped-storage hydroelectric schemes that are a mature and competitive technology. However, the environmental implications and impact of hydroelectricity should be carefully assessed, while the permitting process is usually long and the relevant pumped storage costs are rather high. Other means for storing energy when it is not demanded are also the following: compressed air energy storage, hydrogen, flywheels, batteries, etc.; see also [139], where a review on MRE transmission and storage options has been provided with particular emphasis on small island developing states. As has been mentioned in [140], to date the 
relevant infrastructure for energy storage is still expensive, while frequently it is not necessary to maintain the reliability of the grid; see also [19]. Nevertheless, in [140], it has been highlighted that the fast development of the electric vehicle industry will further reduce the battery costs. In this connection, in situ storage of MRE is an emerging option although in a clearly premature state. Innovative concepts regarding "Deep Sea Energy Storage", i.e., storage of MRE offshore, have been also presented in [141]. In the next sections, the most determining factors that will shape the future development of MRE in the Mediterranean basin are discussed. Specifically, in Section 4.2 estimates of offshore wind, wave and tidal stream energy are provided. Moreover, some important technical (Section 4.3), environmental (Section 4.4), and socio-economic (Section 4.5) issues that are expected to affect MRE development in the basin are presented. In the same section the value of Marine Spatial Planning (MSP) is also discussed.

\subsection{Ocean Energy Potential}

In order to implement an MRE project, in-depth assessment of the energy potential, the annual and inter-annual variabilities (in particular for offshore wind and wave) and relevant uncertainties at fine spatiotemporal scales are necessary components. An efficient analysis should focus on the spatial scale (local or regional) in order to detect available locations with commercially exploitable resources. It should be also borne in mind that results from MRE potential assessment are followed by various types of uncertainties characterizing the specific source of data, and should be accompanied by an evaluation of the climate change impacts on MRE economics; see [142,143].

\subsubsection{Offshore Wind Energy}

OWFs in the Mediterranean do not currently exist. A large number of offshore wind projects are at a concept/early planning stage while many have been cancelled or remain in a dormant status [144]. In [7], the analysis of consented wind farms has indicated that the Mediterranean could begin exploiting its offshore potential ( $1.1 \%$ of consented capacity). It has been also mentioned that no significant momentum is expected before 2020. According to [145], by 2030, the Mediterranean offshore wind energy could be in the same range with onshore wind accounting for $5 \%$ of the Mediterranean electric energy demand.

Offshore Wind Resource Availability

In [146], the available offshore wind power potential has been estimated over the MS using SeaWind II dataset with a 15-km horizontal resolution and 20-year time length. A recent analysis of wind energy density over the MS has been conducted in [147] leading to the selection of potentially suitable sites for wind energy applications. However, the approach has not accounted for bottom depth that is a major technical restriction; see Figure 12, where the mean annual offshore wind power density at $80 \mathrm{~m}$ height above sea level (asl) according to the results obtained from an atmospheric ETA-based model is presented, and Figure 13 below, where the locations satisfying the depth restrictions are depicted. An offshore wind potential assessment in the MS, taking into account bottom depth restrictions, has been also recently performed in [148] using the Blended Sea Winds (BSW) satellite dataset from the US National Oceanic and Atmospheric Administration (NOAA). The data cover the period from 1995 to 2011.

An extended analysis of the offshore wind power potential in the Mediterranean basin has been performed in the recently completed project "Towards COast to COast NETworks of marine protected areas (from the shore to the high and deep sea), coupled with sea-based wind energy potential" (called hereafter COCONET) [149] COCONET was funded by the European Community's Seventh Framework Program (FP7/2007-2013) under Grant Agreement No. 287844. In the context of COCONET, three different wind data sources were thoroughly analyzed:

1. satellite data from the BSW product of NOAA with a 6-h sampling frequency, spatial resolution of $0.25 \times 0.25$, and time period of 17 years (1995-2011) [150]; 
2. ERA-Interim reanalysis data, with a 6-h sampling frequency, spatial resolution of $0.25 \times 0.25$, and time period of 33 years (1979-2011) [151] and

3. numerical results obtained from the ETA-based atmospheric model with a 3-h sampling frequency, spatial resolution of $0.1 \times 0.1$, and a time period of 15 years (1995-2009) [105].

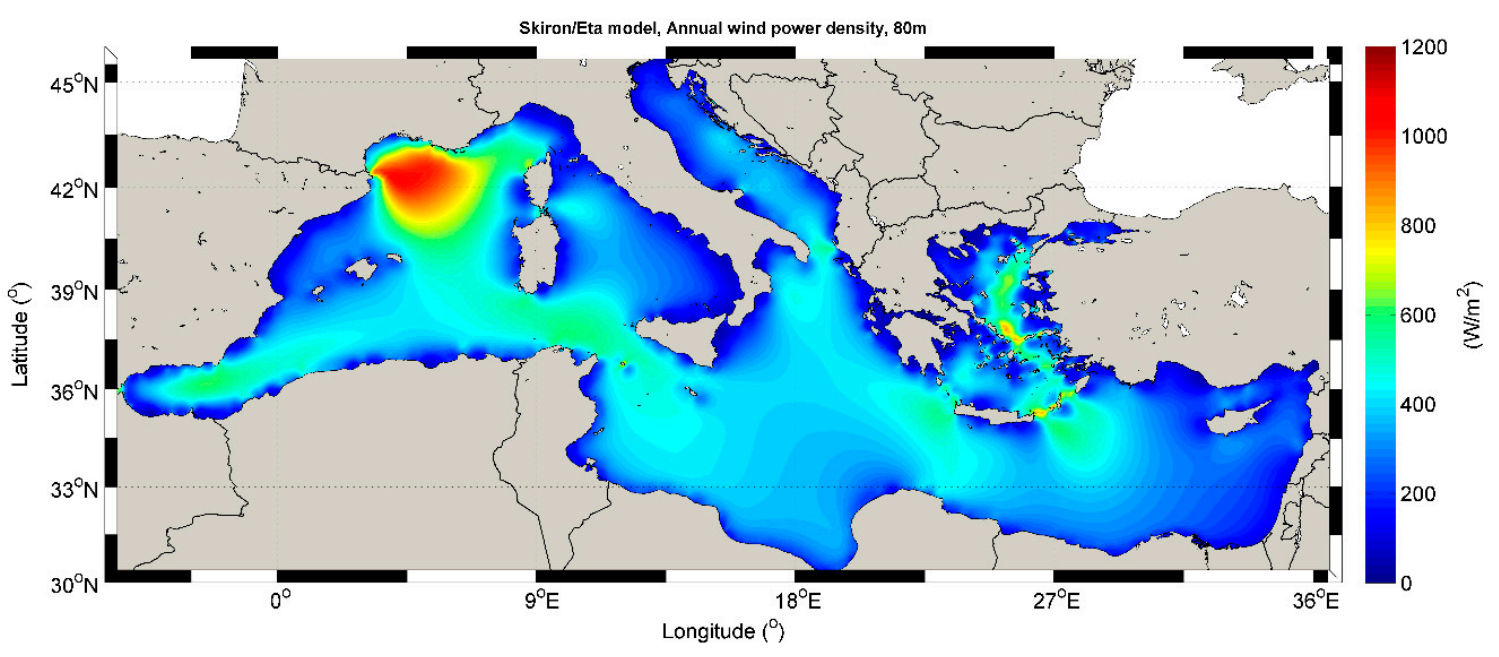

Figure 12. Mean annual offshore wind power density at $80 \mathrm{~m}$ height asl according to the ETA based atmospheric model. Data analyzed by HCMR.

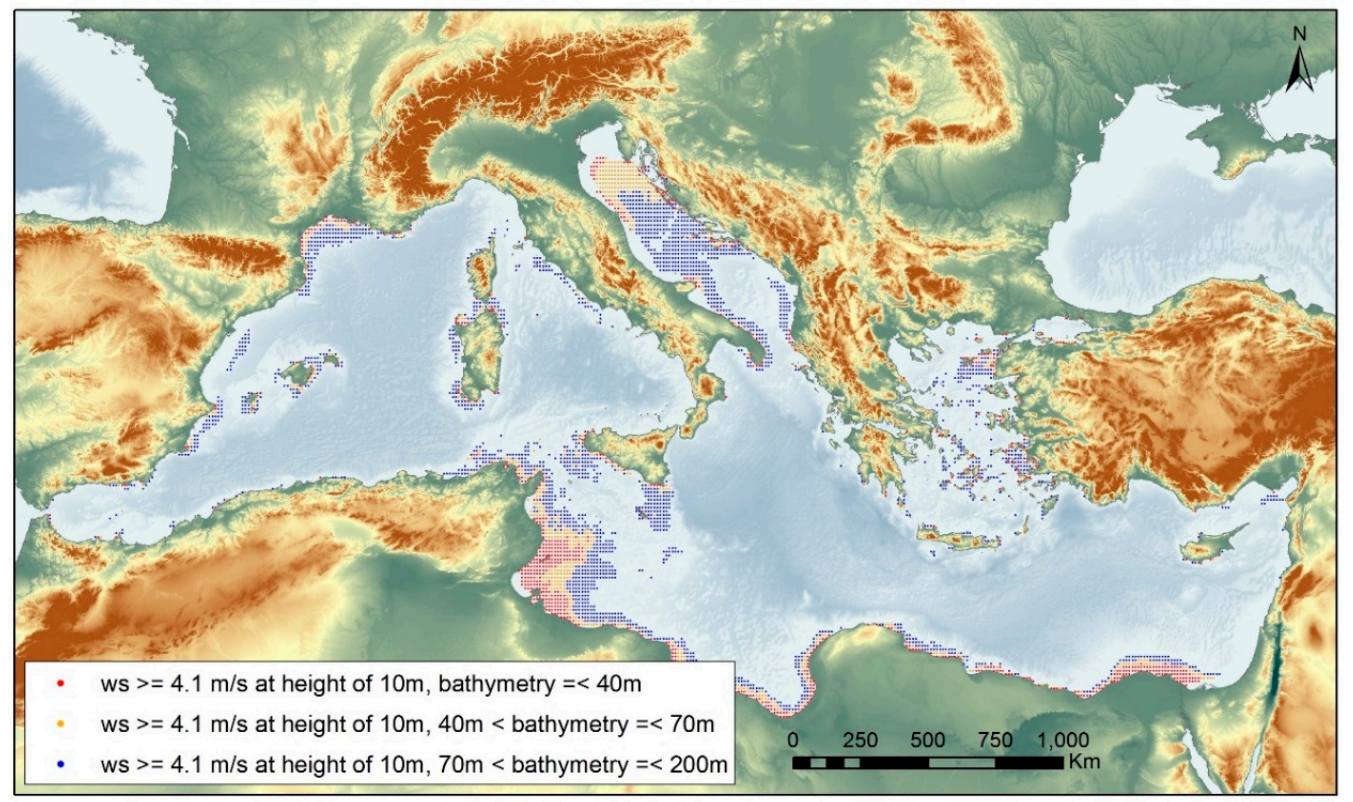

Figure 13. Potential hot-spots for OWF development in the Mediterranean Sea [107]. Data analyzed by HCMR.

The above datasets have been validated by using in situ oceanographic measurements from the Greek POSEIDON system, [152], and the Spanish Puertos del Estado monitoring system, as well as Italian coastal meteorological stations. As mentioned before, the assessment of offshore wind power potential, revealed uncertainties, which are related with the different data sources and spatial resolutions and the sensitivity of the satellite data near the land-sea boundary.

The mean annual offshore wind power density in the MS is depicted in Figure 12. Using the logarithmic law, the estimates are provided at $80 \mathrm{~m}$ height asl, roughly corresponding to a typical 
WT hub height. The obtained results suggest that the highest annual mean power densities are encountered in the Gulf of Lion (approximately $1050 \mathrm{~W} / \mathrm{m}^{2}$ ), and the central Aegean Sea (up to $890 \mathrm{~W} / \mathrm{m}^{2}$ ). High offshore wind resource is also met in areas east and west of Crete, east of the Gibraltar Strait, the western Ligurian Sea, and the Sicily and Otranto Straits.

In Figure 13, candidate locations for potential OWF development in the MS are shown. The main criteria for the selection are the mean annual wind speed (above than $4.1 \mathrm{~m} / \mathrm{s}$ at $10 \mathrm{~m}$ height asl) and the bottom depth suitability. This, rather low, wind speed limit was chosen since it has been proven that the atmospheric model underestimates (sometimes significantly) high values of wind speed [142]. Three different water depths are considered: 'shallow waters' (depths between 0 and $40 \mathrm{~m}$ ), 'intermediate waters' (depths between 40 and $70 \mathrm{~m}$ ), and 'deep waters' (depths between 70 and $200 \mathrm{~m})$; see also Section 4.3.1.

From Figure 13, it can be concluded that large parts of the Adriatic Sea and the Gulf of Gabes are favorable for OWF development for the considered water depths. Favorable locations exist also in the Aegean Sea, the Gulf of Lion, along the Mediterranean coasts of Spain, as well as along and off the north African coasts (especially off the Nile estuary). Let us note though, that in realistic applications, the selection of candidate locations for OWF should consider a variety of additional parameters (environmental, socio-economic, financial, etc.). In this context, using the Smart Wind Chart-Smart Wind Chart is one of the major outcomes of the COCONET project-a pre-evaluation of potential locations in the Mediterranean as regards potential OWF development was performed. A site specific application (Othoni at the northern part of Corfu in the Ionian Sea) of the Smart Wind Chart has been presented in [153].

Regional and local studies regarding wind availability and power potential have been performed in particular locations of the Mediterranean basin, namely in the Croatian coasts, the northern Adriatic Sea, the Greek Seas, the area of Othoni, Gargano Sud (Italy), Gulf of Valencia (Spain) and the Ionian Sea; see [148,153-158].

In [159], the wind energy projections in the MS, based on global climate change scenarios and data from the EU-funded ENSEMBLES project, has been presented in detail. The combinations of available regional and global models evidence high levels of uncertainty as regards future wind conditions. For wind power, according to an adopted consensus rate, for the period 2021-2050, an increase above $5 \%$ is anticipated over the Aegean Sea, while over the sea areas of North Africa and Middle East a decrease of more than $5 \%$ is projected. For the Gulf of Lion, no clear future change signal was detected. Other relevant analyses can be found in $[160,161]$.

\section{Status of Offshore Wind Energy Development}

The existence of the aforementioned numerous favorable Mediterranean areas along with the experience from offshore wind development of north-western European countries and onshore wind development in the Mediterranean countries, constitute important promoting factors for offshore wind sector to start growing in the basin. Floating WTs seem to be well adapted in the Mediterranean geomorphological conditions; see [162], where different floating concepts have been analyzed, and [163]. In the remainder of this section, the status of offshore wind projects in some Mediterranean countries is described; see [144] for current updates of the development status of OWFs in the MS.

In the French Mediterranean coasts, Provence-Alpes-Côte d'Azur region, characterized by considerable offshore wind potential and gentle seabed, was chosen for construction of offshore WTs in 2011. However, coastal municipalities were strongly opposed to the French government due to visual impact concerns and the consequent potential impact on tourism and, finally, projects in the region were not allowed to proceed $[144,164]$. Currently, in the Mediterranean coasts of France, pilot projects for testing offshore floating turbines are in progress in Leucate and Gruissan (region Languedoc-Roussillon), and Faraman (region Provence-Alpes-Côte d'Azur).

Although Spain has shown remarkable progress in alternative energy sources development, MRE projects integration is hampered by the lack of MSP development [165]. The strategic study for the 
implementation of OWFs in Spain and the publication of the Spanish Wind Atlas are indicative efforts to speed up offshore wind development; see also [117]. In the Catalan coasts of Spain two projects of $560 \mathrm{MW}$ concerning tension leg floating platform installation have been cancelled while many projects for the rest of the Spanish Mediterranean coasts (grounded foundations) are currently either at a dormant status or cancelled [144].

Numerous offshore wind projects in Italy (and Malta) have been cancelled mostly due to lack of funding or opposition of local authorities. An offshore wind project in the Gulf of Taranto is currently at consent authorized status. The project foresees the installation of $10 \mathrm{WTs}$, of total capacity $30 \mathrm{MW}$, at depths ranging from 3 to $14 \mathrm{~m}$ and distance from shore $2.9 \mathrm{~km}$ [144]. Many other projects are at a dormant status.

Many offshore projects in Greece are at concept/early planning stage, but there have also been many cancelations. Some offshore wind projects, e.g., Sea of Thrace (region Thrace, capacity $216 \mathrm{MW}$ ), Lemnos (Aegean Islands region, capacity $498 \mathrm{MW}$, depth ranges 12-50 m, number of turbines 135 and distance from shore $10.6 \mathrm{~km}$ ) were granted a production license by the Regulatory Authority for Energy, but have not proceeded with environmental studies and grid connection negotiation yet [144]. Moreover, there are several applications still pending. Detailed feasibility studies regarding offshore wind energy development in Greece by considering various geotechnical, engineering, socio-economic, and environmental parameters are also in progress.

\subsubsection{Wave Energy}

The offshore mean annual wave energy flux in the MS is depicted in Figure 14. The results are derived by using wave spectral parameters estimates for the period 1979-2013 from the ERA-Interim database, obtained from the ECMWF [151].

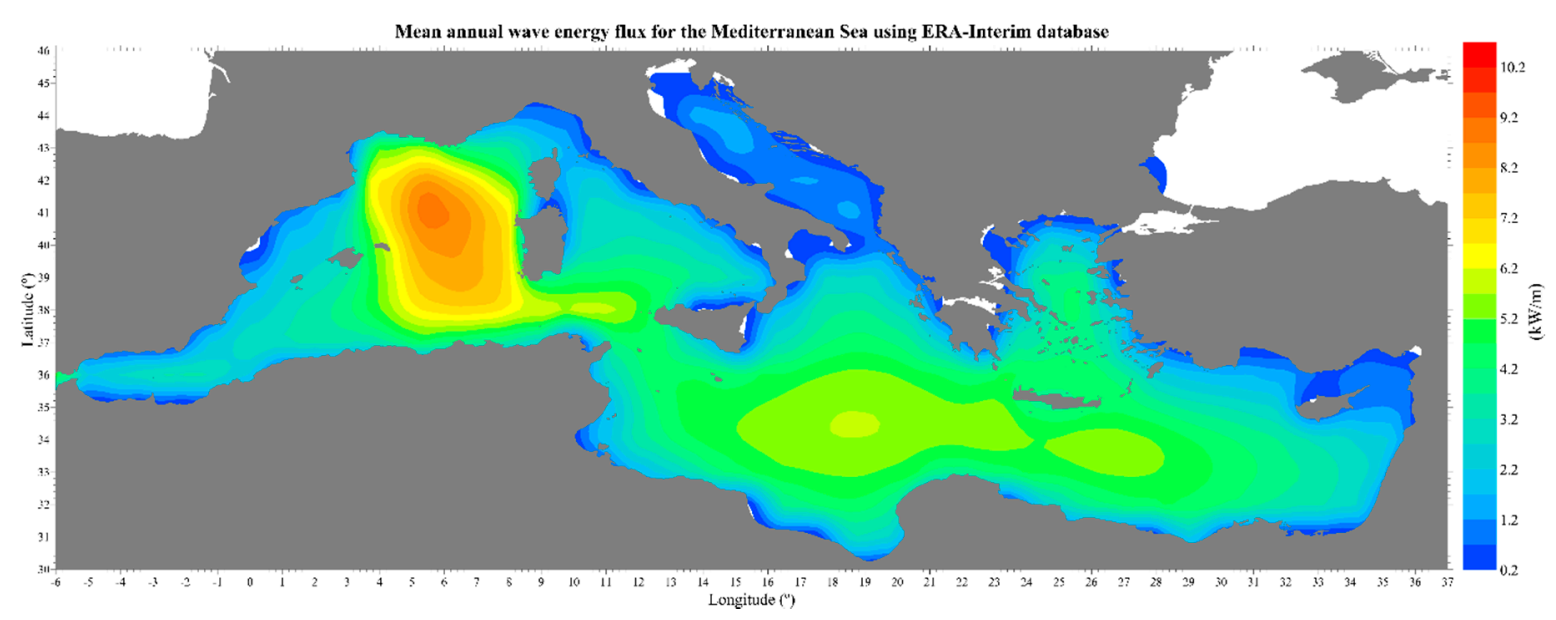

Figure 14. Mean annual wave energy flux in the Mediterranean Sea obtained from the ERA-Interim database, 1979-2013. Data analyzed by HCMR.

The extended area between Sardinia and Balearic Islands exhibits the highest annual wave energy $(\sim 9.4 \mathrm{~kW} / \mathrm{m})$. The Levantine and the Ionian basin, the area between Sicily and Tunisia and the central-northern Aegean present steady wave energy potential. In the area located southwest of Crete, the estimated mean annual wave energy is of the order of $5.8 \mathrm{~kW} / \mathrm{m}$. Comparing to northern and western European locations, wave energy in the MS is considerably smaller. Specifically, wave power in the North Sea ranges within 10-60 kW/m while in front of the French and the Portuguese coasts the annual available values vary from 30 to $50 \mathrm{~kW} / \mathrm{m}$ [166].

In [167], the wave energy potential focusing on the Eastern Mediterranean Levantine basin has been studied. Based on high resolution wind-wave numerical models, results show that, in Eastern Mediterranean, the highest energy potential values are met off the western and southern offshore areas 
of Cyprus and offshore the coasts of Lebanon, Israel and Egypt. It is also claimed that although wave energy potential is relatively low, it is exploitable. In $[168,169]$, assessments of the wave potential in the MS have been performed. Specifically, the authors in [169] aim mainly to identify specific aspects relevant with the design of wave energy harvesters. The same study also highlights that the directional pattern of sea-states affect sea-state statistics and therefore, wave energy harvesters designing; see also [49]. Finally, in [170], a detailed wave resource assessment for the entire Mediterranean basin based on long-term (35 years) high temporal and spatial resolution numerical wave model results has been performed. The most energetic area is located in the Western Mediterranean, while the central and Eastern Mediterranean present moderate wave energy potential (around $6-7 \mathrm{~kW} / \mathrm{m}$ ).

Local/regional assessments of the wave resource have been presented, among others, in $[156,171]$ for offshore areas of the Greek Seas, [172] for the Eastern Mediterranean, [173] for Menorca (Spain), [174] for offshore areas of Italy, [175,176] for Sicily, [177] for Sardinia, [178] for the Balearic Sea, [179,180] for the Aegean Sea, and [181] for northern Latium.

\section{Status of Wave Energy Development}

During the last decade important progress has been achieved as regards wave energy development in the MS, especially in Italy. A (near) full-scale demonstration project has been described in detail in [182-184], where a full scale Inertial Sea Wave Energy Converter (ISWEC) prototype has been developed and tested in Pantelleria and its impact on Posidonia Oceanica meadows has been assessed. The rated power of ISWEC was $100 \mathrm{~kW}$, and the mooring took place at $800 \mathrm{~m}$ from the coast in a water depth of $35 \mathrm{~m}$. The principle of operation of ISWEC consists in the interaction of sea waves with the hull of the device and the gyroscopic system. Moreover, a prototype Overtopping BReakwater for wave Energy Conversion (OBREC) has been implemented and tested at the Port of Naples. The principle of operation of OBREC is based on the difference between the water levels in the reservoir and the sea water level that can be exploited through low head turbines [185,186].

\subsubsection{Tidal/Current Energy}

Tidal energy resource in the Mediterranean is very low with respect to other areas of the world, where tidal energy sector is already under development (e.g., UK, France, Norway, China, and Canada). In the Mediterranean basin, there is no commercial development of the tidal energy sector. As tidal turbines need a stream speed of at least $1.5-2 \mathrm{~m} / \mathrm{s}$ to operate effectively, tidal energy potential of the basin sets specific constraints. Based on the current speed limits provided above, very few Mediterranean sites could be of particular interest. The exceptions of the Straits of Dardanelles, Gibraltar, and particularly the Strait of Messina (where tidal stream energy resource presents its highest values in the Mediterranean) have been under consideration; as only preliminary studies have been conducted regarding the energy potential sufficiency of these areas, further research is essential.

Little attention has been given so far to the weak tides and currents observed in the Mediterranean straits. A recent study focused on the Euripus Strait, close to Chalkis, Greece, has examined the use of turbines that are suitable according to the space limitations of the area and it has been concluded that the potential amount of tidal-stream energy in this strait is insufficient for wide-scale applications [187]. On the contrary, the Strait of Messina is characterized by high-energy tidal currents with maximum velocities at spring peak tides ranging from $1.8 \mathrm{~m} / \mathrm{s}$ to more than $3 \mathrm{~m} / \mathrm{s}$, proving the suitability of the site for tidal energy harnessing [188,189]. However, in [82], it has been suggested that resource feasibility studies should be based on annual average power density instead of mean spring peak tidal velocities because of the significant resource underestimation associated with the latter. It is also suggested that tidal energy generation at lower energy sites may be of lower risk, as they tend to present lower variability in the annual practical power of tidal currents than higher energy sites. An estimation of the marine current energy fluxes in the Gibraltar Strait has been provided in [190], revealing the suitability of certain spots for a power plant installation. Computed averaged fluxes at 
these locations of the strait can exceed $1.8 \mathrm{~kW} / \mathrm{m}$. Finally, in [154], an analysis regarding the potential for development of tidal stream energy in two coastal locations of Croatia has been presented.

\subsubsection{Salinity and Thermal Gradients Energy}

An estimate of the ocean thermal energy availability in the MS has not been provided yet, since the involved parameters in ocean thermal power density calculations (e.g., heat capacity of seawater, turbo-generator efficiency, temperature difference between surface and deep water, pipe loss/fractional energy loss to cold water pumping, and warm water intake temperature for OTEC) are fully site-specific; therefore, general estimates are not directly feasible [191]. To our knowledge, the only detailed assessment of global salinity gradient energy potential, along with the identification of locations with utilizable resource, has been presented in [94]. In that work, specific river mouths of the Mediterranean coasts have been identified as promising candidates for salinity gradient energy utilization.

\subsection{Key Technical Considerations for MRE Development}

\subsubsection{Bathymetry and Distance to Shore}

The type of geomorphological features discussed in Section 3 are of critical importance regarding MRE applications in offshore and coastal areas of the MS. Apart from MRE potential availability, water depth and distance to shore are two major technical factors associated with MRE feasibility. Bottom depth suitability and distance from shore has greatly favored offshore wind industry growth in the Northern Europe. On the contrary, narrow and steep continental shelfs of the MS constitute one of the major technical obstacles for MRE development in the basin, not only for economic reasons (costs of installation, maintenance, and underwater electrical grid connection costs), but also due to visual disturbance associated with the vicinity to coastal areas (especially for offshore wind) and the intense and multiple uses of the same marine areas; see also Section 4.5. Many offshore wind projects (commercial or pilot) in the MS have been cancelled or reconsidered because of the small distances from shore. The three different depth ranges that are considered in Section 4.2.1 (see also Figures 12 and 13) refer to the suitability of different underwater structures: shallow waters (depth between 0 and $40 \mathrm{~m}$ ) and intermediate waters (depth between 40 and $70 \mathrm{~m}$ ) refer to monopile, gravity-based, tripod, jacket, and tri-pile supporting structures, and deep waters (depth between 70 and $200 \mathrm{~m}$ ) refer to floating WTs technologies, including tension leg platforms.

On the other hand, moving away from shore wind becomes less variable, more consistent and intense, and waves become higher resulting in wind and wave energy potential profit. Consequently, in technical terms, favorable sites should be selected mainly according to an optimal combination of water depth and distance to shore, provided that the available resource is exploitable. Selection of sites with the optimal combination of water depth and distance to shore is a complicated task and should be carefully examined. At the same time, the general trend, at least concerning offshore wind installations, is to move into deeper waters. In order to combine economic viability and public acceptance, the concept of floating offshore turbines operating far from coastal areas has started spreading also in the MS. Although some preliminary assessments are available [162,163], to date this concept is still at a preliminary stage; France is the only country currently working on such pilot projects in the basin. Shifting from bottom fixed to floating WTs is also expected to drastically change, in a positive way, socio-economic, legislative and environmental considerations. Therefore, it may be the optimal way to ensure the sustainability of marine wind energy in the MS; see also [28,29].

Tidal and offshore WTs have similar foundations; thus, their installation faces more or less similar technical constraints. Regarding wave energy, to date most of the WECs installed are within $10 \mathrm{~km}$ from shore (the most distant WEC currently deployed at the Wave Hub in South West of the UK is located $16 \mathrm{~km}$ from shore) and no deeper than $75 \mathrm{~m}$ [10]. As mentioned before, some wave energy 
full-scale demonstration projects (of different principles of operation) have been developed in Italy (in Pantelleria and the Port of Naples); see [182-186].

\subsubsection{Electricity Infrastructure}

Offshore energy production requires a transmission infrastructure for the connection of the offshore generated electricity to the onshore electricity network. Such an infrastructure generally consists in onshore and offshore sub-stations, and cabling between offshore platforms and onshore substations, as well as between the onshore substation and the onshore collector station. Relevant construction cost is a major obstacle for MRE development in the MS. As mentioned above, the need for large distances from the shore (in order to minimize visual impact) combined with the large depths of the Mediterranean basin significantly increase the relevant costs. Selection of sites with existent components of the required electricity network (e.g., an onshore substation or submarine grid connections) can mitigate costs and facilitate the integration of a MRE project. Nevertheless, the available electricity grid connection in the basin is very limited. A map of the existing electricity grid connection in the coastal areas of the MS can be obtained from the European Network of Transmission System Operators for Electricity (ENTSO-E) [192]. Local and regional plans for underwater grid interconnections are currently designed in France, Italy, and Greece, but no progress has been achieved so far. Existing and undergoing projects for underwater electricity network systems in the MS have been provided in [144]. Relevant progress can be greatly facilitated, at least at the regional level, by applying joint actions and procedures when developing infrastructures relevant to MRE projects.

Northern European countries are currently aiming for an integrated offshore transmission network allowing connection between offshore renewables and interconnection between countries (Baltic and North Sea). For Mediterranean countries, additional problems originate from the lack of a solid regulatory framework, hampering strategic planning of offshore grid infrastructure that is needed in order to accelerate grid construction and minimize conflicts. The Medgrid initiative, which was set up in 2010, is an industrial consortium aiming to analyze the feasibility of a trans-Mediterranean power grid. If this plan is accomplished, it is expected to boost significantly MRE development in the area; see also [193].

\subsection{Environmental Considerations}

\subsubsection{Potential Environmental Impacts}

Different offshore energy devices and installations may have various environmental impacts during the construction, operation, and decommissioning phases. During construction and decommissioning, impacts are considered to be similar, as similar activities take place. A general review of the environmental and ecological effects of MRE installations can be found in [194], while further anticipated pressures from such technologies can be found in [195]. Over the past years, several studies have examined the potential impacts of installations of OWFs on the marine environment. Although the majority of them is focused on the northern European waters, this information can be considered valid to a great extent also in the MS.

One source of environmental effects, mainly related with offshore WTs, is underwater noise. During construction, mostly mammals and fish are influenced by noise caused by pile-driving during the deployment of monopile and jacket foundations. There is evidence that extreme noise levels cause avoidance behavior of marine mammals and mortality or tissue damage in fish, while drilling, dredging, and increased traffic are associated with less harmful acoustic disturbance. Gravity base foundations are associated with intense dredging activity causing sediment dispersal and increased turbidity, which in turn can damage sensitive organisms [196]. Avoiding construction activities of any MRE installation during particular times of the year for fish and marine mammals is important in order to mitigate impacts on marine life [197]. During the operational phase, acoustic disturbance due to underwater noise is caused mostly by turbine operation. 
Birds can be influenced significantly by OWFs. Change in birds' behavior (avoidance of the vicinity to turbines); birds' response to destruction, modification, or creation of habitat related with offshore infrastructure and collisions with turbines are the most important impacts on birds [198]. Diving birds are also at certain risk because of the presence of underwater elements of wave and tidal devices [199]. Experience from onshore structures has revealed specific ways to mitigate these impacts, especially to prevent collisions, which is the major concern. Available techniques based on radar technology can detect birds approaching and either slow down/seize turbine operation or even emit high-frequency sounds in order to confuse birds and make them avoid the area. Since the MS belongs to one of the world's largest bird migration systems, this consideration is crucial for the development of offshore wind energy sector in the basin. Specifically, a great number of passerines, near-passerines, ducks, and raptors migrate from Europe to Africa mostly along the Mediterranean/Black Sea Flyway. Migration through this north-south axis is hampered by the existence of the basin and therefore, it takes place mostly through land routes such as the Messina Strait, Malta, as well as the Straits of Bosporus and Dardanelles. Several migration species of this flyway are characterized as globally endangered since a population decrease is observed over the past decades [200]. A review as regards the required field variables and the methods to collect them in order to examine the impacts of OWFs on birds, can be found in [201] for Spain. The potential effects of OWFs on birds in the MS have been described in [202]. Careful site-selection for OWFs and use of the available technology are essential measures in order to mitigate negative impacts on birds.

Electromagnetic field (EMF) effects, entanglement of marine species, and disturbances of physical systems due flow pattern changes are common characteristic effects of all MRE devices. Specifically, EMF caused by the presence of electric transmission cables of any MRE device may have negative environmental impacts by disturbing fish and marine mammals. In [203], the risk of entanglement that the various MRE mooring configurations present to large marine animals has been assessed. Results showed that taut configuration is associated with low entanglement risk compared to catenary moorings or nylon ropes. It is recommended that entanglement risk should be considered in environmental impact studies. Moreover, regarding wave and tidal devices, high-priority concerns are the impacts of turbine blades on marine animals.

The underwater structure of WTs, wave and tidal devices may also affect wave propagation and wave driven processes, flow and circulation patterns, and changes in coastal morphology. The wave energy reduction in the area, may influence coastal environment by affecting processes such as sediment transport and coastal morphology $[199,204,205]$. Sea grass meadows and coralligenous formations can be substantially affected by erosion caused by construction activities in the case of bottom-fixed structures. Consequently, selection of suitable areas for MRE production is particularly important in the MS for the protection of habitats. A recent account on the potential environmental effects of offshore wind installations in the MS can be found in [202]. On the other hand, the artificial reef effect (colonization of structures by benthic organisms, which leads to attraction of other marine species) can positively influence biodiversity, tourism, and fisheries. However, negative effects may be caused by the potential alteration of local biodiversity status. Exclusion of fisheries during the operation phase can increase local species abundances as fish is allowed to breed and grow free from fishing pressures [196].

More research is necessary, as the cumulative effects and long-term environmental impacts are hardly clear. A first attempt towards this goal has been presented in [206]. Long-term and continuous environmental monitoring is required since the modifications in the status of the marine environment at OWF sites has not been fully assessed yet. Detection of ecologically meaningful changes will allow further and substantial environmental impact assessments related to MRE installations [207].

\subsubsection{Marine Protected Areas}

The potential of OWFs to act as MPAs or stepping stones in networks of MPAs started being studied in depth during the last few years. A main theme of the COCONET project [149], was the 
detailed assessment and integration of future OWF installations along with existing MPAs in the MS The main goal of the project was shifting from single MPAs into networks of MPAs through the identification of physical and biological connections, which in turn point out suitable areas for OWFs, avoiding too sensitive habitats and acting as stepping stones through MPAs. Coupling MRE installations (in particular OWFs), and MPAs is a rather complicated issue since the accumulated impacts of the aforementioned estimations and observations are not clear yet. OWFs are not operating for a long time in the marine environment and therefore, the information needed to support planning decisions regarding OWFs acting as MPAs is limited [208].

Given the great number of MPAs in the MS and the need for renewable energy production, several studies have focused on offshore wind energy development in relation to MPAs at regional level. An investigation of offshore wind energy perspectives in the western coast of Greece in relation to MPAs in the region showed that even if all protected areas are excluded (along with areas of economic activity), the available space is adequate for offshore wind development [209]. A discussion on the potential coexistence of renewable energy installations and MPAs in European waters has been made in [210] and, a relevant discussion from the economic point of view in [211]; see also [208]. On the other hand, in [212], using the UK as a test case, the authors have concluded that the collocation of OWFs and MPAs could be an efficient solution for mitigating pressure of conflicts on other marine activities.

The concept of combining environmental protection with MRE exploitation is under development in the European countries and several studies aiming to fill knowledge gaps have already been conducted. Environmental monitoring at various locations covering large time scales, as well as during the operation of MRE devices, are necessary for the future perspectives of collocation of activities. Potential environmental impacts on surrounding sites due to fishing activity displacement, EMF effects, piling, and construction impacts are important aspects that need to be clarified.

\subsubsection{Environmental Impact Assessment Studies}

Environmental Impact Assessment (EIA) studies are a significant part of the licensing procedure for any MRE installation. The main purpose of EIA studies is the identification and evaluation of the impacts (positive and negative) that the implementation of a MRE project may have on the surrounding environment in its most general sense, including ecological, social, geomorphological, economic, and aesthetic issues. The necessity of EIA studies has been highlighted by the EU through the Directive 85/337/EEC on EIAs (called hereafter EIA Directive). The latest amended EIA Directive 2014/52/EU (valid since 15/05/2014) aims to simplify the rules for assessing the potential environmental effects that MRE projects may cause. Article 3 of the Directive describes the objectives of EIA studies. According to this Directive, the term 'environment' should be understood at its most general extent and not only as the biotic environment. In this respect, a common misunderstanding as regards environmental impacts is that the impacts are considered only with respect to the biotic elements of the environment (fish, habitats, mammals, etc.). However, a MRE installation may also have impacts on the geomorphological and oceanographic characteristics of the area as, for example, the alteration of the wave propagation schemes, hydrodynamic conditions, sediment transport and equilibrium, coastal geomorphology, etc. Furthermore, according to the EIA Directive, an EIA study requires an integrated and holistic approach and should consider a large variety of processes in the area of MRE development along with the assessment of the potential interactions between these processes. Therefore, it is important for MRE developers to include simulations or experimental studies of potential impacts on the local geophysical and oceanographic characteristics as part of EIA studies. The MS countries do not have the luxury to learn by doing in the field of MRE development. The MS is a very fragile environment, currently experiencing various instabilities; potential failure in any attempt of commercial development of MRE projects will have a lot of consequences (not only on monetary terms).

According to the EU Guidance (referring to offshore wind energy) [213], national protected areas/MPAs and Natura 2000 sites may not be threatened by the presence of OWFs, if they are properly designed and constructed. In particular, the environmental requirements formulated by the 
EU Directives provide guidelines for the protection and conservation of the marine environment, while national protected areas/MPAs and Natura 2000 sites may belong to either "restricted" or "no-go areas". These sites can be definitively characterized as no-go areas after detailed in situ assessment.

Chapter 5 of [213] describes in detail a multi-step procedure for wind farm developments near Natura 2000 sites. Moreover, as has been stated in [214] (based on the Habitats Directive), an appropriate EIA study should be made if a MRE site is part of the Natura 2000 network, while compensatory measures are necessary in order to protect the overall integrity of Natura 2000 sites, if there are negative impacts with no alternatives.

Three different case studies of EIAs on both biotic and physical system have been provided in [204] and a step-by-step description of a rational EIA study has been provided in [215]. A comparison of the legal frameworks governing EIAs, oriented to different marine applications (including MRE) in various countries, has been provided in [216].

The continuous environmental monitoring at the design, construction, and operation phase is an important issue for MRE development in the MS. There are two specific examples of OWFs in Denmark (Horns Rev and Nysted), the experience of which may be used for future MRE development in the Mediterranean. The building permits of these OWFs include the additional obligation to carry out comprehensive environmental monitoring programs that should include measurement of the environmental conditions before and during construction, as well as during the operation of the OWFs. The environmental monitoring programs were initiated following the completion of the EIA and the baseline studies. In our opinion, this approach should also be followed for MRE developments in the MS; see also the review in [217].

\subsection{Socio-Economic Considerations}

Over the past decades, public perception, preferences, and increasing awareness about renewable energy sources (RES) have been under extensive study; see, for example, [218] and references cited there [219-223]. Social acceptance constitutes a critical requirement for the adoption and development of all renewable energy forms, as experience gained from onshore installations has already revealed. The accumulated experience from several attempts regarding OWF development in the basin clearly suggests that societal acceptance is of major concern in the Mediterranean countries; it refers mainly to visual (aesthetic) disturbance of the coastal communities, conflicting uses of the same marine space, and employment opportunities. Social issues are expected to continue arising in the MS, mostly due to the lack of MSP and the consequent conflicts of interest occurring among different user groups. Although a series of projects have focused on this problem, MSP still does not exist even for the northern Mediterranean countries. Marine areas that are either completely excluded from MRE applications or under a restrictive status are those of important coastal tourism activity, fisheries and aquaculture sites, maritime transport routes, Natura 2000 (under certain conditions) and Ramsar sites, offshore oil/gas installations, port entrances, military areas, submarine archaeological sites and sites of cultural heritage. It should be noted though that impacts vary significantly between locations, and site-specific social impact assessment studies are required to accurately evaluate the social effects at and around the project site. Such studies should indispensably also include social perception, which is highly connected with the fate of MRE development in a location; if, for example, local actors are actively involved in the chain of implementing a MRE installation and local population are adequately informed as regards the benefits and valuation of MRE at a local/regional level, then the conflicts may be less pronounced; see, e.g., [222].

Impacts of MRE development on coastal tourism through visual disturbance, as well as impacts on fisheries are considered as issues of the highest importance and are discussed in the following sections. As has been highlighted in [224], economic and societal aspects of offshore renewables are inter-connected and synergistic research areas; therefore, they should be analyzed in a holistic approach in order to guarantee sustainability. This approach may be greatly enriched from the experience gained from onshore and offshore renewable applications, as it constitutes a valuable tool 
towards understanding and overcoming such challenges of MRE development in the Mediterranean; see also the interesting review in [225] with many examples from onshore wind farms in Greece, and [205].

\subsubsection{The Economics of Offshore Renewables}

The main economic constraint of offshore renewables is related to the cost of electricity [1]. Capital expenditures (CAPEX) include the cost of manufacturing, installing, and decommissioning a device (i.e., costs prior to energy generation such as foundation, grid connection, environmental analysis); operational expenditures (OPEX) are related to the costs of operation and maintenance (O\&M) of an installation (e.g., insurance, repair). The levelized cost of energy (LCOE) refers to the costs of electricity for an MRE installation over an assumed financial life and duty cycle. In this respect, LCOE is very useful in comparing different energy generating technologies under different conditions. LCOE includes CAPEX and OPEX and can be calculated using the equation below; see also [226]

$$
\mathrm{LCOE}=\frac{\text { CAPEX } \times \text { FCR }+ \text { OPEX }}{\mathrm{AEP}},
$$

where AEP stands for the annual energy production and FCR is the annual fixed charge rate that depends on the discount rate $r$ and the lifetime of the project $n$. Specifically, FCR can be calculated by the equation:

$$
\mathrm{FCR}=\frac{r(1+r)^{t}}{(1+r)^{t}-1}
$$

where $t$ denotes years and ranges from 0 to $n$.

Based on various economic and technical factors and assumptions (e.g., capital cost, discount rate, number of WTs, installed capacity, distance from shore), different values for the LCOE are obtained when trying to estimate cost of energy production. For instance, as regards tidal energy converters, bottom mounted structures with one rotor are, in financial terms, less attractive than twin turbine rotors [227]. Indicative results for the LCOE are presented in Table 2. Let us note that the above estimates were retrieved from sources with different currencies; therefore, wherever necessary, all currencies were converted to Euro according to historical average exchange rate of the corresponding publication year [228].

Table 2. Values of LCOE for different types of MRE ( $€ / M W h)$.

\begin{tabular}{cccc}
\hline \multirow{2}{*}{ Source } & \multicolumn{3}{c}{ Type of MRE } \\
\cline { 2 - 4 } & Offshore Wind Energy & Tidal Energy & Wave Energy \\
\hline$[229]$ & 94 & 93 & 218 \\
{$[230]$} & $120-250$ & $110-220$ & $140-530$ \\
{$[60]$} & 165 & 190 & 325 \\
{$[231]$} & 216 & $117-252$ & $108-423$ \\
\hline
\end{tabular}

In [232], an attempt has been made to identify the most important factors affecting O\&M costs, in [233] a rational logistics planning has been proposed, and in [234] suggestions for the minimization of the maintenance costs have been provided. A sensitivity analysis regarding the life cycle costs and the most important economic indexes in terms of economic feasibility of a floating OWF has been presented in [235]. It is generally considered that reduction of investment costs are feasible in the near future. In [236], the increase of the load factor and material efficiency, and the decrease of decommissioning costs have been suggested, the author in [237] has concluded that the price of offshore wind power expansion is reasonable and that the support scheme with incentives and enforcement of efficiency improvement proved to be successful, while in [238], scenarios regarding cost reduction of renewable energy in the EU scale have been presented and discussed. The levelized costs of tidal, wave, and offshore wind energy have been evaluated and compared in [60]. 
A set of support tools has been placed in action by the EU Member States in order to efficiently promote all forms of MRE production, [239]. In order to encourage cost-effective deployment of MREs in the Mediterranean, the established mechanisms of public support such as feed-in tariffs (FiTs) are implemented. The two widely used forms of FiTs are fixed FiT and feed-in premium (FiP). FiTs have been used in many cases to ignite and accelerate MRE investments and are considered as a favorable option for market development of MRE in the MS. Such strategies require support of the banking sector and determination of the market organization and sustainability. A steady economic environment favors investments and market development. The EU, through adopting the guidance of the renewable energy support framework [240], suggested that fixed FiTs should be replaced by FiPs and other support instruments since FiPs are more rational, flexible and capable of supporting schemes that should respond to potentially reduced production costs. A detailed discussion as regards the pros and cons of fixed FiTs vs. FiPs has been presented in [241], while the status of the running support instruments in the EU Member States is regularly updated in [242].

Further research is needed in order to survey and evaluate potential strengths and weaknesses of the MRE sector in the Mediterranean basin, and to analyze in depth the costs and profitability of technologies with respect to the MS environment. The value chain of MRE also requires more cost-efficient and tailor-made solutions from the industry. Technology development should seek solutions regarding the operation cost of MRE farms, leading more players to the market. However, as is mentioned in the Introduction with respect to the perspectives of MRE development in the Mediterranean countries, the key role of the national and regional governmental entities and the financing sector of the Mediterranean countries cannot be accurately prescribed. Nevertheless, investments in the MRE sector in the MS cannot thrive without economic stability and financing certainty.

\subsubsection{Legal and Regulatory Framework}

In order to achieve the overall goals of the Renewable Energy Directive, all EU Member States have developed national action plans combined with in advance renewable energy forecasts. Each national plan is formed according to the available resources and the particular energy market [243]. In this connection, the legal-regulatory framework for energy production is critical for MRE development. However, as has been highlighted in [244], existing research on legal and regulatory issues related with MRE is not adequately addressed since the key issues that are involved are also interrelated with several other aspects such as EIAs and consenting processes, rights and ownership, international law, management of ocean space, etc. In [245], a discussion on the policies and governance framework as regards offshore wind in the EU Member States has been presented along with some suggestions as regards the EU role in shaping offshore wind governance while in [246], a review on the consenting processes as regards MRE has been presented for different EU Member States, including France and Spain.

Energy prices at the national level may create a favorable or less favorable environment for investments, shaping in this way the organization of the corresponding markets. The cost of MRE and the relevant competitiveness of investments are formed, to a great extent, by national licensing procedures and regulations, cash liquidity costs and regional/local requirements as regards offshore installations. What makes an investment attractive and supportive of the value chain, strongly depends on the efficient energy market organization, the established licensing procedures and relevant policies at the national and regional level. On the other hand, continuous changes on the regulatory, policy, and market frameworks, and/or financial or political instability, play influential role to the sector's value chain and have evidently negative impacts on the maturation of the MRE market. These issues have been addressed in detail at the Mediterranean level, in the context of the recently completed Med Program "Blue Energy in the Mediterranean (BLUENE)" [247]. In-depth analysis has been made with reference to Italy, Spain, Croatia, and Greece; see also [248] for an overview of two Med projects 
dealing with aspects of MRE (BLUENE and Enercoast). Renewable energy policies and regulatory frameworks in the EU Member States are regularly updated in [242].

\subsubsection{Employment Opportunities}

Employment is a field (positively) affected by MRE production $[249,250]$. MRE industry creates new jobs during all stages of a MRE project and reskills opportunities for people affected by economic restructuring. The broad range of occupations required by the supply chain for each MRE technology create new permanent or part time employment opportunities, especially for residents of the coastal community. Nevertheless, accurate figures as regards current and future creation of new jobs in the MRE sector seem to be lacking. Various and diverging future estimates for Europe have been provided in [251-254].

\subsubsection{Struggling for Space?}

In this section, the most important 'space competitors' of MRE development in the MS are presented, i.e., tourism, maritime transport, fisheries and aquaculture, and seabed mining.

\section{Tourism and Visual Disturbance}

Tourism is highly dependent on the attractiveness of the environment. Visual impact (landscape impact and aesthetic impact [225]) caused by the presence of offshore renewables is believed to have a negative impact on coastal tourism [255]. However, offshore WTs are proved to cause much less visual disturbance than the onshore ones [256,257]. Visual impact is negligible at 5-10 km with respect to aesthetic quality of landscape, while an accumulated effect of greater numbers of WTs is not confirmed [258]. In Denmark and Sweden, where OWFs are located rather nearshore, locals are generally positive towards OWFs but they also prefer future OWFs to be located further offshore and have expressed willingness to pay for this. On the other hand, OWFs in Germany are located outside the 12 nautical mile zone and they are hardly visible from the shore [259].

Extensive studies regarding the impact assessment of OWFs on tourism and coastal communities have been made for the North Sea. Most common concerns are related to impacts on the landscape, use of sea space, noise, shadow flickering as well as risk of ship collision. The most important groups that are associated with stronger visual disturbance are residents of the coastal areas selected for OWF development, those who make use of the beaches as well as people of higher education, income and age $[260,261]$. In Denmark, people with prior experience from OWFs located in large distance from the coast have more favorable attitude towards visual impacts than people familiar with OWFs closer to the coast [261,262]. Moreover, accumulated experience from OWFs installations (in the North Sea) suggests that offshore WT foundations along with the development of artificial reefs may add real recreational value to a coastal area by enabling educational activities such as observational boating [164]. These concepts have already been implemented in the UK, Denmark, and Germany based on the attractiveness of new technologies as well as the promotion of environmental awareness [263].

The importance of tourism in the economy of the Mediterranean coastal communities explains a number of fears that locals express regarding MRE development, and especially OWFs, since gained experience (regarding impacts on tourism) is confined to this MRE form. In the Mediterranean French coasts, offshore wind projects have been cancelled due to locals fearing of destruction of their coastal community resorts. In [164], the authors have studied the impact of OWFs in coastal tourism for the case of the Languedoc-Roussillon region in the Mediterranean coasts. Age, nationality, and vacation activities seem to influence the degree of visual nuisance that tourists experience. The same study has also revealed that no visual impacts exist at distances in the range $8-12 \mathrm{~km}$, while wind farms at $12 \mathrm{~km}$ offshore could lead to a slight increase of tourist visitations. In addition, proper environmental policy as well as recreational activities associated with OWFs could compensate the negative visual impacts of an OWF located at $5 \mathrm{~km}$. 
Social oppositions to MRE projects due to visual impacts and the 'not in my backyard' (NIMBY) attitude can be mitigated or even eliminated by using floating devices deployed offshore, a concept that is gaining ground during the past few years. At present, floating offshore WTs are planned to operate off the Mediterranean French coasts. Apart from shifting offshore, tourism industry may overcome these barriers by turning OWFs into local attraction centers. Furthermore, people's perception of OWFs also depends on the greater context in which they operate, meaning a rational environmental policy of the local coastal community. In this context, visual disturbance issues and the associated impacts on tourism can be substantially minimized [164]. Authors in [264], making particular reference to the MS, have concluded that pluralistic information regarding climate change issues-effectiveness of RES, impacts of offshore WTs on the surrounding biotic and abiotic environment, cost of wind energy compared to other energy sources, etc.-may influence tourist community preferences for OWFs that are visible from the shore. The authors also have suggested that nationality, education level, and proper information on the above issues are important. Overall, distance to shore has the greatest influence in public attitude towards offshore installations.

In [265], public perceptions of tidal stream energy in northwest Spain have been studied. The study has showed that several characteristics of the energy facility such as the number of tidal stream turbines affect people's perception. A generally positive attitude towards tidal energy is also revealed. However, this attitude is expressed by most residents except for those living very close to the power plant, leading to the conclusion that NIMBY attitudes can appear in the tidal energy case too.

Wave energy technologies have minimized visual impacts and therefore, public perceptions are not expected to hamper any future wave energy development. A relative case study analyzing public acceptance of the oscillating water column plant of Mutriku, verifies the particularly positive public attitude but also points out the importance of proper information of the community, as well as the participation in decision making regarding such projects in order to achieve public acceptance [266]. Regarding especially wave overtopping devices installed directly on existing infrastructure (e.g., the OBREC installation in the Port of Naples $[185,186])$ seem to be a sustainable solution, minimizing the potential conflicts between different stakeholders and strongly mitigating NIMBY attitudes.

\section{Maritime Transport}

MRE installations can impose potential hazards to the safe navigation and operation of marine vessels, especially in crowded ship routes; therefore, it is expected that future MRE projects will compete with shipping for space. For instance, apart from collision problems, the mooring system of arrays of marine renewable devices may significantly reduce the underwater visibility of submarine and unmanned underwater vessels and impede counter-pollution and search and rescue operations. Moreover, the presence of a large array with its power cables may cause electronic/magnetic interferences of radar and underwater communication systems, which may be a potential risk to navigation. In [267], it has been suggested that a safety zone of at least $500 \mathrm{~m}$ should exist between OWFs and shipping lanes, while the buffer zone must be wide enough to allow for a turnaround of a vessel. A more detailed approach as regards interactions between MRE installations and ship routes has been presented in [268], while technical guidance and recommendations as regards the impacts of MRE installations on shipping have been provided in [269]. Avoidance of MRE installations by rerouting (due to safety aspects) maybe not a simple task. It may increase environmental pollution (ship air emissions of $\mathrm{CO}_{2}, \mathrm{NO}_{X}, \mathrm{SO}_{X}$, and particulate matter), fuel and operating cost, and capital cost payments, leading thus to an increase of the transportation cost. On the other hand, ship rerouting may reduce the cost of future MRE projects [270].

Another emerging priority relating MRE use and maritime transport is cold ironing (ship electrification) for ships while at berth; this issue is one of the main objectives of the undergoing ELEMED (Electrification of the Eastern Mediterranean Area) project, held in the frame of Connecting Europe Facility-Transport [271]. Nowadays, the main source of power for ships are heavy fuel oil and marine diesel oil [272]. Due to the rapid development of international commerce, and, in turn, 
the increase of the seaborne activities in the Mediterranean area, ship and port emissions have been increased, putting more pressure on the quality of the port and coastal environment and community. Among the proposed solutions for improving air quality in ports and adjacent coastal areas is to adopt cold ironing. The ideal situation, in this respect, would be either to increase the share of MRE in the local grid or to assign some of the ports' operational energy needs to MRE. The ELEMED project studies the above-mentioned issues for four ports of the eastern MS (Limassol, Piraeus, Kyllini, and Koper).

The critical role of ports in the MRE development is additionally supported by the fact that ports are often located in areas that are particularly suitable for power generation from wind (e.g., Rotterdam), waves (e.g., Mutriku in the Basque Country), tide differentials (under study in Dover, UK). In this respect, it is highlighted that North Sea ports may become the onshore hubs for offshore wind energy-based system (including infrastructure connection, manufacturing sites, and operational centers for construction and maintenance of offshore wind) [273]. Such an approach may be adapted for the Mediterranean ports as well. Overall, electrification of ships in the major ports of the MS and the integration of MRE in the electrical power supply systems is considered of great importance nowadays.

\section{Fisheries and Aquaculture}

The presence of MRE installations leads to loss of fishermen's access to a large area. European countries imply a 500-m restriction during construction works and operation of OWFs, while only the UK reduces the exclusion zone to $50 \mathrm{~m}$ around each WT during OWF operation $[274,275]$. Fishermen's work depends on a series of physical and technical parameters unknown to public; thus, moving to other fishing areas, as well as continuing to work inside an OWF, is a rather complicated issue. According to a study on the perceptions of the UK fishing industry, fishermen consider that a 'loss of profit' will occur due to the reduction of the available area for fishing since navigation and fishing activities in the farm area are not safe. Regarding safety, only certain types of fishing can be considered as compatible [276]. Exclusion of fishing activity into the MRE area leads, on the other hand, to positive environmental impacts as pressures in the marine environment decrease (protection of benthic and soft sediment communities, etc.). Moreover, it has been highlighted by several studies that OWFs or other MRE installations can act as artificial reefs, thus providing benefits to fisheries (leading to attraction of high commercial value species), and opportunities of aquaculture inside the farms, while fish catches can increase outside the protected area $[164,212,277,278]$. Similar surveys have been presented in [279] in order to quantify fishermen's perception in Ireland and the UK [280]. Other concerns regarding the impacts on fish behavior patterns and trophic web functioning have been described in $[281,282]$, respectively. Despite the concerns discussed above, results reveal a generally positive attitude (70\% of fishermen) towards the coexistence of fisheries and MRE projects. A consultation process is recommended, so that potential conflicts can be significantly reduced when stakeholders participate in decision making on relevant projects.

In the MS, most aquaculture and fish farm installations are located in weather protected coastal areas (i.e., areas of low wave and wind resource). In this respect, it seems that the conflicts in existing and future uses of marine space are not important. In addition, given the expansion of the aquaculture industry and the consequent increasing energy demand, the applicability of MRE technologies in the Eastern Mediterranean offshore aquaculture has been investigated in [283]. In [284], the application of aquaculture within OWFs has been discussed and the points of view of the different stakeholders involved have been explored.

\section{Marine Mineral Resources}

Exploitation of marine mineral resources (e.g., polymetallic nodules, ores, polymetallic sulphides, cobalt-rich crusts) is another activity taking place in the marine environment and is among the five pillars that could contribute to sustainable growth and provide jobs based on the European Commission's Blue Growth Strategy. As regards the Mediterranean, seabed mining has the potential to 
become a major industry, but several considerations need to be resolved first, such as policy framework, and more research is required, such as ecological impacts and availability of minerals and deposits in order to achieve viable projects. Tyrrhenian and southern Aegean Seas are the most promising areas for exploiting sulphide deposits.

Exploring interactions and conflicts between the above marine uses and MRE is essential for the forthcoming marine environmental management. In a publication of the Directorate-General for Maritime Affairs and Fisheries, [267], the spatial competition between MRE installations and other maritime activities, addressed specifically to stakeholders and decision makers, is discussed.

\subsubsection{The Necessity of Marine Spatial Planning}

Increasing demand for maritime space to host different activities, combined with the multiple pressures on coastal resources, requires an integrated planning and management approach. The concept of collocation of activities has recently gained ground since it constitutes an alternative option to ease demands on space. An assessment using as a test case the UK has been made in [212] with particular reference to MPAs, aquaculture, and commercial fishing. The idea of multi-use offshore platforms (MUP) combining MRE, transportation and aquaculture facilities has been studied in [285-290]. In [286], the methodological steps for the design of a MUP, based on technical, environmental, and socio-economic criteria have been proposed, followed by a test case scenario off the Western Sardinia coasts, where WECs, offshore WTs, and aquaculture are studied in a combined way. An integrated socio-economic assessment of MUPs has been presented in [289], and an application for the area offshore Venice has been provided in [290]. In this context, collocation of MRE installations and aquaculture is feasible since water quality and lack of traffic within a MRE plant favor cultivation of several species [208,291]. Collocation opportunities have been also discussed in [292] in relation to MPAs, fisheries, and offshore renewable energy sites. The study focuses on Northern Ireland's waters and suggests that understanding how the individual sectors are affected, facilitates the identification of the potential conflicts and contributes to mitigation strategies. It is suggested that optimal locations for MRE should depend on collocation opportunities and that a "multi-industry ocean-zoning" within the framework of strategic conservation planning is required; see also [288], where a framework for specifying alternative points of view (such as technical, environmental, socio-economic, and legal factors) as regards MUPs is applied. One of the study areas in the latter work is the MS. Nevertheless, the bigger picture regarding the particularities of the Mediterranean countries, necessarily encompasses a comprehensive Maritime Spatial Planning (MSP) and Integrated Coastal Zone Management (ICZM). MSP and ICZM are complementary aspects that ensure the sustainable development of MRE.

MSP rationally combines multiple users and uses of the sea and its framework is established by the Directive 2014/89/EU of the European Parliament and the Council. It is a policy and decision tool for the sustainable utilization of the maritime resources through analyzing and allocating the spatiotemporal patterns of human activities, [293], supporting the application of a holistic, coordinated, and trans-boundary approach; see also [294-298]. MSP is the foundation on which any further attempt for sustainable development of MRE in the MS should be lying. From another point of view, in [299] it has been suggested to adopt the Ocean Health Index (OHI) with respect to MRE in order to balance the various multiple-competing activities in MSP, considering both environmental and socio-economic aspects. An overview of the MSP status in the MS including case study reports (for the Adriatic and the Alboran Seas, the area surrounding Malta, and Western Mediterranean) and country reports can be found in [300]. Rights and ownership in the marine environment, management of ocean space and of the available resources, environmental sustainability, and improvement of EIA studies by using planning professionals have been discussed in an analysis of modern marine governance frameworks conducted in [301]. This paper also has highlighted the need to understand that MRE is an emerging ocean use and that shaping proper MSP frameworks would improve outcomes for innovative new industries and vice versa. 
It is anticipated that, up to 2021, significant progress as regards MSP in the Mediterranean will be achieved. On the other hand, declaration of the Exclusive Economic Zone (EEZ) of the Mediterranean countries would probably facilitate the development of MSP in the Mediterranean basin. However, it seems that many disputes associated with geopolitical and socio-economic complexities over marine borders and jurisdictions in the basin do not have a critical importance as regards MRE development [302]. Although progress has been made by the Member States in MSP, further development is necessary.

Along with MSP, ICZM can ensure the sustainable regional and local development of coastal and marine areas and the integrated management of human activities through harmonized policies and decision-making structures. Knowledge on the local coastal systems can be improved by taking into consideration diverse activities that take place in the coastal environment [303]. Some examples of ICZM initiatives in the coastal Mediterranean have been provided in [304]. The vision of EU for a common framework for MSP and ICZM will be extremely valuable for the MS. The protocol that was developed to promote and implement ICZM in the Mediterranean through a common framework, and was approved on behalf of the EU, can be found in [305].

\section{A Roadmap for MRE Development in the Mediterranean Sea}

\subsection{General}

The importance of uninterrupted availability of affordable MRE sources is highlighted by the rapidly increasing need to replace fossil fuels with sustainable energy. The maturity of the wind energy market, the existing advanced technology and the proven economic viability of offshore wind production in the North Sea render offshore wind the most promising MRE form for the Mediterranean in the near future. Offshore wind energy is currently gaining ground in the MS since it seems to be the most suitable for the area among MRE forms as regards resource availability.

Financial stability and application of effective financing tools, governance support, enhancing and centralizing of permitting bodies' capacity, the rationalization and simplification of licensing and permitting procedures, and improvement of policy frameworks are considered key issues for facilitating and boosting MRE development in the area. For example, the application of joint actions and procedures when developing infrastructures relevant to MRE projects (grid network, ports, etc.) at the basin level may significantly facilitate its development. This, in turn, requires (i) the revision of national policies and environmental, socio-economic, technical, and legislative considerations; and (ii) the harmonization and integration of national, regional, and transnational policies (at least for the EU Member States) in order to mitigate the problem of conflicting regulations and legislations that hinders the development of activities occurring in overlapping political spaces.

For the sustainable development of MRE in the MS, negative experience and examples may be also of value. In [306], it has been proven that the absence of both strategic design and effective legislative/regulation framework, combined with misinterpretations as regards onshore wind farm development in Greece, leads to " ... anarchic applications for the development of electricity power plants from renewable energy sources...".

A roadmap for Blue Energy (BE) development in Europe has been described in detail in [6] and [307]. Specific recommendations as regards technical, environmental and socio-economic aspects relevant to MRE development in the MS are provided below.

\subsection{Technical Recommendations}

Since the existing wave and tidal/current devices are designed for harsher environments than the MS in order to effectively utilize moderate resources (short-crested waves with rather low wave heights, slower tidal currents) in an economically viable way, there is need for a tailor-made range of concepts, namely smaller WECs and smaller TECs well adapted to the Mediterranean conditions and the available resource. Currently, the lack of mature technologies in WECs and the limited wave 
and tidal/current energy render the commercial and geographically extended development of these MRE forms in the basin unlikely for the next years. Onshore wave devices may be a rational solution for the already existing infrastructure (breakwaters, seawalls, dams, bridges, etc.) [6]. Based on the provided MRE potential estimates, it seems that today only offshore wind energy (and in few specific locations tidal/current energy) meets the requirements for commercial development. Nevertheless, there is currently a discussion as regards combined exploitation of marine wind and wave energy by using collocated, hybrid, and island systems. For the Mediterranean case, the available wave resource is weak and therefore, the combined wind and wave energy resource is also weak [61]. The potential sites that such a synergy can be implemented is the Gulf of Lion, the Greek islands in the Aegean Sea and the sea area between Sicily and Tunisia.

Although any discussion about potential application of OTECs in the MS is currently unlikely, in [308], it has been proposed that the temperature difference between the atmosphere and the sea water may be utilized since it is comparable to the corresponding water temperature differences in a tropical region. Regarding salinity gradient energy, since most of the river mouths in the Mediterranean coasts are environmentally protected areas, potential attempts for installations in these areas are expected to be intensively confronted. Fulfilling our knowledge gaps as regards OTEC and salinity gradient energy potential in the Mediterranean is a priority in order to realistically discuss their perspectives in the basin.

Overall, BE industries of the Mediterranean should either invest in the development of new technologies or adapt existing ones in order to provide tailor-made solutions for BE exploitation in the area. According to [6], other focus areas that should be addressed for technology development refer to testing and modelling (validation of concepts and demonstration of installations in real conditions), reliability and survivability (development of real-time monitoring systems to identify potential failure during the operation), installation and logistics (utilization of existing infrastructure), power generation and grid and standardization of the industry leading to certification.

Another important issue refers to the lack of in situ met-ocean measurements and long-term simulation results obtained from numerical models of high spatial resolution. In particular, the estimation of offshore wind energy characteristics should be made at the offshore WT hub height, while the wind profile should be accurately estimated by utilizing measured wind data obtained by meteorological masts or Lidar measurements. The detailed evaluation of the model results, especially in the nearshore/coastal areas, is also necessary in order to assess the accuracy, performance, and homogeneity of the numerical simulations.

\subsection{Environmental Recommendations}

Some recommendations relevant with OWF development in the MS have been provided by the COCONET project [149]; see also [107]. It was acknowledged that more detailed information on the environmentally sensitive marine areas at depths $0-200 \mathrm{~m}$ is required. The more accurate identification of important habitats, coralligenous, and deep-water white coral formations, is necessary for the efficient planning in the MS. The current lack of mapped bird migration routes is an additional information gap for the offshore wind sector. Taking into consideration the COCONET findings, some general recommendations as regards the interactions of MRE development and environmental issues are summarized below.

In the areas scheduled for MRE development, there is need to screen and map the existing habitats and the distributions of important species, as well as the surrounding water volumes and the sea bottom areas so as to avoid impacts on biodiversity. In this respect, monitoring campaigns are necessary before and during construction, operation and decommissioning of MRE installations in order to enrich knowledge as regards long-term environmental effects and the acting of the installations as stepping stones across MPAs. The monitoring programs shall be standardized in order to assess marine biota shifts, create baseline inventories and identify thresholds so as to understand and predict future changes in marine biodiversity due to the MRE installations. An efficient means to fulfil this task is 
by utilizing pilot sites before MRE development in order to study and assess actual environmental impacts in the surrounding environment. The installation of the main components of a structure might allow the prediction of the impacts as if the whole structure was deployed. In this way, the study of the potential environmental effects in the far- and near-field environment and the optimization and adjustment of the MRE installation will be considerably facilitated.

EIA studies should be followed by consultation of the general public, local authorities, organizations concerned and any stakeholder involved in the MRE project in order to be realistic and of actual value. A necessary, yet overlooked, part of the EIA studies is the simulation of the potential impacts of MRE installations on the local geophysical/oceanographic characteristics (wave propagation, circulation, sediment equilibrium, coastal morphodynamics, etc.). Finally, there is need to review and share the knowledge from the implementation of important EU directives (Marine Strategy Framework Directive, EIA, and the Habitats and Birds Directive) for enabling more consistent approaches across Mediterranean EU Member States, especially in cross-border cooperation issues. This is necessary since the directives as regards licensing and consenting processes for MRE development are often integrated in a non-homogeneous way into the national legislations.

\subsection{Socio-Economic Recommendations}

Taking advantage of the existing experience from northern European countries and France, regarding OWF development in the Mediterranean, there is need to promote floating structures as a rational solution for the offshore wind exploitation in the area. This shift may also contribute to the mitigation of potential environmental effects. Another urgent necessity is to increase the likelihood of social acceptance for MRE development in an area. This can be achieved in several ways, such as:

- Combining other beneficial economic activities with the operation of MRE plants (e.g., the underwater structures of WTs or other MRE devices can be used to farm filtering bivalves or provide space for commercial fish, mimicking artificial reefs) in order to minimize fears and prejudices. These activities might become part of the compensations offered to the local communities.

- Raising environmental awareness of the local communities through informational campaigns and by making explicit the pros and cons of each MRE plant; the advantages for the local communities must be realistically stated, along with proposed compensation measures.

- Providing proper and accurate information of stakeholders about the economic implications of MRE installations on tourism.

- Performing detailed socio-economic valuation surveys during the design phase of MRE projects, with consultation processes for any relevant application, focusing on stakeholders.

Finally, the lack of MSP is expected to raise conflict of interests among different user groups. Creating the conditions to rationally exploit the benefits of MRE development in the MS and mitigating the expected social conflicts is highly dependent and interrelated with the development of MSP and ICZM at the regional/local level. These issues, combined with EIA studies of actual and realistic value, and rational regulation of the uses of the same ocean space constitute key drivers towards MRE sustainability in the Mediterranean basin. The management of marine, maritime, and coastal space must be accomplished in an integrative fashion in order to acquire a complete picture of all existing, scheduled, and foreseen human activities, and associated threats to environmental integrity and, most of all, to maximize its value.

\subsection{Roadmap Summary}

The schematic representation of the roadmap for MRE development in the MS is depicted in Figure 15 and, based on the above discussion, the key points of this roadmap are summarized as follows: 
Data efficiency

- Perform in situ metocean measurements and acquire long-term simulation results from numerical models of high spatial resolution, especially in the nearshore/coastal areas

- Simulate the potential impacts of MRE installations on the local geophysical/oceanographic characteristics

- Acquire detailed information on the environmentally sensitive marine areas and habitats at depths 0-200 m

- Map bird migration routes to facilitate the development of offshore wind sector

- Screen and map the existing habitats and the distributions of important species

- Design and implementation of monitoring campaigns before and during construction, operation, and decommissioning of MRE installations.

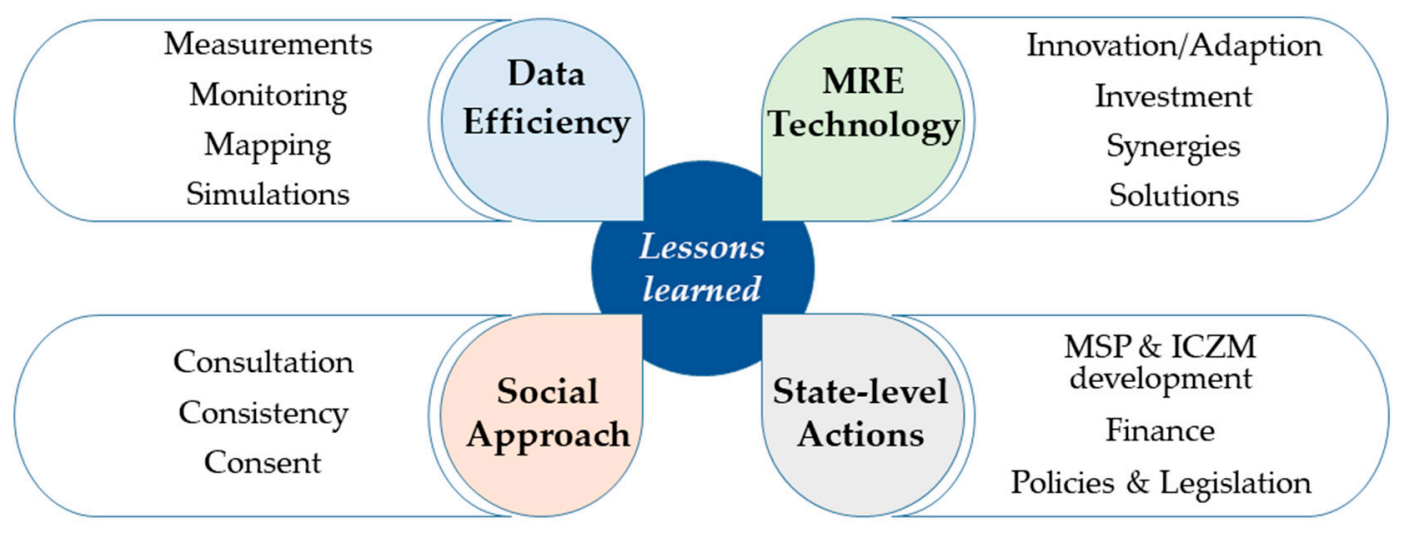

Figure 15. Schematic representation of the roadmap for MRE development in the Mediterranean Sea.

MRE technology

- Invest in the development of new technologies or adapt existing ones in order to provide tailor-made solutions for MRE exploitation in an economically viable way

- Support onshore wave devices as a rational solution for the already existing infrastructure

- Consider synergy of offshore wind and wave energy at carefully selected sites

- Promote offshore wind energy that is mature to meet the requirements for commercial development

- Promote floating structures as a rational solution for offshore wind exploitation and as a measure to mitigate potential environmental effects.

Society involvement

- Perform EIA studies of actual and realistic value followed by consultation of the general public, local authorities, organizations concerned, and any stakeholder involved in the MRE project

- Review and share the knowledge from the implementation of important EU directives for enabling more consistent approaches across Mediterranean EU Member States, especially in cross-border cooperation issues

- Increase the likelihood of social acceptance for MRE development by several means (combining other beneficial economic activities with the operation of MRE plants, raising environmental awareness of the local communities through informational campaigns, providing proper and accurate information of stakeholders about the economic implications of MRE installations on tourism, performing detailed socio-economic valuation surveys during the design phase of MRE projects focusing on stakeholders). 
State level recommendations

- Develop MSP and ICZM at the regional/local level for establishing a holistic management of marine, maritime, and coastal activities in the ocean space

- Strengthen financial stability, application of effective financing tools, governance support, enhancing and centralizing of permitting bodies' capacity, rationalization, and simplification of licensing and permitting procedures, improvement of policy frameworks

- Revise (if necessary) national policies and environmental, socio-economic, technical, and legislative considerations

- Harmonize and integrate national, regional, and transnational policies (at least for the EU Member States) in order to mitigate the problem of conflicting regulations and legislations.

Ultimate recommendation

- $\quad$ Learn from both positive and negative experience and examples at the global level.

Acknowledgments: (1) This research has received funding from the Innovation and Networks Executive Agency (INEA) in the framework of Connecting Europe Facility (CEF)—Transport Sector [Grant Agreement no. INEA/CEF/TRAN/M2015/1124853] for the project "Electrification of the Eastern Mediterranean Area (Use of Cold Ironing and Electricity as a propulsion alternative)_ELEMED"; (2) Part of this research has been also co-funded by the European Regional Development Fund, in the framework of the Interreg MED Program 2014-2020 for the project "Promoting innovative nEtworks and cLusters for mArine renewable energy synerGies in Mediterranean cOasts and iSlands" (PELAGOS), [Project Code No: 1373]; (3) The authors wish to thank P. Axaopoulos for his help in preparing this manuscript.

Author Contributions: Takvor H. Soukissian coordinated this joint work and contributed to all sections; Dimitra Denaxa contributed to all sections; Flora Karathanasi contributed to Sections 4 and 5; Aristides Prospathopoulos contributed to Section 5; Konstantinos Sarantakos and Konstantinos Georgantas contributed to Section 4; Athanasia Iona contributed to Section 3; Spyridon Mavrakos contributed to Section 2.

Conflicts of Interest: The authors declare no conflict of interest.

\section{Abbreviations-Acronyms}

$\begin{array}{ll}\text { AIS } & \text { Automatic Identification System } \\ \text { BE } & \text { Blue Energy } \\ \text { BSW } & \text { Blended Sea Winds } \\ \text { CAPEX } & \text { Capital expenditures } \\ \text { CS } & \text { Conservative Scenario } \\ \text { ECMWF } & \text { European Center for Medium-Range Weather Forecasts } \\ \text { EEZ } & \text { Exclusive Economic Zone } \\ \text { EIA } & \text { Environmental Impact Assessment } \\ \text { ELEMED } & \text { Electrification of the Eastern Mediterranean Area } \\ \text { EMEC } & \text { European Marine Energy Center } \\ \text { EMF } & \text { Electromagnetic field } \\ \text { ENTSO-E } & \text { European Network of Transmission System Operators for Electricity } \\ \text { EU } & \text { European Union } \\ \text { EWEA } & \text { European Wind Energy Association. } \\ \text { FEAP } & \text { Federation of European Aquaculture Producers } \\ \text { FiP } & \text { Feed-in premium } \\ \text { FiT } & \text { Feed-in tariff } \\ \text { GFCM } & \text { General Fisheries Commission for the Mediterranean } \\ \text { HCMR } & \text { Hellenic Center for Marine Research } \\ \text { ICZM } & \text { Integrated Coastal Zone Management } \\ \text { IPCC } & \text { Intergovernmental Panel on Climate Change } \\ \text { ISWEC } & \text { Inertial Sea Wave Energy Converter } \\ \text { ITTC } & \text { International Towing Tank Conference } \\ \end{array}$




$\begin{array}{ll}\text { LCOE } & \text { Levelized cost of energy } \\ \text { MPA } & \text { Marine protected Area } \\ \text { MRE } & \text { Marine Renewable Energy } \\ \text { MS } & \text { Mediterranean Sea } \\ \text { MSP } & \text { Marine Spatial Planning } \\ \text { Mtoe } & \text { Million tonnes oil equivalent } \\ \text { MUP } & \text { Multi-use offshore platforms } \\ \text { NIMBY } & \text { Not in my backyard } \\ \text { NOAA } & \text { National Oceanic and Atmospheric Administration } \\ \text { O\&M } & \text { Operation and Maintenance } \\ \text { OBREC } & \text { Overtopping BReakwater for wave Energy Conversion } \\ \text { OE } & \text { Ocean Energy } \\ \text { OHI } & \text { Ocean Health Index } \\ \text { OPEX } & \text { Operational expenditures } \\ \text { OTEC } & \text { Ocean thermal energy conversion } \\ \text { OWF } & \text { Offshore wind farm } \\ \text { QuikSCAT } & \text { Quick Scatterometer } \\ \text { R\&D } & \text { Research and Development } \\ \text { RAC/SPA } & \text { Regional Activity Center for Specially Protected Areas } \\ \text { RES } & \text { Renewable energy sources } \\ \text { TEC } & \text { Tidal-stream Energy Converter } \\ \text { TS } & \text { Energy Transition Scenario } \\ \text { TWh } & \text { Terawatt-hour } \\ \text { WEC } & \text { Wave Energy Converter } \\ \text { WT } & \text { Wind turbine }\end{array}$

\section{References}

1. Borthwick, A.G.L. Marine Renewable Energy Seascape. Engineering 2016, 2, 69-78. [CrossRef]

2. European Commission. Communication from the Commission to the European Parliament, the Council, the European Economic and Social Committee and the Committee of the Regions: Blue Energy Action Needed to Deliver on the Potential of Ocean Energy in European Seas and Oceans by 2020 and Beyond; European Commission: Brussels, Belgium, 2014; p. 11. Available online: http:/ / eur-lex.europa.eu/legal-content/EN/TXT/PDF/?uri=CELEX: 52014DC0008\&from=EN (accessed on 16 May 2017).

3. Appiott, J.; Dhanju, A.; Cicin-Sain, B. Encouraging Renewable Energy in the Offshore Environment. Ocean Coast. Manag. 2014, 90, 58-64. [CrossRef]

4. Global Wind Energy Council. Global Wind Report 2016-Annual Market Update; Global Wind Energy Council: Brussels, Belgium, 2016; p. 76. Available online: http:/ / www.gwec.net/publications/global-wind-report-2/ (accessed on 9 June 2017).

5. Edenhofer, O.; Pichs-Madruga, R.; Sokona, Y.; Seyboth, K.; Kadner, S.; Zwickel, T.; Eickemeier, P.; Hansen, G.; Schlömer, S.; von Stechow, C.; et al. Renewable Energy Sources and Climate Change Mitigation: Special Report of the Intergovernmental Panel on Climate Change; Cambridge University Press: New York, NY, USA, 2011; p. 1088.

6. Ocean Energy Forum. Ocean Energy Strategic Roadmap 2016, Building Ocean Energy for Europe. Available online: https: / webgate.ec.europa.eu/maritimeforum/sites/maritimeforum/files/OceanEnergyForum_ Roadmap_Online_Version_08Nov2016.pdf (accessed on 30 December 2016).

7. Wind Europe. The European Offshore Wind Industry-Key Trends and Statistics 2016; Wind Europe: Brussels, Belgium, 2017; p. 37.

8. Resch, G.; Welisch, M.; Liebmann, L.; Breitschopf, B.; Held, A. A Prospective Assessment of Costs and Benefits of Renewable energy Use in the European Union. Energy Environ. 2016, 27, 10-27. [CrossRef]

9. Duscha, V.; Fougeyrollas, A.; Nathani, C.; Pfaff, M.; Ragwitz, M.; Resch, G.; Schade, W.; Breitschopf, B.; Walz, R. Renewable energy Deployment in Europe up to 2030 and the Aim of a Triple Dividend. Energy Policy 2016, 95, 314-323. [CrossRef] 
10. Magagna, D.; Uihlein, A. Ocean Energy Development in Europe: Current Status and Future Perspectives. Int. J. Mar. Energy 2015, 11, 84-104. [CrossRef]

11. Taveira-Pinto, F.; Iglesias, G.; Rosa-Santos, P.; Deng, Z.D. Preface to Special Topic: Marine Renewable Energy. J. Renew. Sustain. Energy 2015, 7, 061601. [CrossRef]

12. Manwell, J. Offshore Wind Energy Technology Trends, Challenges and Risks. In Renewable Energy Systems; Kaltschmitt, M.T.N.J., Bronicki, L.Y., Söder, L., Vega, L.A., Eds.; Springer: New York, NY, USA, 2013; pp. 1306-1338.

13. Soukissian, T. Use of Multi-parameter Distributions for Offshore Wind Speed Modeling: The Johnson SB Distribution. Appl. Energy 2013, 111, 982-1000. [CrossRef]

14. Zheng, C.W.; Pan, J. Assessment of the Global Ocean Wind Energy Resource. Renew. Sustain. Energy Rev. 2014, 33, 382-391. [CrossRef]

15. Zheng, C.; Li, C.; Gao, C.; Liu, M. A Seasonal Grade Division of the Global Offshore Wind Energy Resource. Acta Oceanol. Sin. 2017, 36, 109-114. [CrossRef]

16. Capps, S.B.; Zender, C.S. Estimated Global Ocean Wind Power Potential from QuikSCAT observations, Accounting for Turbine Characteristics and Siting. J. Geophys. Res.-Atmos. 2010, 115. [CrossRef]

17. Zheng, C.W.; Li, C.Y.; Pan, J.; Liu, M.Y.; Xia, L.L. An Overview of Global Ocean Wind Energy Resource Evaluations. Renew. Sustain. Energy Rev. 2016, 53, 1240-1251. [CrossRef]

18. Observatoire Méditerranéen de l'Energie. Global Energy for the Mediterranean, Special: COP22 ed.; Observatoire Méditerranéen de l'Energie: Paris, France, 2016; Volume 25.

19. Musial, W.; Ram, B. Large-Scale Offshore Wind Power in the United States: Assessment of Opportunities and Barriers; National Renewable Energy Laboratory: Golden, CO, USA, 2010; p. 240. Available online: http:/ / www.nrel.gov/docs/fy10osti/40745.pdf (accessed on 5 November 2016).

20. International Energy Agency. Technology Roadmap —Wind Energy; International Energy Agency: Paris, France, 2013; p. 58. Available online: https://www.iea.org/publications/freepublications/publication/Wind_2013_ Roadmap.pdf (accessed on 5 November 2016).

21. Arshad, M.; O'Kelly, B.C. Offshore Wind-turbine Structures: A review. Proc. Inst. Civ. Eng.-Energy 2013, 166, 139-152. [CrossRef]

22. Kumar, Y.; Ringenberg, J.; Depuru, S.S.; Devabhaktuni, V.K.; Lee, J.W.; Nikolaidis, E.; Andersen, B.; Afjeh, A. Wind Energy: Trends and Enabling Technologies. Renew. Sustain. Energy Rev. 2016, 53, 209-224. [CrossRef]

23. International Renewable Energy Agency. Innovation Outlook: Offshore Wind; International Renewable Energy Agency: Abu Dhabi, UAE, 2016; p. 160.

24. Borg, M.; Collu, M.; Kolios, A. Offshore Floating Vertical Axis Wind Turbines, Dynamics Modelling State of the Art. Part II: Mooring Line and Structural Dynamics. Renew. Sustain. Energy Rev. 2014, 39, 1226-1234. [CrossRef]

25. Floating Wind Turbine. Available online: https://en.wikipedia.org/wiki/Floating_wind_turbine (accessed on 30 July 2017).

26. James, R.; Ros, M. Floating Offshore Wind: Market and Technology Review; Carbon Trust: UK, 2015; p. 168.

27. European Wind Energy Association. The European Offshore Wind Industry-Key Trends and Statistics 2015; European Wind Energy Association: Brussels, Belgium, 2016; p. 24. Available online: https: / /www.ewea.org/ fileadmin/files/library/publications/statistics/EWEA-European-Offshore-Statistics-2015.pdf (accessed on 5 April 2017).

28. Cruz, J.; Atcheson, M. Floating Offshore Wind Energy. The Next Generation of Wind Energy; Springer International Publishing: Cham, Switzerland, 2016; p. 341.

29. Castro-Santos, L.; Diaz-Casas, V. Floating Offshore Wind Farms; Springer International Publishing: Cham, Switzerland, 2016; p. 193.

30. Floating Wind Energy—World Map 2017. Available online: http:/ / www.floating-wind-energy.nl/ (accessed on 1 September 2017).

31. European Wind Energy Association. Offshore Wind in Europe-Walking the Tightrope to Success; European Wind Energy Association: Brussels, Belgium, 2015.

32. McKenna, R.; von der Leye, P.O.; Fichtner, W. Key Challenges and Prospects for Large Wind Turbines. Renew. Sustain. Energy Rev. 2016, 53, 1212-1221. [CrossRef] 
33. Clement, A.; McCullen, P.; Falcao, A.; Fiorentino, A.; Gardner, F.; Hammarlund, K.; Lemonis, G.; Lewis, T.; Nielsen, K.; Petroncini, S.; et al. Wave Energy in Europe: Current Status and Perspectives. Renew. Sustain. Energy Rev. 2002, 6, 405-431. [CrossRef]

34. Falnes, J. A Review of Wave-energy Extraction. Mar. Struct. 2007, 20, 185-201. [CrossRef]

35. Falcao, A.F.D. Wave Energy Utilization: A Review of the Technologies. Renew. Sustain. Energy Rev. 2010, 14, 899-918. [CrossRef]

36. International Renewable Energy Agency. Wave Energy Technology Brief; International Renewable Energy Agency: Abu Dhabi, UAE, 2014; p. 28. Available online: http:/ / www.irena.org/DocumentDownloads/ Publications/Wave-Energy_V4_web.pdf (accessed on 5 April 2017).

37. Mørk, G.; Barstow, S.; Kabuth, A.; Pontes, M.T. Assessing the Global Wave Energy Potential. In Proceedings of the 29th International Conference on Ocean, Offshore Mechanics and Arctic Engineering, Shanghai, China, 6-11 June 2010; pp. 447-454.

38. Reguero, B.G.; Losada, I.J.; Mendez, F.J. A Global Wave Power Resource and its Seasonal, Interannual and Long-term Variability. Appl. Energy 2015, 148, 366-380. [CrossRef]

39. Arinaga, R.A.; Cheung, K.F. Atlas of Global Wave Energy from 10 years of Reanalysis and Hindcast Data. Renew. Energy 2012, 39, 49-64. [CrossRef]

40. Pecher, A.; Kofoed, J.P. Handbook of Ocean Wave Energy; Springer International Publishing: Berlin, Germay, 2017; Volume 7.

41. Gunn, K.; Stock-Williams, C. Quantifying the Global Wave Power Resource. Renew. Energy 2012, 44, $296-304$. [CrossRef]

42. Archimedes Waveswing Submerged Wave Power Buoy. Available online: http://www.awsocean.com/ archimedes-waveswing.html (accessed on 1 September 2017).

43. Wave Energy Module Successfully Installed on Crete for the First Time. Available online: https:/ / www.sinnpower.com/single-post/2015/12/16/Wave-energy-module-successfully-installed-onCrete-for-the-first-time (accessed on 30 July 2017).

44. List of Wave Power Projects. Available online: https:/ / en.wikipedia.org/wiki/List_of_wave_power_projects (accessed on 30 July 2017).

45. Lopez, I.; Andreu, J.; Ceballos, S.; de Alegria, I.M.; Kortabarria, I. Review of Wave Energy Technologies and the Necessary Power-equipment. Renew. Sustain. Energy Rev. 2013, 27, 413-434. [CrossRef]

46. Day, A.H.; Babarit, A.; Fontaine, A.; He, Y.P.; Kraskowski, M.; Murai, M.; Penesis, I.; Salvatore, F.; Shin, H.K. Hydrodynamic Modelling of Marine Renewable Energy Devices: A State of the Art Review. Ocean Eng. 2015, 108, 46-69. [CrossRef]

47. Bahaj, A.S. Generating Electricity from the Oceans. Renew. Sustain. Energy Rev. 2011, 15, 3399-3416. [CrossRef]

48. Titah-Benbouzid, H.; Benbouzid, M. Ocean Wave Energy Extraction: Up-to-Date Technologies Review and Evaluation. In Proceedings of the 2014 IEEE International Power Electronics and Application Conference and Exposition (PEAC), Shanghai, China, 5-8 November 2014; pp. 338-342.

49. Soukissian, T.H. Probabilistic Modeling of Directional and Linear Characteristics of Wind and Sea States. Ocean Eng. 2014, 91, 91-110. [CrossRef]

50. Pelamis Wave Power. Available online: http://www.emec.org.uk/about-us/wave-clients/pelamis-wavepower/ (accessed on 1 September 2017).

51. Water Powder \& DAM Construction. Available online: http://www.waterpowermagazine.com/features / featurecoastal-conversions / featurecoastal-conversions-5.html (accessed on 30 July 2017).

52. Available online: http:/ / oceanenergy.ie/platform/ (accessed on 1 September 2017).

53. Falcão, A.F.O.; Henriques, J.C.C. Oscillating-water-column Wave Energy Converters and Air Turbines: A Review. Renew. Energy 2016, 85, 1391-1424. [CrossRef]

54. Wave Dragon. Available online: http://www.wavedragon.net/index.php?option=com_frontpage\&Itemid=1 (accessed on 30 July 2017).

55. Sgobbi, A.; Simoes, S.G.; Magagna, D.; Nijs, W. Assessing the Impacts of Technology Improvements on the Deployment of Marine Energy in Europe with an Energy System Perspective. Renew. Energy 2016, 89, 515-525. [CrossRef]

56. Nambiar, A.J.; Collin, A.J.; Karatzounis, S.; Rea, J.; Whitby, B.; Jeffrey, H.; Kiprakis, A.E. Optimising Power Transmission Options for Marine Energy Converter Farms. Int. J. Mar. Energy 2016, 15, 127-139. [CrossRef] 
57. Thorburn, K.; Bernhoff, H.; Leijon, M. Wave Energy Transmission System Concepts for Linear Generator Arrays. Ocean Eng. 2004, 31, 1339-1349. [CrossRef]

58. O'Hagan, A.M.; Huertas, C.; O'Callaghan, J.; Greaves, D. Wave Energy in Europe: Views on Experiences and Progress to Date. Int. J. Mar. Energy 2016, 14, 180-197. [CrossRef]

59. Astariz, S.; Iglesias, G. The Economics of Wave Energy: A review. Renew. Sustain. Energy Rev. 2015, 45, 397-408. [CrossRef]

60. Astariz, S.; Vazquez, A.; Iglesias, G. Evaluation and Comparison of the Levelized Cost of Tidal, Wave, and Offshore Wind Energy. J. Renew. Sustain Energy 2015, 7, 053112. [CrossRef]

61. Perez-Collazo, C.; Greaves, D.; Iglesias, G. A Review of Combined Wave and Offshore Wind Energy. Renew. Sustain. Energy Rev. 2015, 42, 141-153. [CrossRef]

62. Ringwood, J.V.; Simani, S. Overview of Modelling and Control Strategies for Wind Turbines and Wave Energy Devices: Comparisons and Contrasts. Annu. Rev. Control 2015, 40, 27-49. [CrossRef]

63. Ding, S.; Yan, S.; Han, D.; Ma, Q. Overview on Hybrid Wind-wave Energy Systems. In International Conference on Applied Science and Engineering Innovation; Atlantis Press: Amsterdam, The Netherlands, 2015; pp. $502-507$.

64. Available online: http://www.floatingpowerplant.com/ (accessed on 24 August 2017).

65. Kim, K.-H.; Lee, K.; Sohn, J.M.; Park, S.-W.; Choi, J.-S.; Hong, K. Conceptual Design of 10MW Class Floating Wave-Offshore Wind Hybrid Power Generation System. In Proceedings of the Twenty-Fifth International Ocean and Polar Engineering (ISOPE) Conference, Kona, HI, USA, 21-26 June 2015; p. 7.

66. Karimirad, M.; Koushan, K. WindWEC: Combining Wind and Wave Energy Inspired by Hywind and Wavestar. In Proceedings of the 2016 IEEE International Conference on Renewable Energy Research and Applications (ICRERA), Birmingham, UK, 20-23 November 2016; pp. 96-101.

67. Mobilising the Total Offshore Renewable Energy Resource. Available online: http:/ /www.pelagicpower.no/ (accessed on 25 August 2017).

68. Astariz, S.; Perez-Collazo, C.; Abanades, J.; Iglesias, G. Towards the Optimal Design of a Co-located Wind-wave Farm. Energy 2015, 84, 15-24. [CrossRef]

69. Astariz, S.; Perez-Collazo, C.; Abanades, J.; Iglesias, G. Hybrid Wave and Offshore Wind Farms: A Comparative Case Study of Co-located Layouts. Int. J. Mar. Energy 2016, 15, 2-16. [CrossRef]

70. Astariz, S.; Iglesias, G. Selecting Optimum Locations for Co-located Wave and Wind Energy Farms. Part I: The Co-Location Feasibility Index. Energy Convers. Manag. 2016, 122, 589-598. [CrossRef]

71. Astariz, S.; Iglesias, G. Selecting Optimum Locations for Co-located Wave and Wind Energy Farms. Part II: A case study. Energy Convers. Manag. 2016, 122, 599-608. [CrossRef]

72. Veigas, M.; Iglesias, G. A Hybrid Wave-Wind Offshore Farm for an Island. Int. J. Green Energy 2014, 12, 570-576. [CrossRef]

73. Ioannou, A.; Kalfas, A.I.; Karambas, T.V. Integrated Overtopping Wave Energy Converter in a Hybrid Offshore Wind Turbine Power Generation System. In Proceedings of the ASME Turbo Expo 2014: Turbine Technical Conference and Exposition, Düsseldorf, Germany, 16-20 June 2014.

74. Castro-Santos, L.; Martins, E.; Soares, C.G. Cost Assessment Methodology for Combined Wind and Wave Floating Offshore Renewable Energy Systems. Renew. Energy 2016, 97, 866-880. [CrossRef]

75. Bryden, G. Tidal Energy. In Renewable Energy Systems; Kaltschmitt, M., Themelis, N.J., Bronicki, L.Y., Söder, L., Vega, L., Eds.; Springer: New York, NY, USA, 2013; pp. 1466-1474.

76. International Renewable Energy Agency. Tidal Energy Technology Brief; International Renewable Energy Agency: Abu Dhabi, UAE, 2014; p. 36. Available online: http://www.irena.org/DocumentDownloads / Publications/Tidal_Energy_V4_WEB.pdf (accessed on 2 August 2017).

77. Ernst\&Young. Rising Tide: Global Trends in the Emerging Ocean Energy Market; Ernst\&Young: London, UK, 2013; p. 44. Available online: http:/ / www.ey.com/Publication/vwLUAssets/EY-Ocean-energy-Rising-tide2013/\$FILE/EY-Ocean-energy-Rising-tide-2013.pdf (accessed on 2 August 2017).

78. PLAT-O Tidal Turbines Platform up and Running. Available online: http://tidalenergytoday.com/2015/07/ 07/plat-o-tidal-turbines-platform-up-and-running/ (accessed on 1 September 2017).

79. Tidal Project. Available online: http://www.4coffshore.com/windfarms/tidals.aspx (accessed on 1 September 2017).

80. Polagye, B.; Van Cleve, B.; Copping, A.; Kirkendall, K. (Eds.) Environmental Effects of Tidal Energy Development; U.S. Department Commerce: Washington, DC, USA, 2011; p. 181.

81. Rourke, F.O.; Boyle, F.; Reynolds, A. Tidal Energy Update 2009. Appl. Energy 2010, 87, 398-409. [CrossRef] 
82. Robins, P.E.; Neill, S.P.; Lewis, M.J.; Ward, S.L. Characterising the Spatial and Temporal Variability of the Tidal-stream Energy Resource Over the Northwest European Shelf Seas. Appl. Energy 2015, 147, $510-522$. [CrossRef]

83. Mérigaud, A.; Ringwood, J.V. Condition-based Maintenance Methods for Marine Renewable Energy. Renew. Sustain. Energy Rev. 2016, 66, 53-78. [CrossRef]

84. Nihous, G.C. A Preliminary Assessment of Ocean Thermal Energy Conversion Resources. J. Energy Resour. ASME 2007, 129, 10-17. [CrossRef]

85. Rajagopalan, K.; Nihous, G.C. Estimates of Global Ocean Thermal Energy Conversion (OTEC) Resources Using an Ocean General Circulation Model. Renew. Energy 2013, 50, 532-540. [CrossRef]

86. Kim, A.S.; Kim, H.J.; Lee, H.S.; Cha, S. Dual-use Open Cycle Ocean Thermal Energy Conversion (OC-OTEC) Using Multiple Condensers for Adjustable Power Generation and Seawater Desalination. Renew. Energy 2016, 85, 344-358. [CrossRef]

87. Vega, L. Ocean Thermal Energy Conversion. In Renewable Energy Systems; Kaltschmitt, M., Themelis, N., Bronicki, L., Söder, L., Vega, L., Eds.; Springer: New York, NY, USA, 2013; pp. 1273-1305.

88. NEMO-10.7 MW Martinique in Development. Available online: http://www.akuoenergy.com/en/nemo (accessed on 1 September 2017).

89. OTEC Projects around the World. Available online: http://www.otecnews.org/otecprojects/ (accessed on 30 July 2017).

90. Ocean Thermal Energy Conversion. Available online: https://en.wikipedia.org/wiki/Ocean_thermal_ energy_conversion (accessed on 30 July 2017).

91. International Renewable Energy Agency. Ocean Thermal Energy Conversion Technology Brief; International Renewable Energy Agency: Abu Dhabi, UAE, 2014; p. 24. Available online: http://www.irena.org/ DocumentDownloads/Publications/Ocean_Thermal_Energy_V4_web.pdf (accessed on 2 August 2017).

92. Alvarez-Silva, O.; Winter, C.; Osorio, A.F. Salinity Gradient Energy at River Mouths. Environ. Sci. Technol. Lett. 2014, 1, 410-415. [CrossRef]

93. International Renewable Energy Agency. Salinity Gradient Energy Technology Brief; International Renewable Energy Agency: Abu Dhabi, UAE, 2014; p. 28. Available online: http:/ /www.irena.org/DocumentDownloads / Publications/Salinity_Energy_v4_WEB.pdf (accessed on 2 August 2017).

94. Alvarez-Silva, O.A.; Osorio, A.F.; Winter, C. Practical Global Salinity Gradient Energy Potential. Renew. Sustain. Energy Rev. 2016, 60, 1387-1395. [CrossRef]

95. Nijmeijer, K.; Metz, S. Salinity Gradient Energy. In Sustainability Science and Engineering; Escobar, I.C., Schäfer, A.I., Eds.; Elsevier: Amsterdam, The Netherlands, 2010; Volume 2, pp. 95-139.

96. Willemse, R. Case 27: Blue Energy (Salinity Power) in The Netherlands; Report of the Project: Cultural Influences on Renewable Energy Acceptance and Tools for the Development of Communication Strategies to Promote ACCEPTANCE among Key Actor Groups. 2007; p. 19. Available online: http:/ / www.esteem-tool. eu/fileadmin/esteem-tool/docs/CASE_27_def.pdf (accessed on 2 August 2017).

97. United Nations Environment Programme (UNEP)/Mediterranean Action Plan (MAP). State of the Mediterranean Marine and Coastal Environment, UNEP/MAP_Barcelona Convention, Athens; UNEP/MAP: Adler, Russia, 2012; p. 96.

98. Amblàs, D.; Canals, M.; Lastras, G.; Berné, S.; Loubrieu, B. Imaging the Seascapes of the Mediterranean. Oceanography 2004, 17, 144-155. [CrossRef]

99. Anthony, E.J.; Marriner, N.; Morhange, C. Human Influence and the Changing Geomorphology of Mediterranean Deltas and Coasts over the Last 6000 Years: From Progradation to Destruction Phase? Earth-Sci. Rev. 2014, 139, 336-361. [CrossRef]

100. Coll, M.; Piroddi, C.; Steenbeek, J.; Kaschner, K.; Lasram, F.B.; Aguzzi, J.; Ballesteros, E.; Bianchi, C.N.; Corbera, J.; Dailianis, T.; et al. The Biodiversity of the Mediterranean Sea: Estimates, Patterns, and Threats. PLoS ONE 2010, 5, e11842. [CrossRef] [PubMed]

101. Danovaro, R.; Company, J.B.; Corinaldesi, C.; D’Onghia, G.; Galil, B.; Gambi, C.; Gooday, A.J.; Lampadariou, N.; Luna, G.M.; Morigi, C.; et al. Deep-Sea Biodiversity in the Mediterranean Sea: The Known, the Unknown, and the Unknowable. PLoS ONE 2010, 5, e11832. [CrossRef] [PubMed] 
102. Zenetos, A.; Siokou-Frangou, I.; Gotsis-Skretas, O.; Groom, S. The Mediterranean Sea-blue Oxygen-rich, Nutrient-poor Waters. In Europe's Biodiversity—Biogeographical Regions and Seas; European Environment Agency: Copenhagen, Danmark, 2002. Available online: http://reports.eea.eu.int/report_2002_0524_ 154909/en (accessed on 10 May 2017).

103. Lionello, P.; Abrantesc, F.; Congedi, L.; Dulac, F.; Gacic, M.; Gomis, D.; Goodess, C.; Hoff, H.; Kutiel, H.; Luterbacher, J.; et al. Introduction: Mediterranean Climate-Background Information. In The Climate of the Mediterranean Region. From the Past to the Future; Lionello, P., Ed.; Elsevier: Amsterdam, The Nertherlands, 2012; p. xxxv-xc.

104. Tyrlis, E.; Lelieveld, J. Climatology and Dynamics of the Summer Etesian Winds over the Eastern Mediterranean. J. Atmos. Sci. 2013, 70, 3374-3396. [CrossRef]

105. Papadopoulos, A.; Korres, G.; Katsafados, P.; Ballas, D.; Perivoliotis, L.; Nittis, K. Dynamic Downscaling of the ERA-40 Data Using a Mesoscale Meteorological Model. Mediterr. Mar. Sci. 2011, 12, 183-198. [CrossRef]

106. Soukissian, T.; Karathanasi, F.; Axaopoulos, P.; Voukouvalas, E.G.; Kotroni, V. Offshore Wind Climate Analysis and Variability in the Mediterranean Sea. Int. J. Climatol. 2017. [CrossRef]

107. Boero, F.; Foglini, F.; Fraschetti, S.; Goriup, P.; Macpherson, E.; Planes, S.; Soukissian, T.; The CoCoNet Consortium. CoCoNet: Towards Coast to Coast Networks of Marine Protected Areas (from the Shore to the High and Deep Sea), Coupled with Sea-based Wind Energy Potential. SCIRES-IT_Sci. Res. Inf. Technol. 2017, 6, 1-95.

108. Myers, N.; Mittermeier, R.A.; Mittermeier, C.G.; da Fonseca, G.A.B.; Kent, J. Biodiversity Hotspots for Conservation Priorities. Nature 2000, 403, 853-858. [CrossRef] [PubMed]

109. Würtz, M. Mediterranean Pelagic Habitat: Oceanographic and Biological Processes, An Overview; IUCN: Gland, Switzerland; Malaga, Spain, 2010; p. 90.

110. Blondel, J.; Aronson, J. Biology and Wildlife of the Mediterranean Region; Oxford University Press: Oxford, UK, 1999.

111. Pergent, G.; Semroud, R.; Djellouli, A.; Langar, H.; Duarte, C. Posidonia Oceanica. The IUCN Red List of Threatened Species 2010: e.T153534A4516034; International Union for Conservation of Nature (IUCN): Gland, Switzerland, 2010.

112. Marba, N.; Diaz-Almela, E.; Duarte, C.M. Mediterranean Seagrass (Posidonia oceanica) Loss between 1842 and 2009. Biol. Conserv. 2014, 176, 183-190. [CrossRef]

113. United Nations Environment Programme (UNEP)/Mediterranean Action Plan (MAP). The Mediterranean Sea Biodiversity: State of the Ecosystems, Pressures, Impacts and Future Priorities; Bazairi, H., Ben Haj, S., Boero, F., Cebrian, D., De Juan, S., Limam, A., Lleonart, J., Torchia, G., Rais, C., Eds.; RAC/SPA: Paris, France, 2010; p. 100.

114. Gabrié, C.; Lagabrielle, E.; Bissery, C.; Crochelet, E.; Meola, B.; Webster, C.; Claudet, J.; Chassanite, A.; Marinesque, S.; Robert, P.; et al. The Status of Marine Protected Areas in the Mediterranean Sea; MedPAN \& RAC/SPA: Marseille, France, 2012; p. 256.

115. Available online: http://www.medpan.org/documents/10180/0/Poster+The+system+of+Mediterranean+ MPAs+in+2016/95332701-bf0a-4b54-8775-565dc3bc3380 (accessed on 30 July 2017).

116. Portman, M.E.; Nathan, D. Conservation "Identity" and Marine Protected Areas Management: A Mediterranean Case Study. J. Nat. Conserv. 2015, 24, 109-116. [CrossRef]

117. Rodriguez-Rodriguez, D.; Malak, D.A.; Soukissian, T.; Sanchez-Espinosa, A. Achieving Blue Growth Through Maritime Spatial Planning: Offshore Wind Energy Optimization and Biodiversity Conservation in Spain. Mar. Policy 2016, 73, 8-14. [CrossRef]

118. Copernicus Marine Environment Monitoring Service: Providing Products and Services for all Marine Applications. Available online: http:/ / marine.copernicus.eu/ (accessed on 1 September 2017).

119. Borghini, M.; Bryden, H.; Schroeder, K.; Sparnocchia, S.; Vetrano, A. The Mediterranean is Becoming Saltier. Ocean Sci. 2014, 10, 693-700. [CrossRef]

120. Schroeder, K.; Chiggiato, J.; Bryden, H.L.; Borghini, M.; Ismail, S.B. Abrupt Climate Shift in the Western Mediterranean Sea. Sci. Rep.-UK 2016, 6, 23009. [CrossRef] [PubMed]

121. Romanou, A.; Tselioudis, G.; Zerefos, C.; Clayson, C.; Curry, J.; Andersson, A. Evaporation-Precipitation Variability over the Mediterranean and the Black Seas from Satellite and Reanalysis Estimates. J. Clim. 2010, 23, 5268-5287. [CrossRef] 
122. Mediterranean Sea-Temperature and Salinity Observation Collection V2. Istituto Nazionale di Geofisica e Vulcanologia: Roma, Italy, 2015. Available online: http:/ / www.emodnet.eu/ (accessed on 1 September 2017).

123. Troupin, C.; Barth, A.; Sirjacobs, D.; Ouberdous, M.; Brankart, J.-M.; Brasseur, P.; Rixen, M.; Alvera Azcarate, A.; Belounis, M.; Capet, A.; et al. Generation of Analysis and Consistent Error Fields Using the Data Interpolating Variational Analysis (Diva). Ocean Model. 2012, 52-53, 90-101. [CrossRef]

124. Fosse, J.; Le Tellier, J. Sustainable Tourism in the Mediterranean: State of Play and Strategic Directions; Plan Bleu: Valbonne, France, 2017.

125. Piante, C.; Ody, D. Blue Growth in the Mediterranean Sea: The Challenge of Good Environmental Status; WWF: France, 2015; p. 192.

126. Food and Agriculture Organization of the United Nations. The State of Mediterranean and Black Sea Fisheries; Food and Agriculture Organization of the United Nations: Roma, Italy, 2016.

127. Angel, D. Marine Aquaculture in the Mediterranean. In Sustainable Food Production; Christou, P., Savin, R., Costa-Pierce, B., Misztal, I., Whitelaw, C., Eds.; Springer Science + Business Media: New York, NY, USA, 2013; pp. 1121-1138.

128. Countries Producers. Available online: http://www.nireus.com/52_2/Countries-Producers (accessed on 30 July 2017).

129. Federation of National Aquaculture Producers. Annual Report 2017; Federation of National Aquaculture Producers: Liege, Belgium, 2017; p. 36. Available online: http:/ /www.feap.info/ (accessed on 1 September 2017).

130. Maritime Ports Freight and Passenger Statistics. Available online: http:/ / ec.europa.eu/eurostat/statisticsexplained/index.php/Maritime_ports_freight_and_passenger_statistics (accessed on 1 September 2017).

131. Maritime Traffic. Available online: http://medtrends.org/sectors.php?sector=maritime-traffic (accessed on 1 September 2017).

132. Eeurostat: Your Key to European Statistics. Available online: http://ec.europa.eu/eurostat/data/database (accessed on 1 September 2017).

133. MEDENER/OME. Mediterranean Energy Transition: The 2040 Scenario; MEDENER/OME: Paris, France, 2016. Available online: http:/ / www.ademe.fr/sites / default/files / assets / documents / vers_engl_25_oct_bat_web. pdf (accessed on 1 September 2017).

134. MacGillivray, A.; Jeffrey, H.; Hanmer, C.; Magagna, D.; Raventos, A.; Badcock-Broe, A. Ocean Energy Technology: Gaps and Barriers. In Strategic Initiative for Ocean Energy; European Ocean Energy Association: Brussels, Belgium, 2013. Available online: http:/ / www.si-ocean.eu/en/upload/docs/WP3/GapsandBarriersReportFV. pdf (accessed on 1 September 2017).

135. Argaut, P. Cables for Collecting and Transmitting Energy Produced by Offshore Technologies. In Marine Renewable Energy Handbook; Multon, B., Ed.; John Wiley \& Sons, Inc.: Hoboken, NJ, USA, 2012.

136. Courault, J. Electrical Conversion Systems. In Marine Renewable Energy Handbook; Multon, B., Ed.; John Wiley \& Sons, Inc.: Hoboken, NJ, USA, 2012.

137. Chudnovsky, B.H. Transmission, Distribution, and Renewable Energy Generation Power Equipment. Aging and Life Extension Techniques; Taylor \& Francis Group, CRC Press: Boca Raton, FL, USA, 2017.

138. Santos-Mugica, M.; Robles, E.; Endegnanew, A.G.; Tedeschi, E.; Giebhardt, J. Grid Integration and Power Quality Testing of Marine Energy Converters: Research Activities in the MaRINET Project. In Proceedings of the 2014 Ninth International Conference on Ecological Vehicles and Renewable Energies (EVER), Monte-Carlo, Monaco, 25-27 March 2014; pp. 1-9.

139. Greenhill, L.; Day, J.G.; Hughes, A.D.; Stanley, M.S. Marine Renewable Energy; Commonwealth Blue Economy Series (Book 4); Commonwealth Secretariat: London, UK, 2016.

140. How Energy Storage Works. Available online: http://www.ucsusa.org/clean-energy/how-energy-storageworks (accessed on 27 August 2017).

141. Marine Renewable Energy, Storage and Services. Available online: http:/ / www.cluster-maritime.fr/en/ maritime-economy/580/marine-renewable-energy-storage-and-services (accessed on 27 August 2017).

142. Soukissian, T.H.; Papadopoulos, A. Effects of Different Wind Data Sources in Offshore Wind Power Assessment. Renew. Energy 2015, 77, 101-114. [CrossRef]

143. Soukissian, T.H.; Karathanasi, F.E. On the Use of Robust Regression Methods in Wind Speed Assessment. Renew. Energy 2016, 99, 1287-1298. [CrossRef]

144. Offshore Wind Farms. Available online: http://www.4coffshore.com/windfarms/ (accessed on 1 September 2017). 
145. Gaudiosi, G. Offshore Wind Energy in the World Context. Renew. Energy 1996, 9, 899-904. [CrossRef]

146. Menendez, M.; Garcia-Diez, M.; Fita, L.; Fernandez, J.; Mendez, F.J.; Gutierrez, J.M. High-resolution Sea Wind Hindcasts over the Mediterranean Area. Clim. Dyn. 2014, 42, 1857-1872. [CrossRef]

147. Balog, I.; Ruti, P.M.; Tobin, I.; Armenio, V.; Vautard, R. A Numerical Approach for Planning Offshore Wind Farms from Regional to Local Scales over the Mediterranean. Renew. Energy 2016, 85, 395-405. [CrossRef]

148. Soukissian, T.; Karathanasi, F.; Axaopoulos, P. Satellite-based Offshore Wind Resource Assessment in the Mediterranean Sea. IEEE J. Ocean. Eng. 2017, 42, 73-86. [CrossRef]

149. Towards Coast and Coast Networks of Marine Protected Areas: Coupled with Sea-Based Wind Energy Potential. Available online: http:/ / www.coconet-fp7.eu/ (accessed on 1 September 2017).

150. Zhang, H.-M.; Bates, J.J.; Reynolds, R.W. Assessment of Composite Global Sampling: Sea Surface Wind Speed. Geophys. Res. Lett. 2006, 33. [CrossRef]

151. Dee, D.P.; Uppala, S.M.; Simmons, A.J.; Berrisford, P.; Poli, P.; Kobayashi, S.; Andrae, U.; Balmaseda, M.A.; Balsamo, G.; Bauer, P.; et al. The ERA-interim Reanalysis: Configuration and Performance of the Data Assimilation System. Q. J. R. Meteorol. Soc. 2011, 137, 553-597. [CrossRef]

152. Soukissian, T.H.; Chronis, G. Poseidon: A Marine Environmental Monitoring, Forecasting and Information System for the Greek Seas. Mediterr. Mar. Sci. 2000, 1, 71. [CrossRef]

153. Soukissian, T.; Reizopoulou, S.; Drakopoulou, P.; Axaopoulos, P.; Karathanasi, F.; Fraschetti, S.; Bray, L.; Foglini, F.; Papadopoulos, A.; De Leo, F.; et al. Greening Offshore Wind with the Smart Wind Chart Evaluation Tool. Web Ecol. 2016, 16, 73-80. [CrossRef]

154. Hadzic, N.; Kozmar, H.; Tomic, M. Offshore Renewable Energy in the Adriatic Sea with Respect to the Croatian 2020 energy strategy. Renew. Sustain. Energy Rev. 2014, 40, 597-607. [CrossRef]

155. Schweizer, J.; Antonini, A.; Govoni, L.; Gottardi, G.; Archetti, R.; Supino, E.; Berretta, C.; Casadei, C.; Ozzi, C. Investigating the Potential and Feasibility of an Offshore Wind Farm in the Northern Adriatic Sea. Appl. Energy 2016, 177, 449-463. [CrossRef]

156. Soukissian, T.; Gizari, N.; Fytilis, D.; Papadopoulos, A.; Korres, G.; Prospathopoulos, A. Wind and Wave Potential in Offshore Locations of the Greek Seas. In Proceedings of the 22nd International Offshore and Polar Engineering Conference (ISOPE), Rhodes, Greece, 17-22 June 2012; pp. 525-532.

157. Soukissian, T.; Papadopoulos, A.; Skrimizeas, P.; Karathanasi, F.; Axaopoulos, P.; Avgoustoglou, E.; Kyriakidou, H.; Tsalis, C.; Voudouri, A.; Gofa, F.; et al. Assessment of Offshore Wind Power Potential in the Aegean and Ionian Seas Based on High-resolution Hindcast Model Results. Aims Energy 2017, 5, 268-289. [CrossRef]

158. Bagiorgas, H.S.; Mihalakakou, G.; Rehman, S.; Al-Hadhrami, L.M. Wind Power Potential Assessment for Three Buoys Data Collection Stations in the Ionian Sea Using Weibull Distribution Function. Int. J. Green Energy 2015, 13, 703-714. [CrossRef]

159. Koletsis, I.; Kotroni, V.; Lagouvardos, K.; Soukissian, T. Assessment of Offshore Wind Speed and Power Potential over the Mediterranean and the Black Seas under Future Climate Changes. Renew. Sustain. Energy Rev. 2016, 60, 234-245. [CrossRef]

160. Reyers, M.; Moemken, J.; Pinto, J.G. Future Changes of Wind Energy Potentials over Europe in a Large CMIP5 Multi-model Ensemble. Int. J. Climatol. 2016, 36, 783-796. [CrossRef]

161. Carvalho, D.; Rocha, A.; Gomez-Gesteira, M.; Santos, C.S. Potential Impacts of Climate Change on European Wind Energy Resource under the CMIP5 Future Climate Projections. Renew. Energy 2017, 101, $29-40$. [CrossRef]

162. Aghaalikhani, A.; Arsuffi, G.; Borello, D.; Rispoli, F. Offshore Floating Wind Turbines for Mediterranean Sites: Preliminary Analysis of Different Concepts. Wind Eng. 2016, 40, 475-480. [CrossRef]

163. Zountouridou, E.I.; Kiokes, G.C.; Chakalis, S.; Georgilakis, P.S.; Hatziargyriou, N.D. Offshore Floating Wind Parks in the Deep Waters of Mediterranean Sea. Renew. Sustain. Energy Rev. 2015, 51, 433-448. [CrossRef]

164. Westerberg, V.; Jacobsen, J.B.; Lifran, R. The Case for Offshore Wind Farms, Artificial Reefs and Sustainable Tourism in the French Mediterranean. Tourism Manag. 2013, 34, 172-183. [CrossRef]

165. De Vivero, J.L.S.; Mateos, J.C.R. The Spanish Approach to Marine Spatial Planning. Marine Strategy Framework Directive vs. EU Integrated Maritime Policy. Mar. Policy 2012, 36, 18-27. [CrossRef]

166. Beels, C.; Henriques, J.C.C.; De Rouck, J.; Pontes, M.T.; De Backer, G.; Verhaeghe, H. Wave Energy Resource in the North Sea. In Proceedings of the European Wave and Tidal Energy Conference (EWTEC), Porto, Portugal, 11-13 September 2007. 
167. Zodiatis, G.; Galanis, G.; Nikolaidis, A.; Kalogeri, C.; Hayes, D.; Georgiou, G.C.; Chu, P.C.; Kallos, G. Wave Energy Potential in the Eastern Mediterranean Levantine Basin. An Integrated 10-year Study. Renew. Energy 2014, 69, 311-323. [CrossRef]

168. Liberti, L.; Carillo, A.; Sannino, G. Wave Energy Resource Assessment in the Mediterranean, the Italian Perspective. Renew. Energy 2013, 50, 938-949. [CrossRef]

169. Arena, F.; Laface, V.; Malara, G.; Romolo, A.; Viviano, A.; Fiamma, V.; Sannino, G.; Carillo, A. Wave Climate Analysis for the Design of Wave Energy Harvesters in the Mediterranean Sea. Renew. Energy 2015, 77, 125-141. [CrossRef]

170. Besio, G.; Mentaschi, L.; Mazzino, A. Wave Energy Resource Assessment in the Mediterranean Sea on the Basis of a 35-year Hindcast. Energy 2016, 94, 50-63. [CrossRef]

171. Emmanouil, G.; Galanis, G.; Kalogeri, C.; Zodiatis, G.; Kallos, G. 10-year High Resolution Study of Wind, Sea Waves and Wave Energy Assessment in the Greek Offshore Areas. Renew. Energy 2016, 90, 399-419. [CrossRef]

172. Ayat, B. Wave Power Atlas of Eastern Mediterranean and Aegean Seas. Energy 2013, 54, 251-262. [CrossRef]

173. Sierra, J.P.; Mosso, C.; Gonzalez-Marco, D. Wave Energy Resource Assessment in Menorca (Spain). Renew. Energy 2014, 71, 51-60. [CrossRef]

174. Vicinanza, D.; Cappietti, L.; Ferrante, V.; Contestabile, P. Estimation of the Wave Energy in the Italian Offshore. J. Coast. Res. 2011, 64, 613-617.

175. Monteforte, M.; Lo Re, C.; Ferreri, G.B. Wave Energy Assessment in Sicily (Italy). Renew. Energy 2015, 78, 276-287. [CrossRef]

176. Iuppa, C.; Cavallaro, L.; Vicinanza, D.; Foti, E. Investigation of Suitable Sites for Wave Energy Converters Around Sicily (Italy). Ocean Sci. 2015, 11, 543-557. [CrossRef]

177. Vicinanza, D.; Contestabile, P.; Ferrante, V. Wave Energy Potential in the North-west of Sardinia (Italy). Renew. Energy 2013, 50, 506-521. [CrossRef]

178. de Leon, S.P.; Orfila, A.; Simarro, G. Wave Energy in the Balearic Sea. Evolution from a 29 year Spectral Wave Hindcast. Renew. Energy 2016, 85, 1192-1200. [CrossRef]

179. Jadidoleslam, N.; Ozger, M.; Agiralioglu, N. Wave Power Potential Assessment of Aegean Sea with an Integrated 15-year Data. Renew. Energy 2016, 86, 1045-1059. [CrossRef]

180. Lavidas, G.; Venugopal, V. A 35 Year High-resolution Wave Atlas for Nearshore Energy Production and Economics at the Aegean Sea. Renew. Energy 2017, 103, 401-417. [CrossRef]

181. Paladini de Mendoza, F.; Bonamano, S.; Stella, G.; Giovacchini, M.; Capizzi, D.; Fraticelli, F.; Muratore, S.; Burgio, C.; Scanu, S.; Peviani, M.A.; et al. Where is the Best Site for Wave Energy Exploitation? Case Study Along the Coast of Northern Latium (ITALY). J. Coast. Conserv. 2015, 20, 13-29. [CrossRef]

182. Cagninei, A.; Raffero, M.; Bracco, G.; Giorcelli, E.; Mattiazzo, G.; Poggi, D. Productivity Analysis of the Full Scale Inertial Sea Wave Energy Converter Prototype: A Test Case in Pantelleria Island. J. Renew. Sustain. Energy 2015, 7, 061703. [CrossRef]

183. Borfecchia, F.; Micheli, C.; Belmonte, A.; Cecco, L.D.; Sannino, G.; Bracco, G.; Mattiazzo, G.; Struglia, M.V. Impact of ISWEC sea Wave Energy Converter on Posidonia Oceanica Meadows Assessed by Satellite Remote Sensing in the Coastal Areas of Pantelleria Island. Geophys. Res. Abstr. 2016, 18, 16787.

184. Bracco, G.; Giorcelli, E.; Giorgi, G.; Mattiazzo, G.; Passione, B.; Raffero, M.; Vissio, G. Performance Assessment of the Full Scale ISWEC System. In Proceedings of the 2015 IEEE International Conference on Industrial Technology (ICIT), Seville, Spain, 17-19 March 2015; pp. 2499-2505.

185. Iuppa, C.; Contestabile, P.; Cavallaro, L.; Foti, E.; Vicinanza, D. Hydraulic Performance of an Innovative Breakwater for Overtopping Wave Energy Conversion. Sustainability (Basel) 2016, 8, 1226. [CrossRef]

186. Contestabile, P.; Ferrante, V.; Di Lauro, E.; Vicinanza, D. Prototype Overtopping Breakwater for Wave Energy Conversion at Port of Naples. In Proceedings of the International Ocean and Polar Engineering Conference, International Society of Offshore and Polar Engineers, Rhodes, Greece, 26 June-2 July 2016.

187. Kontoyiannis, H.; Panagiotopoulos, M.; Soukissian, T. The Euripus Tidal Stream at Halkida/Greece: A Practical, Inexpensive Approach in Assessing the Hydrokinetic Renewable Energy from Field Measurements in a Tidal Channel. J. Ocean Eng. Mar. Energy 2015, 1, 325-335. [CrossRef]

188. El-Geziry, T.M.; Bryden, I.G.; Couch, S.J. Environmental Impact Assessment for Tidal Energy Schemes: An Exemplar Case Study of the Strait of Messina. J. Mar. Eng. Technol. 2009, 39-48. [CrossRef] 
189. Cucco, A.; Quattrocchi, G.; Olita, A.; Fazioli, L.; Ribotti, A.; Sinerchia, M.; Tedesco, C.; Sorgente, R. Hydrodynamic Modelling of Coastal Seas: The Role of Tidal Dynamics in the Messina Strait, Western Mediterranean Sea. Nat. Hazard. Earth Syst. 2016, 16, 1553-1569. [CrossRef]

190. Quesada, M.C.C.; Lafuente, J.G.; Garrido, J.C.S.; Sammartino, S.; Delgado, J. Energy of Marine Currents in the Strait of Gibraltar and a Renewable Energy Resource its Potential as a Renewable Energy Resource. Renew. Sustain. Energy Rev. 2014, 34, 98-109. [CrossRef]

191. Nihous, G.R.C. An Order-of-Magnitude Estimate of Ocean Thermal Energy Conversion Resources. J. Energy Resour. Technol. 2005, 127, 328. [CrossRef]

192. European Network of Transmission System Operators for Electricity. Available online: https://www.entsoe.eu/ (accessed on 30 July 2017).

193. Adam, P.; Kowal, J. Medgrid-an Industrial Initiative for the Development of Interconnections between the Mediterranean Power Grids. In Proceedings of the 2013 15th European Conference on Power Electronics and Applications (EPE), Lille, France, 2-6 September 2013; pp. 1-10.

194. Boehlert, G.W.; Gill, A.B. Environmental and Ecological Effects of Ocean Renewable Energy Development a Current Synthesis. Oceanography 2010, 23, 68-81. [CrossRef]

195. Hammar, L.; Gullström, M.; Dahlgren, T.G.; Asplund, M.E.; Goncalves, I.B.; Molander, S. Introducing Ocean Energy Industries to a Busy Marine Environment. Renew. Sustain. Energy Rev. 2017, 74, 178-185. [CrossRef]

196. Bergström, L.; Kautsky, L.; Malm, T.; Rosenberg, R.; Wahlberg, M.; Capetillo, N.Å.; Wilhelmsson, D. Effects of Offshore Wind Farms on Marine Wildlife-A Generalized Impact Assessment. Environ. Res. Lett. 2014, 9 , 034012. [CrossRef]

197. Frid, C.; Andonegi, E.; Depestele, J.; Judd, A.; Rihan, D.; Rogers, S.I.; Kenchington, E. The Environmental Interactions of Tidal and Wave Energy Generation Devices. Environ. Impact Assess. 2012, 32, 133-139. [CrossRef]

198. Fox, A.D.; Desholm, M.; Kahlert, J.; Christensen, T.K.; Petersen, I.K. Information Needs to Support Environmental Impact Assessment of the Effects of European Marine Offshore Wind Farms on Birds. IBIS 2006, 148, 129-144. [CrossRef]

199. Leeney, R.H.; Greaves, D.; Conley, D.; O’Hagan, A.M. Environmental Impact Assessments for Wave Energy Developments-learning from Existing Activities and Informing Future Research Priorities. Ocean Coast. Manag. 2014, 99, 14-22. [CrossRef]

200. Hahn, S.; Bauer, S.; Liechti, F. The Natural Link between Europe and Africa-2.1 Billion Birds on Migration. Oikos 2009, 118, 624-626. [CrossRef]

201. Mateos-Rodríguez, M.; Muñoz, A.-R.; Arroyo, G.M. Assessment of Offshore Wind Farm Effects on Birds and Needs to Plan their Future Development in Spain. Ardeola 2012, 59, 217-236. [CrossRef]

202. Bray, L.; Reizopoulou, S.; Voukouvalas, E.; Soukissian, T.; Alomar, C.; Vázquez-Luis, M.; Deudero, S.; Attrill, M.; Hall-Spencer, J. Expected Effects of Offshore Wind Farms on Mediterranean Marine Life. J. Mar. Sci. Eng. 2016, 4, 18. [CrossRef]

203. Harnois, V.; Smith, H.C.M.; Benjamins, S.; Johanning, L. Assessment of Entanglement Risk to Marine Megafauna Due to Offshore Renewable Energy Mooring Systems. Int. J. Mar. Energy 2015, 11, $27-49$. [CrossRef]

204. Copping, A.; Battey, H.; Brown-Saracino, J.; Massaua, M.; Smith, C. An International Assessment of the Environmental Effects of Marine Energy Development. Ocean Coast. Manag. 2014, 99, 3-13. [CrossRef]

205. Bonar, P.A.J.; Bryden, I.G.; Borthwick, A.G.L. Social and Ecological Impacts of Marine Energy Development. Renew. Sustain. Energy Rev. 2015, 47, 486-495. [CrossRef]

206. Willsteed, E.; Gill, A.B.; Birchenough, S.N.R.; Jude, S. Assessing the Cumulative Environmental Effects of Marine Renewable Energy Developments: Establishing Common Ground. Sci. Total Environ. 2017, 577, 19-32. [CrossRef] [PubMed]

207. Franco, A.; Quintino, V.; Elliott, M. Benthic Monitoring and Sampling Design and Effort to Detect Spatial Changes: A case Study Using Data from Offshore Wind Farm Sites. Ecol. Indic. 2015, 57, 298-304. [CrossRef]

208. Ashley, M.C.; Mangi, S.C.; Rodwell, L.D. The Potential of Offshore Windfarms to Act as Marine Protected Areas-A Systematic Review of Current Evidence. Mar. Policy 2014, 45, 301-309. [CrossRef]

209. Spiropoulou, I.; Karamanis, D.; Kehayias, G. Offshore Wind Farms Development in Relation to Environmental Protected Areas. Sustain. Cities Soc. 2015, 14, 305-312. [CrossRef] 
210. Kyriazi, Z.; Maes, F.; Degraer, S. Coexistence Dilemmas in European Marine Spatial Planning Practices. The Case of Marine Renewables and Marine Protected Areas. Energy Policy 2016, 97, 391-399. [CrossRef]

211. Karloseva, A.; Nommann, S.; Nommann, T.; Urbel-Piirsalu, E.; Budzinski, W.; Czajkowski, M.; Hanley, N. Marine Trade-offs: Comparing the Benefits of Off-shore Wind Farms and Marine Protected Areas. Energy Econ. 2016, 55, 127-134. [CrossRef]

212. Christie, N.; Smyth, K.; Barnes, R.; Elliott, M. Co-location of Activities and Designations: A means of Solving or Creating Problems in Marine Spatial Planning? Mar. Policy 2014, 43, 254-261. [CrossRef]

213. European Commission. Available online: http://ec.europa.eu/environment/nature/natura2000/management/ docs/Wind_farms.pdf (accessed on 1 September 2017).

214. Vaissière, A.-C.; Levrel, H.; Pioch, S.; Carlier, A. Biodiversity Offsets for Offshore Wind Farm Projects: The Current Situation in Europe. Mar. Policy 2014, 48, 172-183. [CrossRef]

215. Huertas-Olivares, C.; Norris, J. Environmental Impact Assessment. In Ocean Wave Energy. Green Energy and Technology (Virtual Series); Cruz, J., Ed.; Springer: Berlin/Heidelberg, Germany, 2008; pp. 397-423.

216. Guerra, F.; Grilo, C.; Pedroso, N.M.; Cabral, H. Environmental Impact Assessment in the Marine Environment: A comparison of Legal Frameworks. Environ. Impact Assess. 2015, 55, 182-194. [CrossRef]

217. Lindeboom, H.; Degraer, S.; Dannheim, J.; Gill, A.B.; Wilhelmsson, D. Offshore Wind Park Monitoring Programs, Lessons Learned and Recommendations for the Future. Hydrobiologia 2015, 756, 169-180. [CrossRef]

218. Stigka, E.K.; Paravantis, J.A.; Mihalakakou, G.K. Social Acceptance of Renewable Energy Sources: A Review of Contingent Valuation Applications. Renew. Sustain. Energy Rev. 2014, 32, 100-106. [CrossRef]

219. Karytsas, S.; Theodoropoulou, H. Socioeconomic and Demographic Factors that Influence Publics' Awareness on the Different Forms of Renewable Energy Sources. Renew. Energy 2014, 71, 480-485. [CrossRef]

220. Soma, K.; Haggett, C. Enhancing Social Acceptance in Marine Governance in Europe. Ocean Coast. Manag. 2015, 117, 61-69. [CrossRef]

221. Vecchiato, D.; Tempesta, T. Public Preferences for Electricity Contracts Including Renewable Energy: A Marketing Analysis with Choice Experiments. Energy 2015, 88, 168-179. [CrossRef]

222. Bertsch, V.; Hall, M.; Weinhardt, C.; Fichtner, W. Public Acceptance and Preferences Related to Renewable Energy and Grid Expansion Policy: Empirical Insights for Germany. Energy 2016, 114, 465-477. [CrossRef]

223. Petrova, M.A. From NIMBY to acceptance: Toward a Novel Framework-VESPA-For Organizing and Interpreting Community Concerns. Renew. Energy 2016, 86, 1280-1294. [CrossRef]

224. Dalton, G.; Allan, G.; Beaumont, N.; Georgakaki, A.; Hacking, N.; Hooper, T.; Kerr, S.; O'Hagan, A.M.; Reilly, K.; Ricci, P.; et al. Economic and Socio-economic Assessment Methods for Ocean Renewable Energy: Public and Private Perspectives. Renew. Sustain. Energy Rev. 2015, 45, 850-878. [CrossRef]

225. Kaldellis, J.K.; Apostolou, D.; Kapsali, M.; Kondili, E. Environmental and Social Footprint of Offshore Wind Energy. Comparison with Onshore Counterpart. Renew. Energy 2016, 92, 543-556. [CrossRef]

226. Hdidouan, D.; Stafflell, I. The Impact of Climate Change on the Levelized Cost of Wind Energy. Renew. Energy 2017, 101, 575-592. [CrossRef]

227. De Andres, A.; MacGillivray, A.; Roberts, O.; Guanche, R.; Jeffrey, H. Beyond LCOE: A Study of Ocean Energy Technology Development and Deployment Attractiveness. Sustain. Energy Technol. Assess. 2017, 19, 1-16. [CrossRef]

228. View Twenty Years of Exchange Rate Data for over 55 Currencies. Available online: https:/ /www.ofx.com/ en-au/forex-news/historical-exchange-rates/yearly-average-rates/ (accessed on 31 August 2017).

229. Allan, G.; Gilmartin, M.; McGregor, P.; Swales, K. Levelized Costs of Wave and Tidal Energy in the UK: Cost Competitiveness and the Importance of "banded" Renewables Obligation Certificates. Energy Policy 2011, 39, 23-39. [CrossRef]

230. Salvatore, P.; Ercoli, E.; Julien, A.S.; Kristine, M. Investment and Grant Opportunities for Offshore Renewable Energy Projects in Europe, FP7 ORECCA Project. 2011. Available online: http:/ / www.orecca.eu/ c/document_library/get_file?uuid=3f2f5122-906a-4b82-9fa2-c626aba62399\&groupId=10129 (accessed on 1 September 2017).

231. Ocean Energy Systems. International Levelized Cost of Energy for Ocean Energy Technologies; Ocean Energy Systems: Lisbon, Portugal, 2015; p. 48. Available online: https://www.ocean-energy-systems.org/news/ international-lcoe-for-ocean-energy-technology / ?source=newsletter (accessed on 1 September 2017). 
232. Martin, R.; Lazakis, I.; Barbouchi, S.; Johanning, L. Sensitivity Analysis of Offshore Wind Farm Operation and Maintenance Cost and Availability. Renew. Energy 2016, 85, 1226-1236. [CrossRef]

233. Dalgic, Y.; Lazakis, I.; Dinwoodie, I.; McMillan, D.; Revie, M. Advanced Logistics Planning for Offshore Wind Farm Operation and Maintenance Activities. Ocean Eng. 2015, 101, 211-226. [CrossRef]

234. Sarker, B.R.; Faiz, T.I. Minimizing Maintenance Cost for Offshore Wind Turbines Following Multi-level Opportunistic Preventive Strategy. Renew. Energy 2016, 85, 104-113. [CrossRef]

235. Castro-Santos, L.; Diaz-Casas, V. Sensitivity Analysis of Floating Offshore Wind Farms. Energy Convers. Manag. 2015, 101, 271-277. [CrossRef]

236. Schwanitz, V.J.; Wierling, A. Offshore Wind Investments-realism about Cost Developments is Necessary. Energy 2016, 106, 170-181. [CrossRef]

237. Ederer, N. The Price of Rapid Offshore Wind Expansion in the UK: Implications of a Profitability Assessment. Renew. Energy 2016, 92, 357-365. [CrossRef]

238. Bigerna, S.; Bollino, C.A.; Micheli, S. Renewable Energy Scenarios for Costs Reductions in the European Union. Renew. Energy 2016, 96, 80-90. [CrossRef]

239. European Ocean Energy Association. Position Paper: Towards European Industrial Leadership in Ocean Energy in 2020; European Ocean Energy Association: Brussels, Belgium, 2011; p. 59. Available online: https:/ /www.gov. uk/government/publications/towards-european-industrial-leadership-in-ocean-energy-in-2020 (accessed on 10 April 2017).

240. European Commission. European Commission Guidance for the Design Of Renewables Support Schemes. In SWD(2013) 439 Final; European Commission: Brussels, Belgium, 2013.

241. Bigerna, S.; Bollino, C.A.; Micheli, S. The Sustainability of Renewable Energy in Europe; Springer International Publishing: Cham, Switzerland, 2015.

242. Available online: http:/ / www.res-legal.eu (accessed on 30 July 2017).

243. National Action Plans. Available online: http:/ / ec.europa.eu/energy/node/71 (accessed on 1 September 2017).

244. Wright, G.; O’Hagan, A.M.; de Groot, J.; Leroy, Y.; Soininen, N.; Salcido, R.; Castelos, M.A.; Jude, S.; Rochette, J.; Kerr, S. Establishing a Legal Research Agenda for Ocean Energy. Mar. Policy 2016, 63, 126-134. [CrossRef]

245. Fitch-Roy, O. An Offshore Wind Union? Diversity and Convergence in European Offshore Wind Governance. Clim. Policy 2015, 16, 586-605. [CrossRef]

246. Simas, T.; O’Hagan, A.M.; O'Callaghan, J.; Hamawi, S.; Magagna, D.; Bailey, I.; Greaves, D.; Saulnier, J.-B.; Marina, D.; Bald, J.; et al. Review of Consenting Processes for Ocean Energy in Selected European Union Member States. Int. J. Mar. Energy 2015, 9, 41-59. [CrossRef]

247. Bluene. Available online: http:/ /www.medmaritimeprojects.eu/section/bluene (accessed on 1 September 2017).

248. Prieto, J.G.; Caldes, N. MED Program and Transnational Cooperation Contributions to Marine Renewable Energy in the Mediterranean Area: What next? Int. J. Ocean Clim. Syst. 2016, 7, 95-99. [CrossRef]

249. Ortega, M.; del Rio, P.; Ruiz, P.; Thiel, C. Employment Effects of Renewable Electricity Deployment. A novel Methodology. Energy 2015, 91, 940-951. [CrossRef]

250. Meyer, I.; Sommer, M.W. Employment Effects of Renewable Energy Deployment-A review. Int. J. Sustain. Dev. 2016, 19, 217. [CrossRef]

251. European Commision Memo. Questions and Answers on An Action Plan to Support the Development of Blue Energy; European Commision Memo: Brussels, Belgium, 2014; p. 3.

252. $\mathrm{Xu}, \mathrm{L}$. The Ocean Energy Sector Report. Deliverable 1.4.3 of the Project "The Knowledge Center for Renewable Energy Jobs - KnowRES"; The Knowledge Center for Renewable Energy Jobs: Brussels, Belgium, 2015; p. 45. Available online: http:/ / www.knowres-jobs.eu/en/upload/Documents/KnowRES\%20D1.4.3\%20\%200cean\%20sectoral\%20report.pdf (accessed on 9 June 2017).

253. European Ocean Energy Association. Oceans of Energy European Ocean Energy Roadmap 2010-2050; European Ocean Energy Association: Brussels, Belgium, 2010; p. 36. Available online: https:/ /www.icoeconference.com/publication/oceans_of_energy_european_ocean_energy_roadmap_2010_2050/(accessed on 1 September 2017).

254. Available online: https://www.oceanenergy-europe.eu/en/communication/why-ocean-energy/oceanenergy-could-create-400-000-jobs-by-2050 (accessed on 30 July 2017). 
255. Brownlee, M.T.J.; Hallo, J.C.; Jodice, L.W.; Moore, D.D.; Powell, R.B.; Wright, B.A. Place Attachment and Marine Recreationists' Attitudes toward Offshore Wind Energy Development. J. Leisure Res. 2015, 47, 263-284.

256. Ek, K. Quantifying the Environmental Impacts of Renewable Energy: The Case of Swedish Wind Power. In Environmental Valuation in Developed Countries; Pearce, D., Ed.; Edward Elgar Publishing Incorporated: Cheltenham, UK, 2006; pp. 181-210.

257. Ladenburg, J. Attitudes Towards On-land and Offshore Wind Power Development in Denmark; Choice of Development Strategy. Renew. Energy 2008, 33, 111-118. [CrossRef]

258. Betakova, V.; Vojar, J.; Sklenicka, P. Wind Turbines Location: How Many and How Far? Appl. Energy 2015, 151, 23-31. [CrossRef]

259. Transportation Research Board of the National Academies. Structural Integrity of Offshore Wind Turbines: Oversight of Design, Fabrication, and Installation; The National Academies Press: Washington, DC, USA, 2011.

260. Westerberg, V.; Jacobsen, J.; Lifran, R. Offshore Wind Farms in the Mediteranean Seascape: A Tourist Appeal or a Tourist Repellent. In Proceedings of the 18th Annual Conference EAERE, Rome, Italy, 29 June-2 July 2011.

261. Ladenburg, J.; Lutzeyer, S. The Economics of Visual Disamenity Reductions of Offshore Wind Farms-review and Suggestions from an Emerging Field. Renew. Sustain. Energy Rev. 2012, 16, 6793-6802. [CrossRef]

262. Bishop, I.D.; Miller, D.R. Visual Assessment of Off-shore Wind Turbines: The Influence of Distance, Contrast, Movement and Social Variables. Renew. Energy 2007, 32, 814-831. [CrossRef]

263. British Wind Energy Association. The Impact of Wind Farms on the Tourist Industry in the UK; British Wind Energy Association: London, 2006; p. 23.

264. Westerberg, V.; Jacobsen, J.B.; Lifran, R. Offshore Wind Farms in Southern Europe-determining Tourist Preference and Social Acceptance. Energy Res. Soc. Sci. 2015, 10, 165-179. [CrossRef]

265. Vazquez, A.; Iglesias, G. Public Perceptions and Externalities in Tidal Stream Energy: A Valuation for Policy Making. Ocean Coast. Manag. 2015, 105, 15-24. [CrossRef]

266. Heras-Saizarbitoria, I.; Zamanillo, I.; Laskurain, I. Social Acceptance of Ocean Wave Energy: A Case Study of an OWC Shoreline Plant. Renew. Sustain. Energy Rev. 2013, 27, 515-524. [CrossRef]

267. Directorate-General for Maritime Affairs and Fisheries of the European Commission. Energy Sectors and the Implementation of the Maritime Spatial Planning Directive. Information for Stakeholders and Planners; European Commission: Luxembourg, 2015.

268. Patraiko, D.; Holthus, P. The Shipping Industry and Marine Spatial Planning. A Professional Approach; The Nautical Institute: London, UK, 2013; p. 14. Available online: http://www.nautinst.org/en/forums/msp/ (accessed on 1 September 2017).

269. Maritime and Coastguard Agency. Offshore Renewable Energy Installations: Impact on Shipping; Maritime and Coastguard Agency: Aberdeen, UK, 2016. Available online: https:/ /www.gov.uk/guidance/offshorerenewable-energy-installations-impact-on-shipping (accessed on 1 September 2017).

270. Samoteskul, K.; Firestone, J.; Corbett, J.; Callahan, J. Changing Vessel Routes Could Significantly Reduce the Cost of Future Offshore Wind Projects. J. Environ. Manag. 2014, 141, 146-154. [CrossRef] [PubMed]

271. Elemed Electrification in the Eastern Mediterranean. Available online: http://www.elemedproject.eu/ (accessed on 1 September 2017).

272. Mofor, L.; Nuttall, P.; Newell, A. Renewable Energy Options for Shipping; Technology Brief; International Renewable Energy Agency: Abu Dhabi, UAE, 2015; p. 60.

273. Navigant Ecofys. The North Sea as a Hub for Renewable Energy, Sustainable Economies, and Biodiversity; Navigant Ecofys: Utrecht, The Netherlands, 2017; p. 14. Available online: http:/ /www.ecofys.com/files/files/ecofysnavigant-2017-the-north-sea-as-a-hub.-for-re-sust-econ-biodiv.pdf) (accessed on 1 September 2017).

274. Maritime and Coastguard Agency. Offshore Renewable Energy Installations (OREIs): Guidance to Mariners Operating in the Vicinity of UK OREIs; Maritime and Coastguard Agency: Southampton, UK, 2008; p. 14. Available online: https://www.gov.uk/government/uploads/system/uploads/attachment_data/file/ 440734/MGN_372.pdf (accessed on 1 September 2017).

275. Q\&A Fishing Near Wind Farms in England. Available online: http://www.seakeeper.org/?page_id=971 (accessed on 30 July 2017).

276. Johnson, M.L.; Rodmell, D.P. Fisheries, the Environment and Offshore Wind Farms: Location, location, location. Food Ethics 2009, 4, 23-24. 
277. Fayram, A.H.; de Risi, A. The Potential Compatibility of Offshore Wind Power and Fisheries: An Example Using Bluefin Tuna in the Adriatic Sea. Ocean Coast. Manag. 2007, 50, 597-605. [CrossRef]

278. Benassai, G.; Mariani, P.; Stenberg, C.; Christoffersen, M. A Sustainability Index of Potential Co-location of Offshore Wind Farms and Open Water Aquaculture. Ocean Coast. Manag. 2014, 95, 213-218. [CrossRef]

279. Reilly, K.; O'Hagan, A.M.; Dalton, G. Attitudes and Perceptions of Fishermen on the Island of Ireland Towards the Development of Marine Renewable Energy Projects. Mar. Policy 2015, 58, 88-97. [CrossRef]

280. Hooper, T.; Ashley, M.; Austen, M. Perceptions of Fishers and Developers on the Co-location of Offshore Wind Farms and Decapod Fisheries in the UK. Mar. Policy 2015, 61, 16-22. [CrossRef]

281. Mackinson, S.C.H.; Brown, R.; McTaggart, K.; Taylor, N.; Neville, S.; Rogers, S. A Report on the Perceptions of the Fishing Industry into the Potential Socio-Economic Impacts of Offshore Wind Energy Developments on Their Work Patterns and Income; CEFAS: Lowestoft, UK, 2006; p. 99.

282. Raoux, A.; Tecchio, S.; Pezy, J.-P.; Lassalle, G.; Degraer, S.; Wilhelmsson, D.; Cachera, M.; Ernande, B.; Le Guen, C.; Haraldsson, M.; et al. Benthic and Fish Aggregation Inside an Offshore Wind Farm: Which Effects on the Trophic Web Functioning? Ecol. Indic. 2017, 72, 33-46. [CrossRef]

283. Menicou, M.; Vassiliou, V. Prospective Energy Needs in Mediterranean offshore Aquaculture: Renewable and Sustainable Energy Solutions. Renew. Sustain. Energy Rev. 2010, 14, 3084-3091. [CrossRef]

284. Weyer, L.; Krause, G.; Buck, B.H. Lessons from Stakeholder Dialogues on Marine Aquaculture in Offshore Wind Farms: Perceived Potentials, Constraints and Research Gaps. Mar. Policy 2015, 51, 251-259.

285. Zanuttigh, B.; Angelelli, E.; Bellotti, G.; Romano, A.; Krontira, Y.; Troianos, D.; Suffredini, R.; Franceschi, G.; Cantu, M.; Airoldi, L.; et al. Boosting Blue Growth in a Mild Sea: Analysis of the Synergies Produced by a Multi-Purpose Offshore Installation in the Northern Adriatic, Italy. Sustainability (Basel) 2015, 7, 6804-6853. [CrossRef]

286. Zanuttigh, B.; Angelelli, E.; Kortenhaus, A.; Koca, K.; Krontira, Y.; Koundouri, P. A Methodology for Multi-criteria Design of Multi-use Offshore Platforms for Marine Renewable Energy Harvesting. Renew. Energy 2016, 85, 1271-1289. [CrossRef]

287. Van den Burg, S.; Stuiver, M.; Norrman, J.; Garção, R.; Söderqvist, T.; Röckmann, C.; Schouten, J.-J.; Petersen, O.; García, R.; Diaz-Simal, P.; et al. Participatory Design of Multi-use Platforms at Sea. Sustainability (Basel) 2016, 8, 127. [CrossRef]

288. Stuiver, M.; Soma, K.; Koundouri, P.; van den Burg, S.; Gerritsen, A.; Harkamp, T.; Dalsgaard, N.; Zagonari, F.; Guanche, R.; Schouten, J.J.; et al. The Governance of Multi-use Platforms at Sea for Energy Production and Aquaculture: Challenges for Policy Makers in European Seas. Sustainability (Basel) 2016, 8, 333. [CrossRef]

289. Koundouri, P.; Dávila, O.G.; Stithou, M.; Babalos, V.; Xepapadeas, A.; Anastasiou, I.; Antypas, A.; Kourogenis, N.; Mousoulides, A.; Mousoulides, M.; et al. Methodology for Integrated Socio-economic Assessment of Multi-use Offshore Platforms. In The Ocean of Tomorrow: Investment Assessment of Multi-Use Offshore Platforms: Methodology and Applications; Springer International Publishing: Cham, Switzerland, 2017; pp. 11-26.

290. Koundouri, P.; Giannouli, A.; Airoldi, L.; Bas, B.; Broszeit, S.; Elginoz, N.; Giannakis, E.; Zagonari, F.; Krontira, Y.; Moussoulides, A.; et al. Socio-economic Analysis of a Selected Multi-use Offshore Site in the Mediterranean Sea. In The Ocean of Tomorrow: Investment Assessment of Multi-Use Offshore Platforms: Methodology and Applications; Springer International Publishing: Cham, Switzerland, 2017; pp. 85-101.

291. Hooper, T.; Austen, M. The Co-location of Offshore Windfarms and Decapod Fisheries in the UK: Constraints and Opportunities. Mar. Policy 2014, 43, 295-300. [CrossRef]

292. Yates, K.L.; Schoeman, D.S.; Klein, C.J. Ocean Zoning for Conservation, Fisheries and Marine Renewable Energy: Assessing Trade-offs and Co-location Opportunities. J. Environ. Manag. 2015, 152, 201-209. [CrossRef] [PubMed]

293. Katsanevakis, S.; Levin, N.; Coll, M.; Giakoumi, S.; Shkedi, D.; Mackelworth, P.; Levy, R.; Velegrakis, A.; Koutsoubas, D.; Caric, H.; et al. Marine Conservation Challenges in an Era of Economic Crisis and Geopolitical Instability: The case of the Mediterranean Sea. Mar. Policy 2015, 51, 31-39. [CrossRef]

294. Gopnik, M.; Fieseler, C.; Cantral, L.; McClellan, K.; Pendleton, L.; Crowder, L. Coming to the Table: Early Stakeholder Engagement in Marine Spatial Planning. Mar. Policy 2012, 36, 1139-1149. [CrossRef]

295. Borger, T.; Hooper, T.L.; Austen, M.C. Valuation of Ecological and Amenity Impacts of an Offshore Windfarm as a Factor in Marine Planning. Environ. Sci. Policy 2015, 54, 126-133. [CrossRef] 
296. Shucksmith, R.; Gray, L.; Kelly, C.; Tweddle, J.F. Regional Marine Spatial Planning—the Data Collection and Mapping Process. Mar. Policy 2014, 50, 1-9. [CrossRef]

297. Flannery, W.; Ellis, G.; Ellis, G.; Flannery, W.; Nursey-Bray, M.; van Tatenhove, J.P.M.; Kelly, C.; Coffen-Smout, S.; Fairgrieve, R.; Knol, M.; et al. Exploring the Winners and Losers of Marine Environmental Governance/Marine Spatial Planning: Cui Bono?/"More than Fishy Business": Epistemology, Integration and Conflict in Marine Spatial Planning/Marine Spatial Planning: Power and Scaping/Surely not all Planning is Evil?/Marine Spatial Planning: A Canadian Perspective/Maritime Spatial Planning-“ad Utilitatem Omnium"/Marine Spatial Planning: "It is Better to be on the Train than being Hit by it" / Reflections from the Perspective of Recreational Anglers and Boats for Hire/Maritime Spatial Planning and Marine Renewable Energy. Plan. Theory Pract. 2016, 17, 121-151.

298. Johnson, C. Advances in Marine Spatial Planning: Zoning Earth's Last Frontier. J. Environ. Law Litig. 2014, 29, 191-246.

299. Lam, W.H.; Roy, C.B. Insights into the Ocean Health Index for Marine Renewable Energy. Renew. Sustain. Energy Rev. 2014, 33, 26-33. [CrossRef]

300. Exploring the Potential of Maritime Spatial Planning in the Mediterranean Sea. Available online: https: / / ec.europa.eu/maritimeaffairs/documentation/studies/study_msp_med_en (accessed on 30 July 2017).

301. Wright, G. Marine Governance in an Industrialised Ocean: A Case Study of the Emerging Marine Renewable Energy Industry. Mar. Policy 2015, 52, 77-84. [CrossRef]

302. Gimpel, A.; Stelzenmuller, V.; Grote, B.; Buck, B.H.; Floeter, J.; Nunez-Riboni, I.; Pogoda, B.; Temming, A. A GIS Modelling Framework to Evaluate Marine Spatial Planning Scenarios: Co-location of Offshore Wind Farms and Aquaculture in the German EEZ. Mar. Policy 2015, 55, 102-115. [CrossRef]

303. Maccarrone, V.; Filiciotto, F.; Buffa, G.; Mazzola, S.; Buscaino, G. The ICZM Balanced Scorecard: A tool for Putting Integrated Coastal Zone Management into Action. Mar. Policy 2014, 44, 321-334. [CrossRef]

304. Soriani, S.; Buono, F.; Tonino, M.; Camuffo, M. Participation in ICZM Initiatives: Critical Aspects and Lessons Learnt from the Mediterranean and Black Sea Experiences. Mar. Pollut. Bull. 2015, 92, 143-148. [CrossRef] [PubMed]

305. Official Journal of the European Union: Protocol on Integrated Coastal Zone Management in the Mediterrane. Available online: http:/ / eur-lex.europa.eu/legal-content/EN/TXT/PDF/?uri=CELEX:22009A0204(01) \&from=EN (accessed on 1 September 2017).

306. Katsaprakakis, D.; Christakis, D.G. The Exploitation of Electricity Production Projects from Renewable Energy Sources for the Social And Economic Development of Remote Communities. The case of Greece: An Example to Avoid. Renew. Sustain. Energy Rev. 2016, 54, 341-349. [CrossRef]

307. Jeffrey, H.; Sedgwick, J. ORECCA European Offshore Renewable Energy Roadmap; ORECCA (Offshore Renewable Energy Conversion platforms Coordination Action) Project: Edinburgh, UK, 2011.

308. Georgiou, D.P.; Milidonis, K.F.; Theodoropoulos, N.G. Optimal Plant Configuration for the Nearly Ideal Processes of an OTEC Concept Driven by the Sea-Air Temperature Difference. In Engineering Systems Design and Analysis; ASME: New York, NY, USA, 2012; Volume 2, pp. 525-533.

(c) 2017 by the authors. Licensee MDPI, Basel, Switzerland. This article is an open access article distributed under the terms and conditions of the Creative Commons Attribution (CC BY) license (http:// creativecommons.org/licenses/by/4.0/). 